University of Windsor

Scholarship at UWindsor

\title{
The Effect of Backing Profile on Cutting Blade Wear During High Volume Production of Carbon Fiber-Reinforced Composites
}

\author{
Evan Freeman-Gibb \\ University of Windsor
}

Follow this and additional works at: https://scholar.uwindsor.ca/etd

\section{Recommended Citation}

Freeman-Gibb, Evan, "The Effect of Backing Profile on Cutting Blade Wear During High Volume Production of Carbon Fiber-Reinforced Composites" (2018). Electronic Theses and Dissertations. 7354.

https://scholar.uwindsor.ca/etd/7354

This online database contains the full-text of PhD dissertations and Masters' theses of University of Windsor students from 1954 forward. These documents are made available for personal study and research purposes only, in accordance with the Canadian Copyright Act and the Creative Commons license-CC BY-NC-ND (Attribution, Non-Commercial, No Derivative Works). Under this license, works must always be attributed to the copyright holder (original author), cannot be used for any commercial purposes, and may not be altered. Any other use would require the permission of the copyright holder. Students may inquire about withdrawing their dissertation and/or thesis from this database. For additional inquiries, please contact the repository administrator via email (scholarship@uwindsor.ca) or by telephone at 519-253-3000ext. 3208. 
The Effect of Backing Profile on Cutting Blade Wear During High Volume Production of Carbon Fiber-Reinforced Composites

\author{
By \\ Evan Freeman-Gibb
}

\begin{abstract}
A Thesis
Submitted to the Faculty of Graduate Studies

through the Department of Mechanical, Automotive, and Materials Engineering in Partial Fulfillment of the Requirements for the Degree of Master of Applied Science at the University of Windsor

Windsor, Ontario, Canada

(c) 2018 Evan Freeman-Gibb
\end{abstract}




\section{The Effect of Backing Profile on Cutting Blade Wear During High Volume Production of Carbon Fiber-Reinforced Composites}

by

Evan Freeman-Gibb

ApProved By:

R. Riahi

Department of Mechanical, Automotive, and Materials Engineering

W. Altenhof

Department of Mechanical, Automotive, and Materials Engineering

J. Johrendt, Co-Advisor

Department of Mechanical, Automotive, and Materials Engineering

R. Tutunea-Fatan, Co-Advisor

Department of Mechanical and Materials Engineering, Western University

February 2, 2018 


\section{DeClaration of ORIGinality}

I hereby certify that I am the sole author of this thesis and that no part of this thesis has been published or submitted for publication.

I certify that, to the best of my knowledge, my thesis does not infringe upon anyones copyright nor violate any proprietary rights and that any ideas, techniques, quotations, or any other material from the work of other people included in my thesis, published or otherwise, are fully acknowledged in accordance with the standard referencing practises. Furthermore, to the extent that I have included copyrighted material that surpasses the bounds of fair dealing within the meaning of the Canada Copyright Act, I certify that I have obtained a written permission from the copyright owner(s) to include such material(s) in my thesis and have included copies of such copyright clearances to my appendix.

I declare that this is a true copy of my thesis, including any final revisions, as approved by my thesis committee and the Graduate Studies office, and that this thesis has not been submitted for a higher degree to any other University or Institution. 


\begin{abstract}
As vehicle lightweighting continues to become a widespread trend in the automotive industry, production methods for composite materials must continue to improve. Carbon fiber SMC (sheet molding compound) utilizes rotary chopping to produce sheets of composite material which can be molded to form lightweight vehicle parts, but high blade wear rates are seen when cutting carbon fibers. Experiments were performed to examine the wear progression of cutting blades during rotary carbon fiber chopping and to investigate the effect that profiled backing has on blade wear. Blade wear measurements were obtained by measuring worn regions and blade tips, and extensive micrographs of blade surfaces at different wear levels were collected. Most intentionally-profiled backings did not improve blade wear rates; however, backings prone to forming their own deep grooves reduced wear rate by up to $65 \%$. Several explanations of how wear occurs and progresses under different conditions were developed.
\end{abstract}




\section{ACKNOWLEDGEMENTS}

I would like to thank Dr. Johrendt and Dr. Tutunea-Fatan for their guidance, mentorship, and patience as my advisors throughout this process. I would like to thank Dr. Altenhof and Dr. Riahi for their valuable input and recommendations. I would like to thank Dr. Alpas and Zafar Ullah Khan for generously granting me access to their lab and equipment. I would like to thank Andy Jenner, Dean Poublon, and Bruce Durfy for all of their assistance with machining and fabrication. Finally, I would like to thank Vanja Ugresic and the Fraunhofer Project Centre at Western University for supplying the carbon fibers and chopper used in this work. 


\section{Contents}

Declaration of Originality ................ iii

Abstract ........................ . . . . . . .

Acknowledgements ..................... . . . .

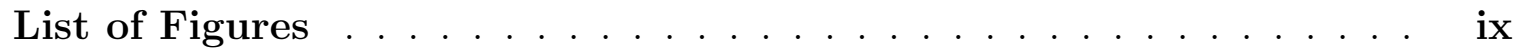

List of Tables . . . . . . . . . . . . . . . . . . . xii

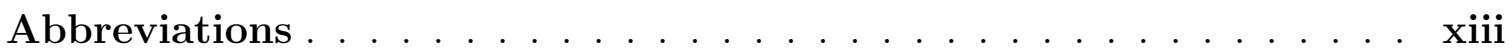

1 Introduction . . . . . . . . . . . . . . . . . . . 1

1.1 Types of FRPs . . . . . . . . . . . . . . . . . 3

1.1.1 Glass fiber-reinforced composites . . . . . . . . . . . . 3

1.1.2 Carbon fiber-reinforced composites . . . . . . . . . . . . . . 3

1.1.3 Other types of composites ............. . . 5

1.2 Composite Production Methods . . . . . . . . . . . . . 5

1.2.1 Sheet molding compound . . . . . . . . . . . . . . . 5

1.2.2 Other production methods . . . . . . . . . . . . . 7

1.3 D-SMC and the Present Problem . . . . . . . . . . . . . . 8

1.3.1 Rotary fiber chopping . . . . . . . . . . . . . . . . . 9

2 Literature Survey . . . . . . . . . . . . . . . . . . . . 11

2.1 Carbon Fibers and Their Properties . . . . . . . . . . . . . . . 11

2.2 CFRP Machining and Tool Wear . . . . . . . . . . . . . . . . 12

2.3 Fiber Tow Chopping . . . . . . . . . . . . . . . . 14

2.3.1 Previous research at Western University . . . . . . . . . . 15

2.3.2 Other relevant literature . . . . . . . . . . . . . . . . 17

2.3.3 Backing roll grooves and fiber chopping . . . . . . . . . . . 21

2.4 Research Objectives . . . . . . . . . . . . . . . . 23 
3 Experimental Setup . . . . . . . . . . . . . . . . 25

3.1 Apparatus ............................ 25

3.1.1 Rotary fiber chopper ............... 25

3.2 Materials . . . . . . . . . . . . . . . 27

3.2.1 Carbon fibers ................... 27

3.2.2 Blades .......................... 28

3.2.3 Backing rolls ................... 28

3.3 Procedure . . . . . . . . . . . . . . . . . . . 30

3.3.1 Experiments . . . . . . . . . . . . . 30

3.3.2 Measurement .................... 33

3.3.3 Data analysis ................. 36

4 Results . . . . . . . . . . . . . . . . . . . . . . 40

4.1 Blade Wear Measurements . . . . . . . . . . . . . . . . 40

4.1.1 Front and rear face worn distances . . . . . . . . . . . . . 40

4.1.2 Blade wear based on tip measurement . . . . . . . . . . . 44

4.2 Wear Patterns . . . . . . . . . . . . . . . . . 45

4.3 Cutting Edge Rounding . . . . . . . . . . . . . 49

4.3.1 Comparison of worn blade outlines . . . . . . . . . . 55

5 Discussion . . . . . . . . . . . . . . . . . . . 58

5.1 Blade Wear Measurements . . . . . . . . . . . . . . 58

5.1.1 Front and rear face worn distances . . . . . . . . . . . 58

5.1.2 Blade wear based on tip measurement . . . . . . . . . . 59

5.2 Wear Patterns . . . . . . . . . . . . . . . . 59

5.3 Cutting Edge Rounding .................. 63

5.3.1 Tip radii ......................... 63

5.3.2 Cross-section profiles .................. 64

5.3.3 Comparison of worn blade outlines . . . . . . . . . . 66

5.4 Front and Back Face Wear Mechanism . . . . . . . . . . . . 66

5.4.1 Blade wear physical explanation . . . . . . . . . . . 68

5.5 Wear Differences with Profiled Backings . . . . . . . . . . . 73 
6 Conclusions ........................ 76

6.1 Conclusions ........................ 76

6.2 Future Work . . . . . . . . . . . . . . . . . . 77

References ........................ 79

Appendix $1 \ldots \ldots \ldots$. . . . . . . . . . . . . . . . . . 83

Appendix $2 \ldots \ldots \ldots \ldots$

Vita Auctoris . . . . . . . . . . . . . . . . . . . . 91 


\section{List OF FiguRES}

1.1 Traditional SMC production process $\ldots \ldots \ldots \ldots$

1.2 Comparison of various FRP production methods . . . . . . . . 7

1.3 D-SMC production line layout . . . . . . . . . . . . . . . 9

2.1 Internal structure of carbon fibers . . . . . . . . . . . . . 12

2.2 Rotary fiber chopping setup . . . . . . . . . . . . . . . . 14

2.3 Small-scale rotary fiber chopper . . . . . . . . . . . . . . 16

2.4 Comparison of crescent-shaped worn regions on cutting blades . . . . 18

2.5 Force-displacement chart for flexible-backed single fiber chopping . . . 19

2.6 Fracture surfaces of fibers subjected to tensile and flexural loads . . . 20

2.7 Minor and major grooves formed in the backing roll . . . . . . . . . 21

2.8 Cross-section of a major groove formed in the backing roll . . . . 22

2.9 Force versus displacement curves for different chopping conditions . . 23

3.1 Annotated picture of actual fiber chopping setup used . . . . . . . 26

$3.225 \mathrm{~mm}$ backing roll section on lathe fixture . . . . . . . . . . . 29

3.3 Backing roll blank and machining fixture mounted on vertical mill . . 30

3.4 Naturally-formed helical grooves in full-size SMC fiber chopper backing 31

3.5 Side view of all control test backing rolls stacked . . . . . . . . . 33

3.6 Measured micrograph of blade worn region . . . . . . . . . . 35

3.7 Steps in the blade tip minimum radius extraction method . . . . . . 38

3.8 Blade tip worn distance measurement method . . . . . . . . . . 39

4.1 Blade wear versus mass of chopped fiber for all 80A durometer test runs 40

4.2 Blade wear versus mass of chopped fiber for all 90A durometer test runs 41

4.3 Blade wear versus mass of chopped fiber for all 95A durometer test runs 42

4.4 Blade wear versus mass of chopped fiber for all test runs . . . . . . 43

4.5 Plot of blade tip worn distances measured from cross-sections . . . . 44

4.6 Comparison of maximum wear regions for tests $\mathrm{C} 1$ and $\mathrm{C} 2 \ldots \ldots$

4.7 Comparison of maximum wear regions for tests C3 and S3D $\ldots . .46$

4.8 Comparison of maximum wear regions for tests S1D and Sw3 . . . . 47

4.9 Maximum wear regions for test Sw2D . . . . . . . . . . . . 48 
4.10 C1 test blade tip rounding, front face to left . . . . . . . . . . . 49

4.11 C1 test blade tip rounding, front face to right . . . . . . . . . . . 49

4.12 S3D test blade tip rounding, front face to left . . . . . . . . . . 50

4.13 S3D test blade tip rounding, front face to right . . . . . . . . . . 50

4.14 Sw3 test blade tip rounding, front face to left . . . . . . . . . . 51

4.15 Sw3 test blade tip rounding, front face to right . . . . . . . . . . . 51

4.16 Sw2D test blade tip rounding, front face to left . . . . . . . . . . . 52

4.17 Sw2D test blade tip rounding, front face to right . . . . . . . . . . 52

4.18 S1D test blade tip rounding, front face to left . . . . . . . . . 53

4.19 S1D test blade tip rounding, front face to right . . . . . . . . . . 53

4.20 Plot of minimum tip radius versus number of chops for select blades . $\quad 54$

4.21 C1 tips with C1 blade outlines overlay, front faces to left . . . . . . 55

4.22 Sw2D tips with C1 blade outlines overlay, front faces to left . . . . 55

4.23 S3D tips with $\mathrm{C} 1$ blade outlines overlay, front faces to left . . . . . 55

4.24 C1 tips with C1 blade outlines overlay, front faces to right . . . . . . 56

4.25 Sw2D tips with C1 blade outlines overlay, front faces to right . . . . . 56

4.26 S3D tips with $\mathrm{C} 1$ blade outlines overlay, front faces to right . . . . . 56

5.1 S1D low-power micrographs, comparing dark regions on front and back 60

5.2 Sw3 85k blade front face, low-magnification, labelled . . . . . . . . 61

5.3 Front (left) and back (right) grind regions wear, low magnification . . 62

5.4 Front and back (L and R) of C3 115k . . . . . . . . . . . . . . . 62

5.5 Combined tip wear and cutting edge rounding plot . . . . . . . . 64

5.6 Typical cross-section profile for a worn blade (around 45k chops) . . . 65

5.7 S3D 20k back face, non-EDF image, with several gouges highlighted . 67

5.8 Front (left) and back (right) faces with gouges highlighted . . . . . . 67

5.9 Four steps of the grooved fiber chopping process . . . . . . . . . 70

5.10 Steps in the non-grooved chopping process . . . . . . . . . . . . 71

5.11 Comparison of grind lines on back faces . . . . . . . . . . . . . 72

5.12 2.5k and 20k chop front face wear for C1, S1, and C3 . . . . . 75

A1.1 Baseline blade dimensions (blades were cut into $25 \mathrm{~mm}$ segments) . . 84

A1.2 Groove cutting fixture overall assembly . . . . . . . . . . . . 85 
A1.3 Groove cutting fixture locking pin component . . . . . . . . . . . 86

A1.4 Groove cutting fixture base component . . . . . . . . . . . . . 87

A1.5 Groove cutting fixture roll holder rod component . . . . . . . . . . 88

A2.1 TR50S 15K carbon fiber material data . . . . . . . . . . . . 90 


\section{LIST OF TABLES}

3.1 Configuration of conditions for each experiment . . . . . . . . . . . 32

5.1 Performance measures from Figure 4.4 (ordered by wear rate) . . . . 59 


\section{AbBreviations}

\begin{tabular}{ll}
\hline FRP & Fiber Reinforced Plastic/polymer \\
GFRP & Glass Fiber Reinforced Plastic/polymer \\
CFRP & Carbon Fiber Reinforced Plastic/polymer \\
SMC & Sheet Molding Compound \\
D-SMC & Direct Sheet Molding Compound \\
RTM & Resin Transfer Molding \\
HP-RTM & High Pressure Resin Transfer Molding \\
LFT & Long Fiber Thermoplastic \\
LFT-D & Long Fiber Thermoplastic - Direct \\
BMC & Bulk Molding Compound \\
CER & Cutting Edge Rounding \\
EDF & Enhanced Depth-of-Field \\
\hline
\end{tabular}




\section{Chapter 1}

\section{INTRODUCTION}

"Composite materials" are any sort of material that is composed of two or more different heterogeneous components, typically intended to simultaneously take advantage of the favourable properties of the multiple material components, and often having anisotropic material properties. While this field encompasses countless different types of material combinations including metals, ceramics, plastics, fibers, and spheres, for the purposes of this thesis "composites" will be more narrowly defined as a combination of reinforcing fibers in a polymer matrix. The term fiber-reinforced polymers/plastics (FRPs) is also commonly used to refer to this class of composites, as they are most often composed of glass or carbon fibers in a polymer matrix.

FRPs present themselves as an attractive alternative to metals or other materials in numerous applications, due in large part to their impressive specific strengths and moduli [18]. While a FRP component may be weaker than a steel component of the same volume, when their properties are compared on a per-weight basis the composite material is actually considerably stronger than the metal part. For example, SAE 1010 cold-worked steel has a tensile strength to weight ratio of 4.72 , whereas glass fiber SMC (sheet molding compound) composite has a tensile strength to weight ratio of 8.9; thus, if a steel part and composite part of the same strength were made, the composite part would be nearly half the weight of the steel part [18]. Consequently, this means that FRPs can be used in many industries as an alternative to metals to make lightweight components. Some other favourable qualities of FRPs include their good dimensional stability and low tooling costs relative to formed metals (for compression-molded composites like glass and carbon SMC). Likewise, the properties of fiber-reinforced composites can be tailored to specific applications with relative ease 
by changing any number of processing parameters, including fiber volume content, fiber grade/type, resin/filler formulas, and the addition of reinforcing tapes and mats.

Despite their many impressive characteristics, FRPs are not without their drawbacks. Most importantly, the high cost of composite part production is a key reason why FRPs do not see as widespread adoption as many other materials [13]. Many of the earliest FRP parts were made through hand layup methods, with workers cutting fiber fabric sheets, placing them onto a form, and laminating them together with coats of epoxy resin [18]. This labour-intensive production process has been acceptable for low-volume aircraft producers since the initial development of FRPs, starting with glass fiber-reinforced plastics, or GFRPs, in the 1930s, but it is unfeasible when annual part production volumes reach the tens- to hundreds-of-thousands required by the modern automotive industry. Modern production technologies, like high pressure resin transfer molding (HP-RTM) and direct sheet molding compound (D-SMC) are now able to keep up with the high production rates and volumes required of the automotive industry; thus, FRP parts are now becoming increasingly more common in automobiles [5].

The material costs of FRPs are also relatively high compared to metals traditionally used to make automotive components, like steel or aluminum. While compression-molded composite materials do require less robust tooling than metal forming tools due to the lower pressures and forces encountered during part manufacturing, these parts' constituent materials are still expensive. In particular, some high-performance handmade carbon FRPs (CFRPs) can cost several hundreds of dollars per kilogram of finished material [13]; this is prohibitively expensive for all but the most exclusive premium automotive applications. GFRPs do not have nearly as high raw material costs, but they also do not offer the same dramatic weight savings that CFRPs can achieve; thus, reduced material and production costs are key targets to be achieved before CFRPs will see widespread use in the automotive industry. 


\subsection{TYPES OF FRPs}

A number of production processes are currently used to make automotive components for mass-market vehicles, although the production numbers achieved are not nearly as high as traditional metal or plastic parts. By far, the most commonly used fiberreinforced composites are glass FRPs (GFRPs) [27]; aside from automotive parts, these are also used for heavy transportation and commercial vehicles, sporting goods, marine vessels, and in numerous industrial applications.

\subsubsection{Glass fiber-reinforced composites}

Glass fibers are one of the most widely used reinforcing materials in fiber-reinforced polymers; in Europe alone, the estimated production volume of glass fiber-reinforced

plastics in 2015 was over one million tonnes [27]. These materials are most commonly used in the automotive, transportation, and marine sectors due to their low cost relative to carbon fibers [13]. Two of the most common grades of glass fibers are Eglass and S-glass; E-glass is the most readily available and least-expensive glass fiber, while S-glass is a higher-performance reinforcing fiber for more demanding structural applications. Both of these grades of glass fiber are significantly cheaper than carbon fibers to produce and purchase due to their ease of manufacture and large volumes of production; consequently, they have been used in a myriad of applications far more commonly than carbon fibers and have proven effective building materials in applications where low cost trumps the extreme lightweighting capabilities of carbon fibers [6].

\subsubsection{Carbon fiber-reinforced composites}

Possessing impressive physical properties, carbon fiber-reinforced plastics (CFRP) have been a key material used within the aerospace industry for many years. From 
their earliest applications in prototype parts on military aircraft, to the advent of modern-day commercial airliners made almost exclusively with composite parts, these materials have been used with great success in aviation applications. Their favourable strength-to-weight ratios make these composite materials an attractive weight-saving alternative to metals, but one of the main reasons they were not instantly adopted as the material of choice for aircraft construction was due to their labour-intensive production methods and expensive material and production costs [13].

Likewise, until recently these materials were far too expensive to be used in many applications outside of the aircraft industry due to the high costs of producing CFRP parts; however, a modern trend of automakers using carbon fiber parts in high-performance applications can be seen [5]. It is hypothesized that the prevalence of CFRP in the automotive industry, particularly in everyday vehicles, will continue to increase as manufacturers work on reducing vehicle weight to meet increasingly stringent fuel economy and emissions regulations [7].

A current roadblock to large-scale adoption of composite materials in massmarket cars is the requirement for low part production cycle times to keep up with just-in-time and lean vehicle manufacturing practices. To eliminate the wastes caused by part overproduction, waiting, and warehousing of parts, modern automotive production requires parts to be produced quickly and in the exact quantities needed to be put directly onto vehicles being assembled [24]. In Figure 1.2 a comparison of various composite materials and their associated cycle times can be seen. Hand lay-up and spray-up techniques - along with traditional RTM - cannot generate parts as quickly as automotive suppliers require, so newer mass-production techniques are utilized for automotive applications. The red line seen in Figure 1.2 is the approximate "dividing line" between processes which are too time-consuming for high-volume vehicle part production and those which can be used; as a general rule, the higher production volumes are the faster parts need to be produced to keep up with assembly demand. 


\subsubsection{Other types of composites}

While carbon and glass fiber-reinforced plastics make up a large percentage of the composite materials market (approximately $60 \%$ for carbon fiber-reinforced composites [27]), there do exist many other types of fiber-reinforced composites using myriad matrix and fiber materials. Metal matrix composites (MMCs) and ceramic matrix composites (CMCs) are two such examples; these materials are structured much the same was as FRPs, but a metal or ceramic material is used in place of the polymer matrix. These materials have been developed for similar reasons as FRPs; namely, to take advantage of the high specific strengths of reinforcing fibers and to combine several favourable properties of dissimilar materials to make an overall stronger product [18]. Also similarly to FRPs, these composites too can have their material properties tailored to specific applications through varying the reinforcing fiber content, size, type, and orientation.

\subsection{Composite Production Methods}

\subsubsection{Sheet molding compound}

Sheet molding compound, or SMC, is one composite production method that is suited to the rapid production rates and high production volumes required from the automotive industry [18]. SMC involves the chopping of reinforcing fibers onto a resin-coated carrier film; these fibers are then sandwiched between a second layer of resin and film, and this is passed through several layers of offset rollers to fully mix the composite together. The discontinuous-fiber sheets produced are then left to mature for anywhere from several hours to several days, after which they are cut to form a mold charge and are then compression molded to whatever geometry is desired. Figure 1.1 
shows a detailed outline of the traditional production process that is normally used to produce various SMC composite parts.

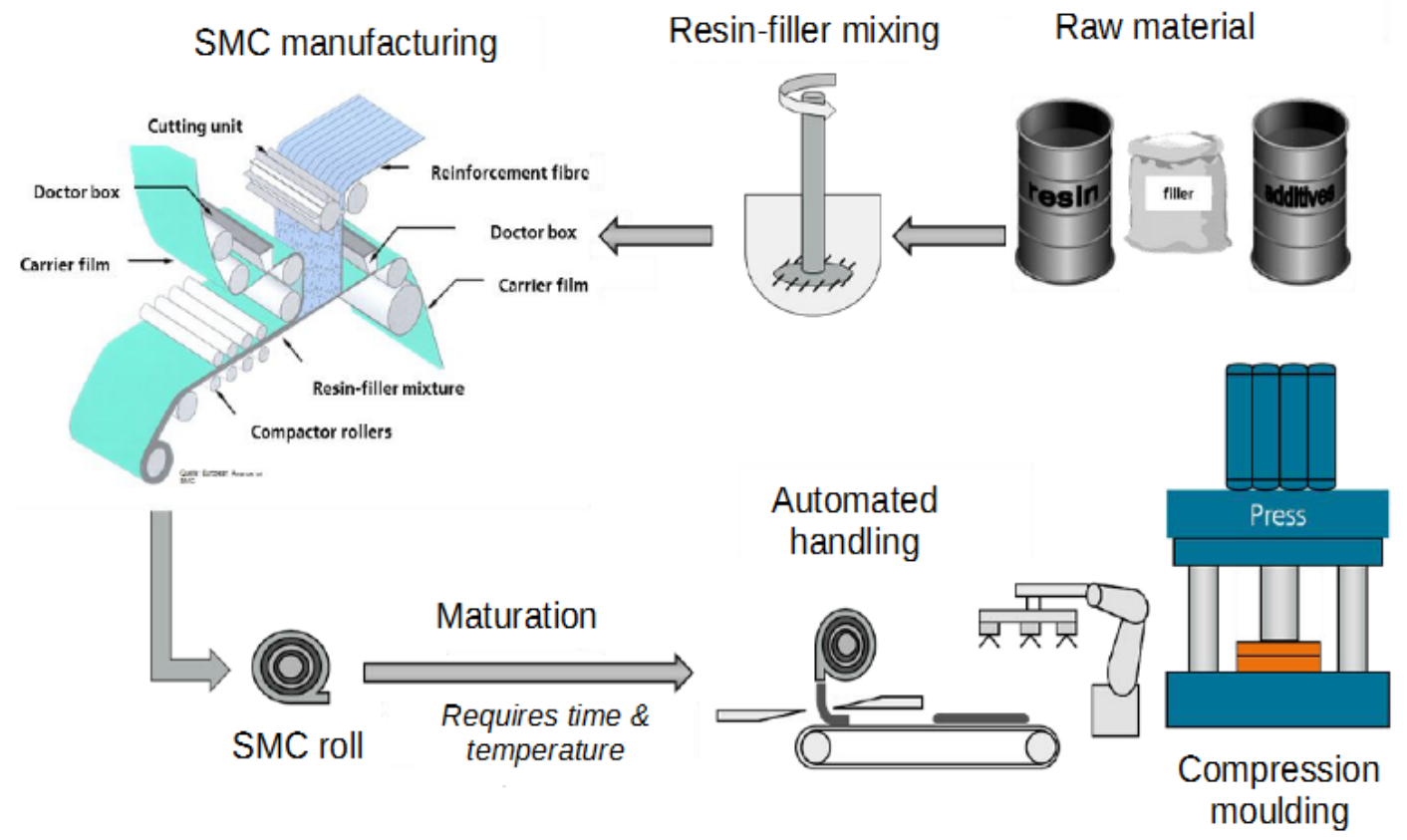

FiguRE 1.1: Traditional SMC production process

- modified from [11]

This process can produce material much faster than manual wet lay-up processes, albeit SMC material has a lower specific strength. Still, in non- and semistructural applications where weight reduction while maintaining favourable physical properties is the goal, SMC is an important composite production method. SMC can be used to produce parts from any sort of fiber, including carbon fibers, glass fibers, and even basalt fibers. Currently, the vast majority of SMC parts produced are glass fiber composites; in Europe, 191 kilo-tonnes of glass fiber SMC were produced in 2015 , compared to the worldwide production volume of roughly 8 kilo-tonnes of carbon fiber SMC (only about $10 \%$ of the global CFRP production) [27]. This glass fiber SMC is mainly used for producing electrical infrastructure (junction boxes, cabinets, housings, and panels), as well as automotive parts like trunk lids and hoods [27]. 
Carbon SMC is also most commonly manufactured for use in automotive applications, seeing deployment in vehicles like the Dodge Viper and the BMW i3 and i8 [5, 27]. It is projected that demand for carbon fiber composites and carbon fiber SMC will grow considerably in the coming decade, with the expected global demand in 2021 estimated to be around 175 kilo-tonnes of CFRP material [27]. Even if carbon SMC continues to account for approximately $10 \%$ of the total CFRP market, this still means a doubling of production volume; thus, this growth needs to be supported through continued improvement of material production techniques.

\subsubsection{Other production methods}

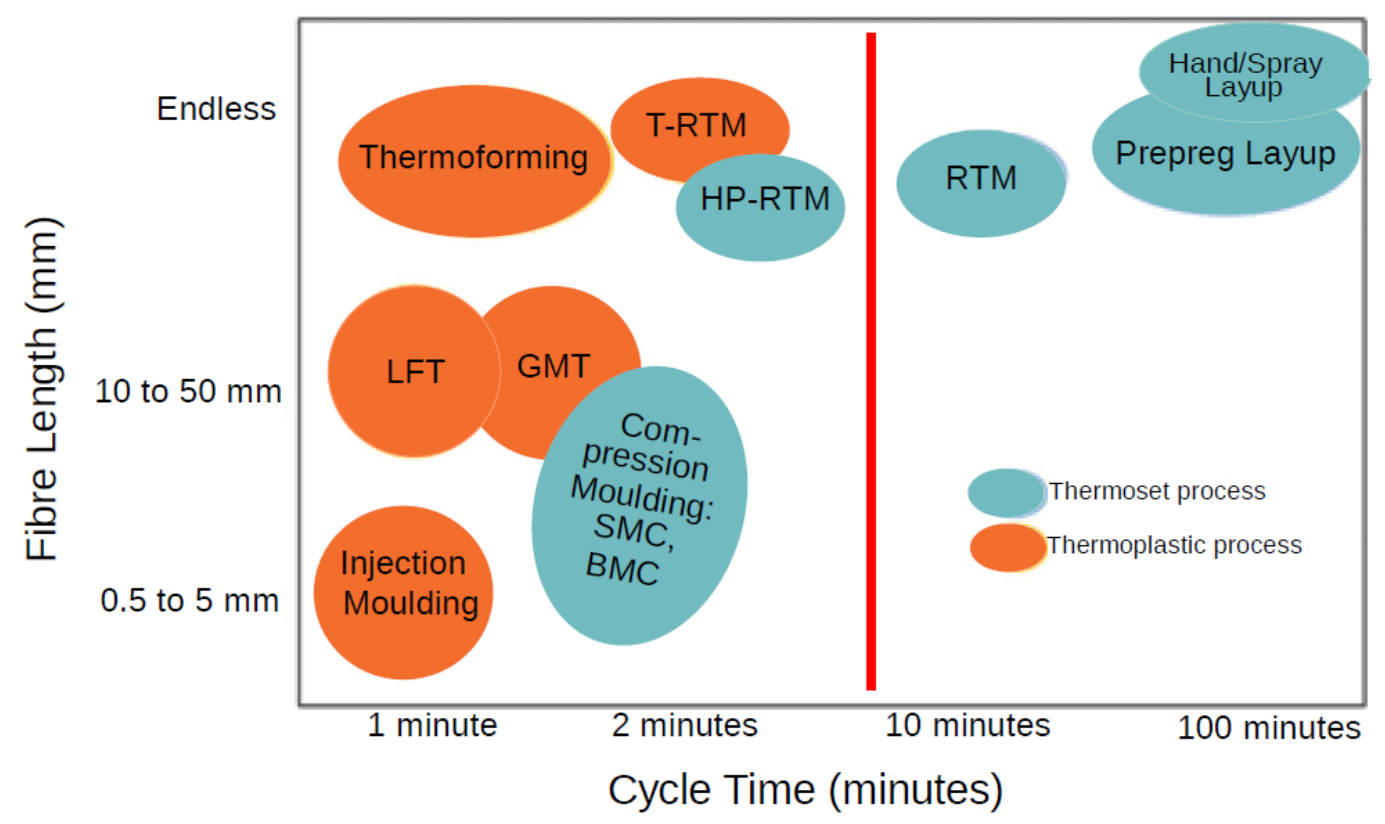

FiguRE 1.2: Comparison of various FRP production methods

- modified from [19]

$\mathrm{SMC}$ is far from the only composite material production method. Figure 1.2 compares several composite production methods on axes of fiber length versus cycle time. Continuous or "endless" fiber composites (like RTM, HP-RTM, or hand layup) tend to have the highest strengths of all composites; however, they also tend to 
offer the lowest level of geometric complexity and require the longest per-part production cycle times. Conversely, compression-molded long-fiber composites (LFT, SMC, GMT, BMC) and short-fiber composites (injection-molded thermoplastics) have lower specific strengths, but these processes can be more easily automated, have lower cycle times, and can achieve much higher degrees of geometric complexity.

In Figure 1.2, the various production processes are also labelled "thermoset" or "thermoplastic". Due to the nature of each production method, only certain resin systems can be used with each; methods like injection molding and LFT utilize thermoplastic resins, while SMC and HP-RTM use thermoset resin systems. Just as each production method has specific applications for which it is useful, so too does each type of resin have its own strengths and weaknesses: thermoset plastics can be handled and processed at low temperatures and have good high-temperature properties after curing, while thermoplastic resins have better fracture toughness and can be melted down to be recycled [12]. As thermoplastics are solid at room temperature, the SMC process is designed exclusively for making thermoset parts.

\subsection{D-SMC and the Present Problem}

D-SMC (Direct-SMC) is an SMC production method developed through collaboration between the Fraunhofer ICT (Institute for Chemical Technology) and the German equipment manufacturer Dieffenbacher GmbH. This process has several key differences from the standard SMC process illustrated in Figure 1.1; these differences can seen in Figure 1.3 below.

One of the main differences seen between standard SMC and D-SMC is the use of an automated extruder and material measurement system to combine the various parts of the resin system and dose the carrier films. This setup is better suited for large-scale production of parts as the D-SMC line can be set to continuously 


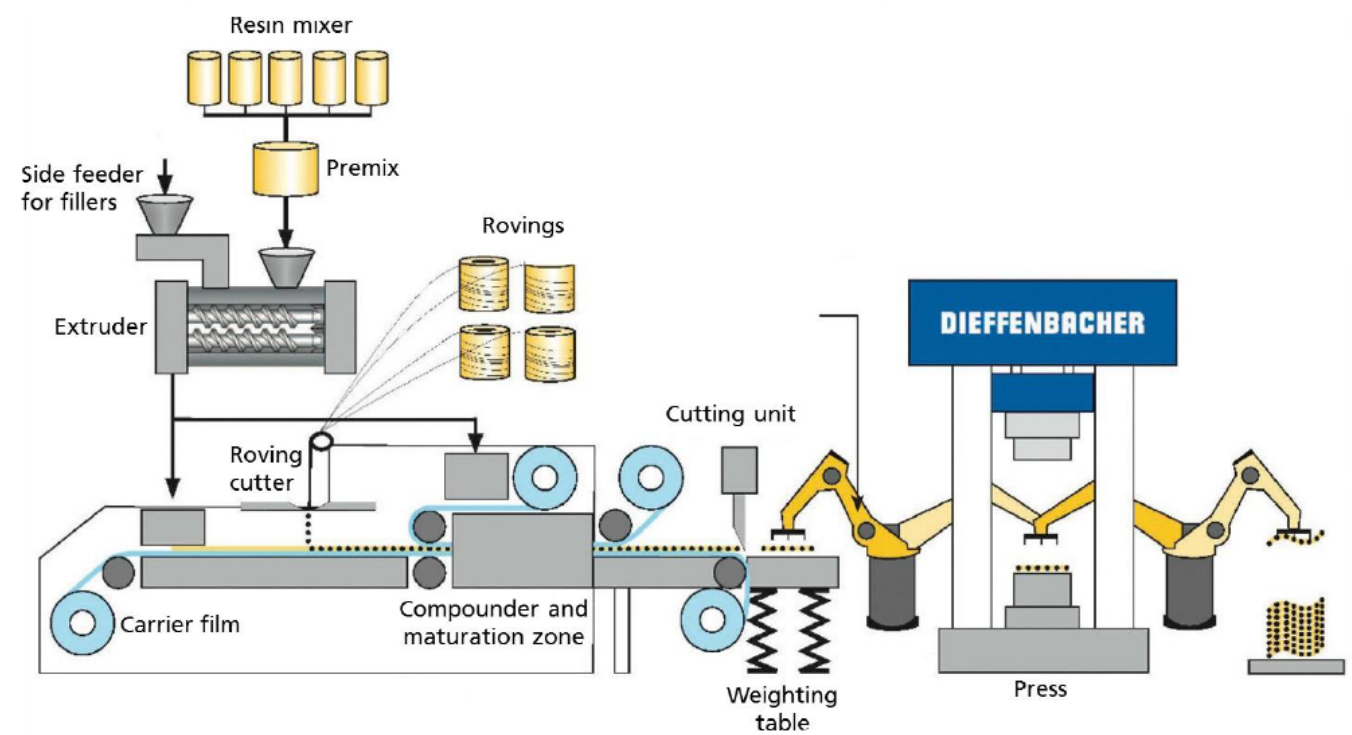

FiguRE 1.3: D-SMC production line layout - from $[11]$

produce material, with human operators only needed at each end to load material into the extruder and to collect finished parts after they have been extracted from the press. The second defining feature of D-SMC, and the main reason for the "direct" part of its name, is the addition of a heated maturation zone after the compounder. Typically, SMC requires several days of maturation time to reach a state at which it can be molded. This is not compatible with the commonly used automotive industry method of just-in-time manufacturing; however, with D-SMC the total time from raw material to finished parts is cut to less than 30 minutes [11].

\subsubsection{Rotary fiber chopping}

A key requirement of the D-SMC production process is the need for continuous fiber chopping during material production. Continuous fibers (glass, carbon, basalt, or any number of other reinforcing materials) are one of the raw materials fed into the compounder region of the SMC production line; these are then chopped and combined with resin to produce semi-finished SMC mold charges. During full-scale industrial D-SMC production this would require chopping many hundreds of kilograms of fiber 
daily to keep up with automotive mass production rates; this presents technical problems with regards to process down-time caused by blade replacement stoppages.

Fiber chopping is not a new process, being commonly performed in both the textile and composite industries, but carbon fibers present a unique challenge for chopping because of their impressive physical properties. The same things that make carbon fibers valuable as a reinforcing fiber (very high strength and stiffness, high resistance to shear [20]) also make them a challenge to cut, as they quickly abrade metal cutting tools during machining $[21,26]$. This high rate of tool wear is also seen during chopping of individual fibers; possible reasons for this will be discussed in detail in section 2.2. Thus, one area of the D-SMC production method that requires further research and improvement is carbon fiber chopping, as this high rate of blade wear leads to frequent blade replacements in a production environment; this is unacceptable for a process that is meant to produce composite material continuously at a rate suitable for automotive part production. By finding methods to reduce cutting blade wear, and through furthering the overall understanding of the fiber chopping process, process improvements can be made to existing and new rotary carbon fiber choppers to prolong blade life and reduce process downtime. 


\section{Chapter 2}

\section{LiterATURE SURVEY}

\subsection{Carbon Fibers and Their Properties}

Carbon fibers are produced from the stabilization, pyrolysis, and carbonisation of pitch or PAN (polyacrylonitrile) precursor fibers, converting the ductile polymer filaments into cross-linked strands of nearly-pure (approximately 90\%) carbon [15]. During the stabilization phase of fiber production, cross-linking occurs between the PAN polymers, and the thermoplastic material is converted to a thermoset polymer; this material then undergoes high temperature pyrolysis and carbonisation, converting it to a near-amorphous mostly-carbon combination of disorganized graphite sheets and carbon micro-crystals [20]. Depending on fiber production process parameters and precursor materials used, the carbon fiber structure can vary from mostly granular crystals to a highly-oriented graphitic structure [15], hence why various grades and types of carbon fiber have differing single-fiber properties. Figure 2.1 shows the various structures present within a carbon fiber cross-section, along with high-resolution SEM micrographs of actual fiber ends.

The turbostratic carbon structure of typical PAN-based carbon fibers can be clearly seen in Figure 2.1 (B), and the SEM micrographs in (A) show the random order of these compacted carbon sheets and carbon microcrystals. It is this complicated mostly-carbon structure that gives carbon fibers their exceptional physical properties; likewise, it is this high strength that leads to high tool wear rates when cutting both CFRPs and plain carbon fiber tows [21,23]. 


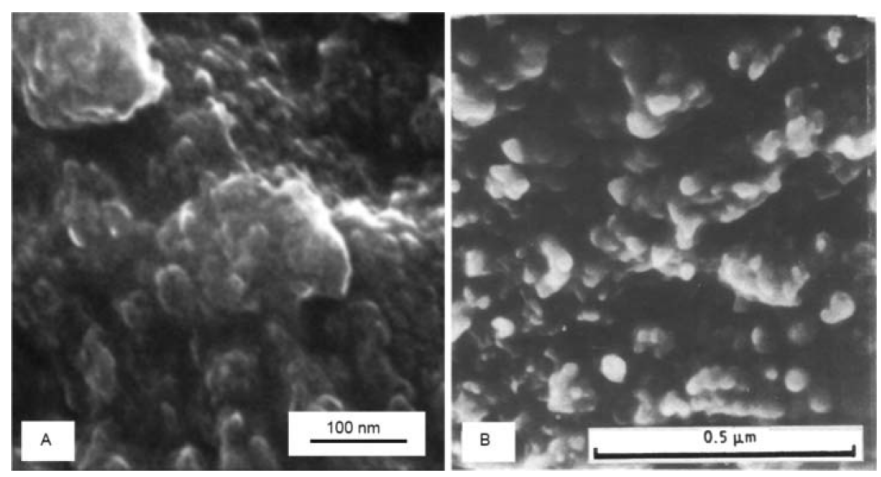

(A) SEM images of carbon fibers

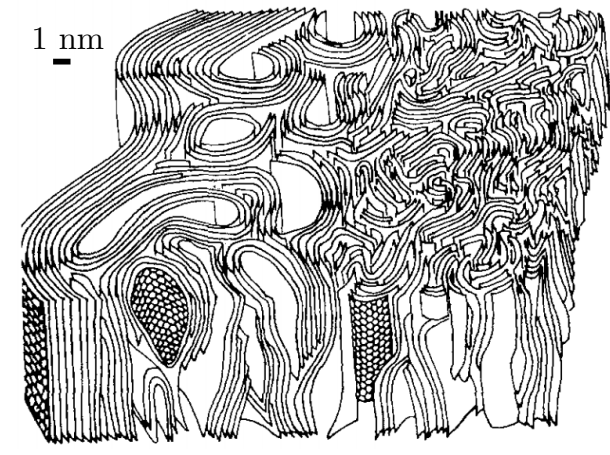

(в) Cross-section structure

FIgURE 2.1: Internal structure of carbon fibers Sub-figure (A) from [15], sub-figure (B) modified from [4]

\subsection{CFRP Machining and Tool Wear}

Carbon fiber composites have long been notorious for their difficult-to-machine nature; researchers have been investigating how to improve CFRP machining and decrease tool wear since as early as the 1980s [14, 22]. Whereas traditional machining processes for metals and plastics have evolved with the assumption of isotropic material properties, FRPs pose a unique challenge when milling, drilling, and cutting as they are inhomogeneous and highly anisotropic [25]. Machining FRPs is particularly challenging due to the presence of abrasive reinforcing fibers or particles; this can be exacerbated by fiber orientation, as unidirectional FRPs show significant differences in both tool wear and part surface finish depending on cutting angle and fiber orientation [25].

Since both the scientific and manufacturing communities have recognized that challenges exist in machining FRPs, many methods have been developed to reduce tool wear and improve finished part quality. The early investigations by Sakuma et al. into milling and drilling CFRPs concluded that standard high-speed steel tools were unacceptable for machining CFRP parts, and it was suggested that cemented tungsten 
carbide cutters be used to prolong tool life and ensure high-quality surface finish $[21,22]$. Likewise, more recent studies have shown PCD (poly-crystalline diamond) tools to be very effective at cutting CFRPs without damaging the parts or wearing out the tools [8], and work has also been done showing that thin diamond-like coatings can be effective at further prolonging the lifespan of tungsten carbide tools [26].

Aside from tool materials, researchers have also examined the effect of tool geometry on wear during CFRP machining and have developed some improved cutting blade designs for CFRP-specific machining applications [17]. When cut, CFRPs typically do not lose material in the form of long, cohesive chips; instead, material flakes off as short, discontinuous chips [25]. If these small discontinuous chips are not fully flushed from the cutting tool area then they can cause significant abrasion of the cutting tool as parts are being processed. Unlike when machining metals, CFRPs typically cannot be doused with coolants or cutting fluids as these can react with the matrix or permeate the fibers and negatively affect the composite strength, but novel tool geometries allow dry chips to be removed from the surface and past the tool without generating excessive wear [17].

Overall, a decent body of work has been accumulated on machining CFRPs, although it pales in comparison to the amount of research conducted on machining metals, plastics, and other homogeneous materials. Due to the anisotropy and inhomogeneity of CFRPs, and particularly because of the high strength of the individual carbon fibers, traditional machining of CFRPs still faces many issues that will need to be overcome in the near future as the popularity of CFRPs continues to rise. It is no wonder then that the chopping of plain carbon fibers also faces similar tool wear challenges as CFRP machining, again due to the high strength of these fibers. 


\subsection{Fiber Tow Chopping}

Much like CFRP machining processes, carbon fiber tow chopping machines experience high rates of cutting blade wear due to the hard and abrasive nature of carbon fibers. Tow chopping involves severing long continuous fiber strands into sections of uniform length; this process has numerous applications in manufacturing and the textile industry, and it is important to composite part production as well for making chopped fiber composites. SMC, BMC, and spray-up composite production techniques all require chopped fibers, thus continuous fiber tows (bundles of individual fiber strands) need to be chopped into uniform size segments before mixing with the matrix resin material. This is commonly done with a rotary chopper setup (see Figure 2.2) which uses a rotating blade roller and backing roller to sever the fibers.

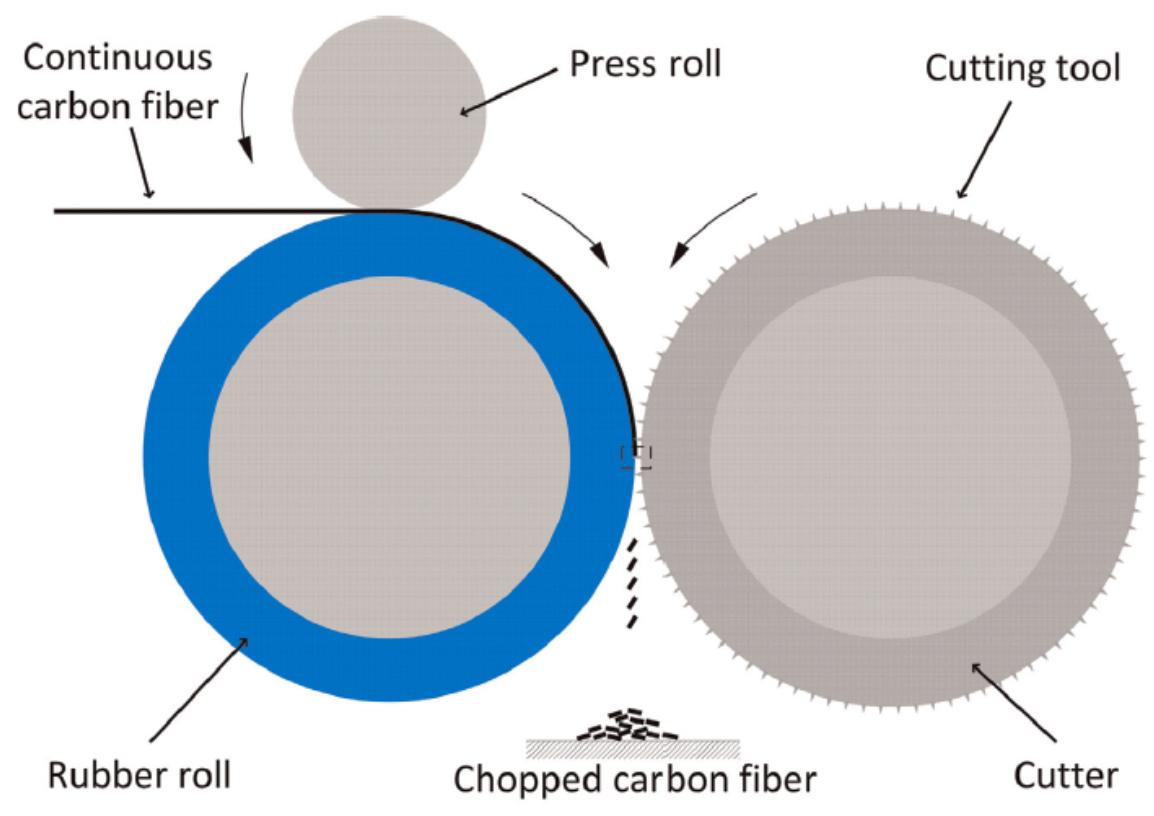

FiguRE 2.2: Rotary fiber chopping setup

- from [23]

Typically, the backing roll (labelled "rubber roll") is a natural or synthetic rubber material with sufficient flexibility to allow the cutting blades (protrusions on 
the cutting tool) to plunge into the backing and sever the continuous fiber tows. The cutting blades are often made of steel or another hard, sharpened material, and these blade edges experience high wear rates primarily due to chopping carbon fibers $[2,3,23]$.

\subsubsection{Previous research at Western University}

Previous research into the issues associated with rotary carbon fiber chopping has been conducted in master's theses by Adamovsky [2] and Alexander [3] at Western University in London, Ontario. The work by Adamovsky focused on the effects of blade material and geometry on wear during the fiber chopping process, while the thesis by Alexander looked at the effects of backing roll material on blade wear.

Both of these theses used a modified Chopcot fiber chopping unit that had been altered to more closely reflect the rotary fiber chopping process used in D-SMC part production. This setup consisted of a polyurethane rubber backing roller contacting a 10-bladed blade roller, severing the fiber tows into 1-inch segments. The blade roller was powered by an electric motor connected to a variable frequency drive, allowing the speed of fiber chopping to be finely tuned. Both the cutting blades and the backing rolls could be changed relatively easily to allow different configurations to be tested. A CAD model of this setup can be seen in Figure 2.3. Data was collected in various forms, including measurements from micrographs of the worn blade surfaces and measurements of the force and displacement required to chop fiber tows with worn blades.

In the work conducted by Adamovsky, the effects of cutting blade geometry and material were examined. The backing material was kept constant, and a number of different blades were used to conduct short-term (50000 chops) and extended wear (197500 chops) tests. The blade materials used included M2 tool steel, 440A stainless steel, 1085 carbon steel, and cemented tungsten carbide. Likewise, blade geometries 


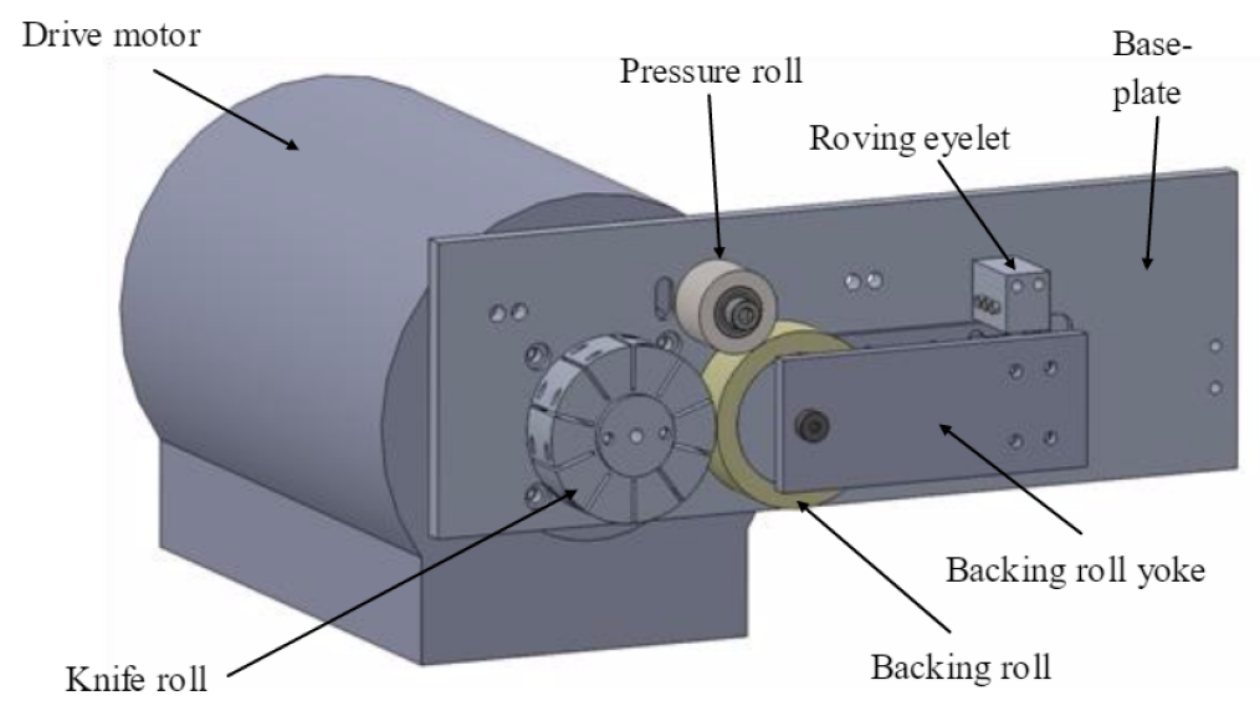

FiguRe 2.3: Small-scale rotary fiber chopper

Used by Adamovsky and Alexander in $[2,3]$

and thicknesses were varied, ranging from 0.010 inches to 0.035 inches thick, and included a chisel edge blade as well as both single- and double-bevel ground and honed blades [2]. This thesis produced a large amount of evidence suggesting that the hardest blade materials experienced the least amount of wear; this was seen in measurements of the blade worn distance and tip rounding, as well as in micrographs of the worn blade surfaces [2]. Additionally, the various blade geometries tested (thick, thin, wedge-shaped, etc.) had negligible impact on blade wear, as significantly higher wear rates were seen in the various steel blades versus the tungsten carbide blades [2].

In the work by Alexander, the effects of backing roll material on the chopping process were examined. As the modified Chopcot rotary chopper is set up to mimic the rotary fiber chopping process used in the D-SMC production process, one half of the chopper setup consists of polyurethane rubber backing rolls into which the chopping blades plunge (labelled Backing roll in Figure 2.3). The work by Alexander paired backing rolls of varying hardness, ranging from 42 Shore A durometer to 
92 Shore A, with different chopper blades and backing roll material thickness to examine the force required to chop a fiber bundle. The blades used in the extended wear tests by Adamovsky [2] were also used by Alexander to examine how worn blades cut on backing rolls of varying hardness, and some initial investigation was done into fiber cutting in grooves on the backing roll as well. This thesis produced data suggesting that softer backing roll material reduced the wear rate of the cutting blades, and that blade wear and cutting force were very closely correlated. Additionally, both this thesis and the work by Adamovsky began initial investigation into fiber cutting in backing roll grooves; this is discussed further in subsection 2.3.3.

\subsubsection{Other relevant literature}

Though research into this topic is still in its infancy, a handful of other works studying carbon fiber chopping have been published. Zhongfu Shen et al. at the South China University of Technology published a paper detailing some preliminary investigations into carbon fiber chopping and the progression of blade wear during this process [23]. In this work, a rotary chopper with steel blades was used to chop carbon fibers to 21,000 chops per blade using 12K (12,000 filament) fiber. The blade wear progression, cutting edge rounding (CER), and rake face wear were all measured after various quantities of fiber were chopped (from 2,000 to 21,000 chops). The steel blades used in this paper showed high wear rates compared to those seen in the work by Adamovsky [2], as the carbon steel used had a Vickers hardness of 670 versus the $745 \mathrm{HV}$ of Adamovsky's "baseline" blades. A peak blade tip wear of approximately $100 \mu \mathrm{m}$ ( $\Delta d$ from blade edge to max worn region) was seen after only 21,000 chops; this was also when the researchers began to see incomplete tow chopping on $>5 \%$ of cuts and so ended the tests.

One key finding from the work by Shen et al. was the confirmation that an abrasive phenomenon is responsible for the wear and rounding of cutter blades; also 
proposed in this work was an analytical model of how the cutting edge rounding and rake face wear progressed based on 3-body abrasive wear calculations. It was also suggested that the majority of wear occurs on the blade rake face, and that the crescent-shaped wear pattern of the blades (seen in Figure 2.4) may increase the rate of wear and rounding as cutting progresses.

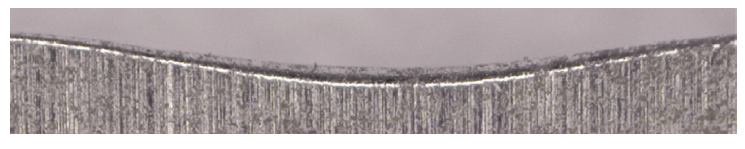

(A) Worn region from [23]

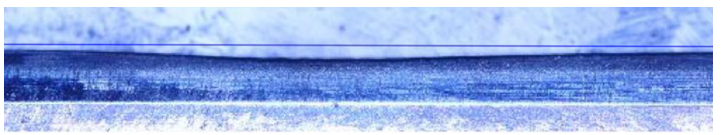

(B) Worn region from [2]

Figure 2.4: Comparison of crescent-shaped worn regions on cutting blades Sub-figure (A) from Shen et al., sub-figure (B) from Adamovsky

Another work related to fiber tow chopping was published by Lu et al., also from the South China University of Technology [16]. This research focused on the fracture behaviour of carbon fibers during flexible and rigid-backed chopping. Their experiments involved linear chopping of a single carbon fiber on a flat plate made of either soft polyurethane or glass. These researchers investigated fracture surfaces and failure modes, with their findings suggesting that the flexible-backed chopping led to a flexural failure of the carbon fiber, while the rigid-backed chopping caused a crushing failure mode [16]. The force-versus-displacement curves of single fiber chopping under both conditions were also examined, with their experiments suggesting that - during flexible-backed chopping - increasingly-soft backings reduced the cutting force only marginally, while causing a considerable increase in the displacement required to fully sever the fiber. Figure 2.5 shows this force-displacement trend for various flexible backings.

This increased length of cutting stroke required to sever the fiber was due to the softer backings yielding to the hard blades before the fiber strand hit its critical bending radius and fractured. For rigid-backed chopping, the stroke was an order of magnitude lower than the flexible-backed tests, with the total stroke being around 


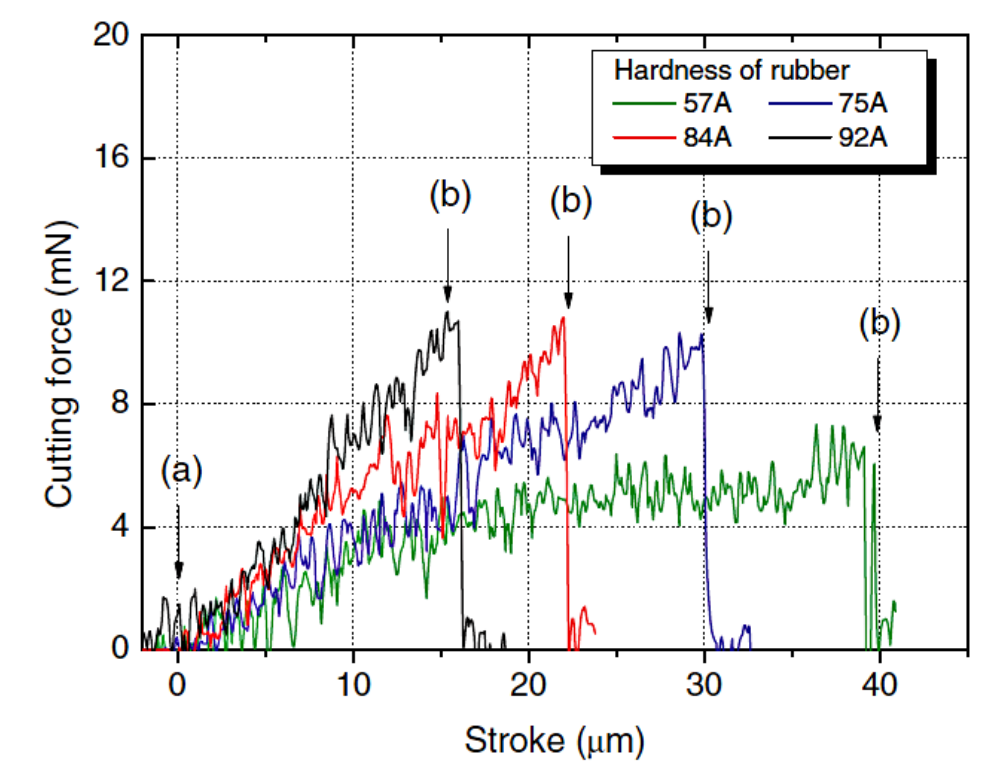

FiguRE 2.5: Force-displacement chart for flexible-backed single fiber chopping - from [16]

$5 \mu \mathrm{m}$, just under the average carbon fiber thickness of approximately $7 \mu \mathrm{m}$. The force required for rigid-backed chopping was much higher as well, averaging $244 \mathrm{mN}$, and crushing failure of the fibers was seen as opposed to the brittle fracture phenomenon seen during the flexible-backed tests.

A third work by the same lab group, conducted by Xie et al., looked again at flexible-backed chopping of fibers, but used entire fiber tow bundles instead of just single carbon fiber strands [28]. This research involved vertical chopping of $12 \mathrm{~K}$ carbon fiber tows on flat polyurethane backing plates to again examine the forces and failure modes present during this process. As with their previous works, the failure mode of the fiber tows was again identified as brittle fracture when a critical fiber bending radius around the cutting blade tip is reached. The failure order of the individual fibers in the tow was also investigated, with results suggesting that the outermost fibers on the fiber bundle edges fracture first, and that the fracture propagates towards the middle of the tow such that the central fibers are the last to break; likewise, the fracturing of the tow is initiated on the side of the bundle in 
contact with the blade, and this cascades outward through the tow [28]. Figure 2.6 shows micrographs of the fracture surfaces of a fiber subjected to pure tensile loads compared to a flexural load, along with sketches of the loading in each case.

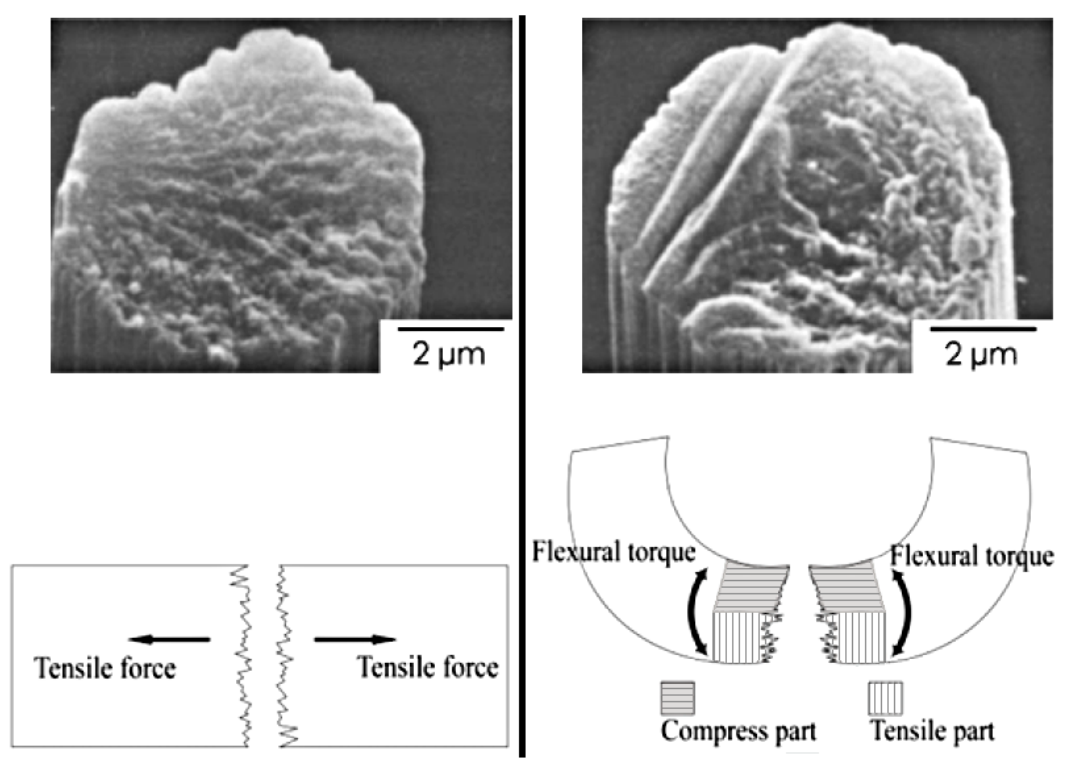

FiguRE 2.6: Fracture surfaces of fibers subjected to tensile and flexural loads - modified from [28]

This same failure pattern was seen on individual fibers taken from a chopped tow, thus strengthening the hypothesis that flexural fracture is the process through which fibers are severed during flexible-backed chopping [28]. This also explains why the individual fibers in a tow fail in the order they do, as the fibers in contact with the blade (innermost side of the curve, as seen in Figure 2.6) hit the critical bending radius required for breakage first, with this breakage then cascading outward through the tow [28]. How this bending and breaking failure mode interacts with the blades to cause wear and rounding of the blade tips has only just begun to be investigated, so this is a key area that is examined further in the present work. 


\subsubsection{Backing roll grooves and fiber chopping}

A key observation among the various findings in the previous works by Adamovsky and Alexander was that the peak force to cut fiber bundles was dramatically reduced when the blades aligned with grooves that had formed in the backing roll [2, 3]. After approximately 100,000 cuts, or around $19 \mathrm{~kg}$ of $12 \mathrm{~K}$ fiber, distinct grooves began to form in the backing roll where the blades had repeatedly plunged into the same spot. These grooves (10 "major grooves" and 40 "minor grooves") were evenly spaced around the backing roll, aligned with the locations of the 10 cutting blades on the knife roll. Figure 2.8 shows the profile of one of these grooves, and Figure 2.7 shows a backing roll spread out with the different grooves identified.

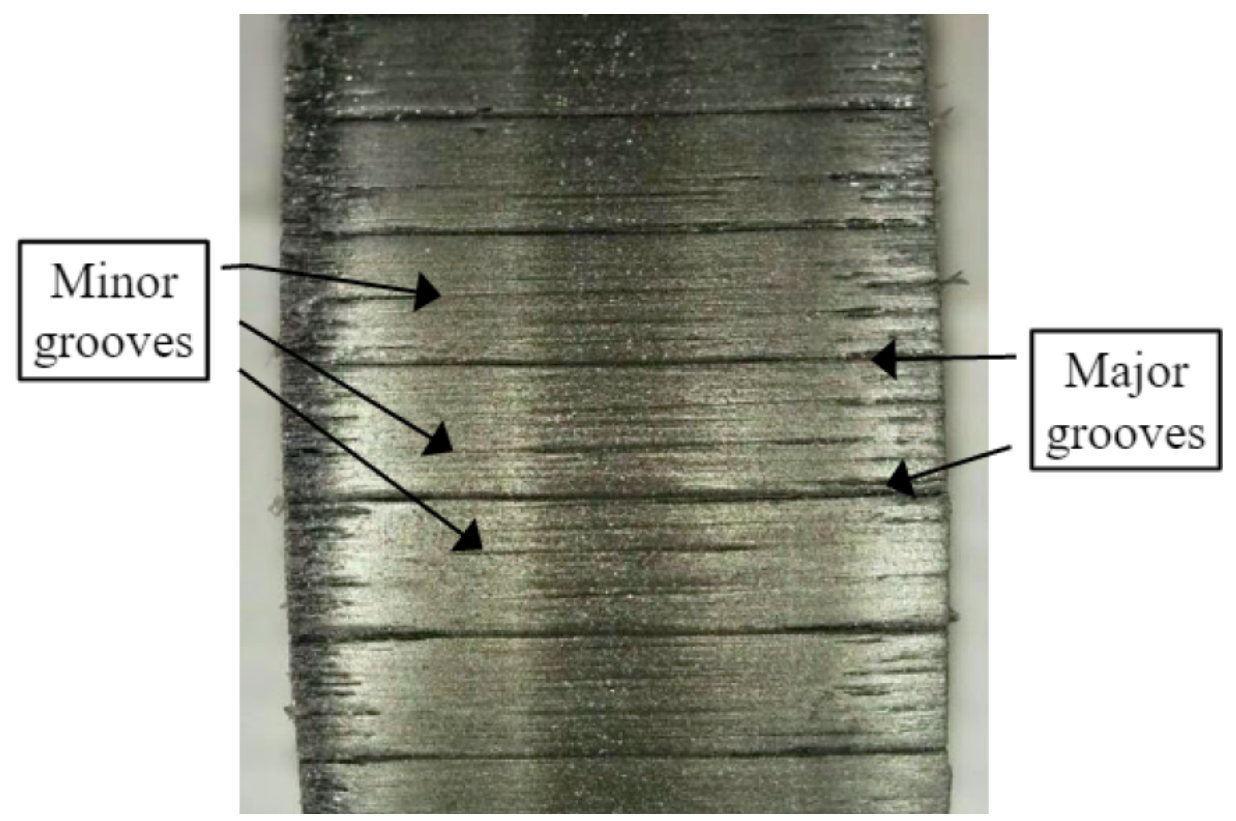

FIGURE 2.7: Minor and major grooves formed in the backing roll - from $[3]$

This phenomenon is important for two reasons. Firstly, the formation of these grooves in the backing roll over time suggests that the blades are not just cutting the fiber tows during the rotary chopping process; instead, they are cutting through the fiber bundles and then cutting into the backing roll as well. This means that 


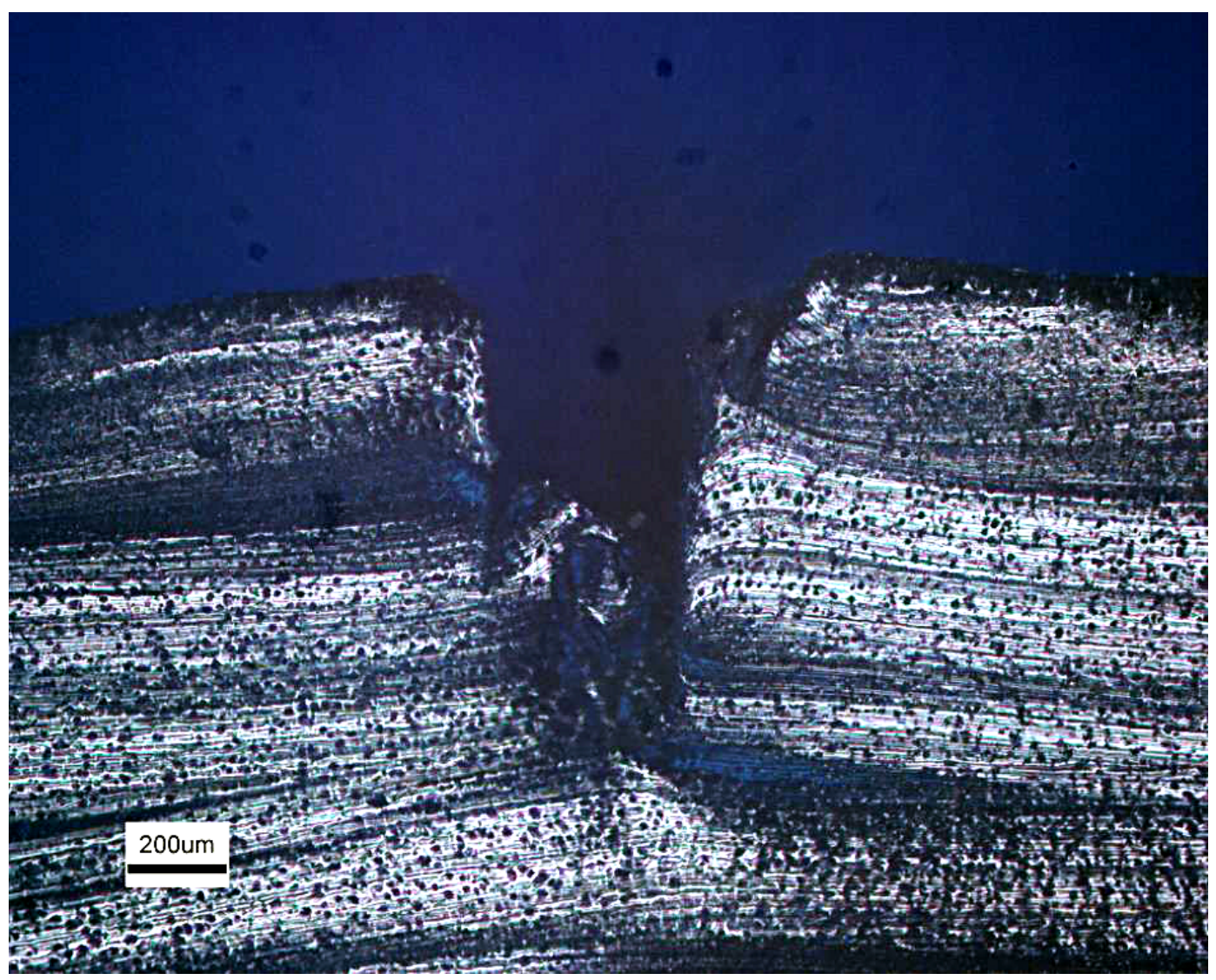

FiguRE 2.8: Cross-section of a major groove formed in the backing roll - from $[3]$

some amount of energy is being expended to cut the backing roll as well as the fibers, which likely means unnecessary blade wear is occurring during the chopping of the backing roll. This is supported by the second point, which is that the cutting force required to chop a fiber bundle has shown a dramatic drop when the cutting blades are aligned with a groove in the backing roll $[2,3]$. Figure 2.9 is a plot of force versus displacement during an instrumented linear fiber chopping experiment, with a dramatic force reduction seen when the cutting blade is aligned with a backing roll groove. A force reduction of over $77 \%$ was seen in the tests run by Adamovsky and Alexander when the blades were aligned with the naturally-formed major grooves, as compared to chopping on the same worn backing material but adjacent to the 
grooves.

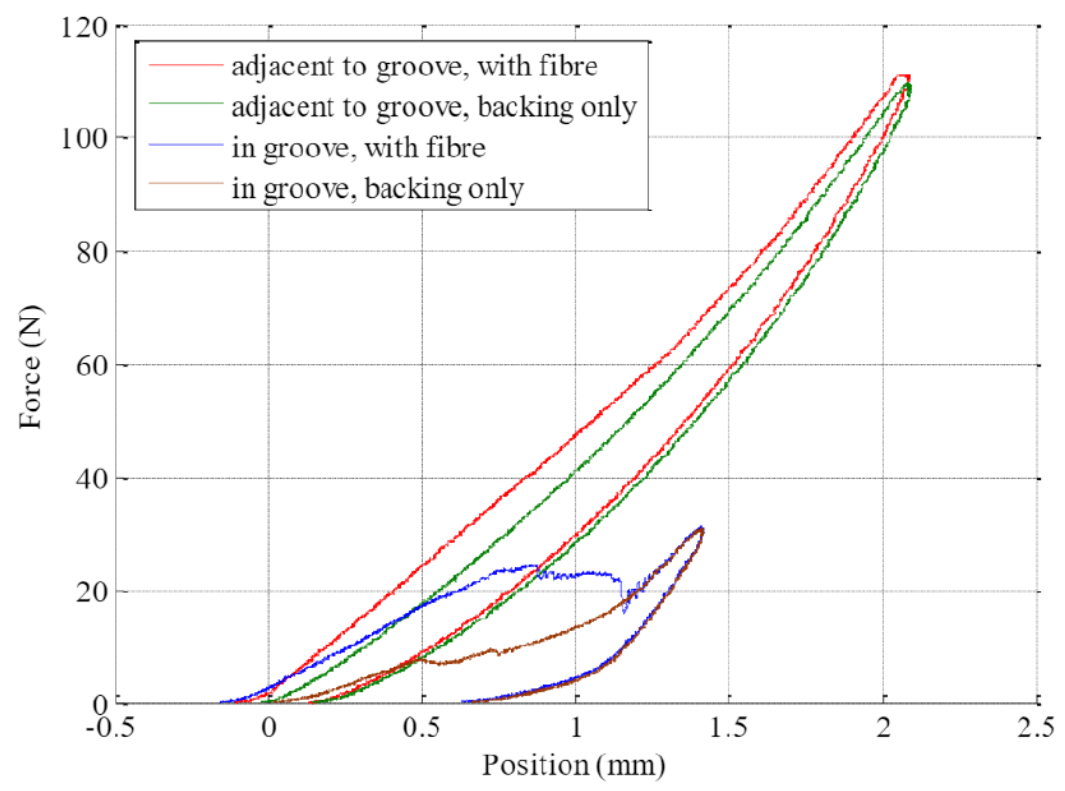

FiguRE 2.9: Force versus displacement curves for different chopping conditions - from $[3]$

\subsection{Research Objectives}

The backing roll grooves seen in the aforementioned literature were the main inspiration for the present work. Based on the observed force reduction seen previously when chopping carbon fibers in grooves $[2,3]$, the intent was to use this force reduction to reduce cutting blade wear during extended chopping runs. By intentionally profiling backing rolls and comparing blade wear performance with standard non-grooved, the effects of backing profile on blade wear could be determined.

There were several key research objectives of this work:

- To investigate the effect of backing profile on blade wear,

- To manufacture grooved backing rolls which reduce blade wear as compared to standard plain backings, 
- To examine how process parameters impact blade wear performance, and

- To identify physical processes responsible for blade wear during rotary carbon fiber chopping.

Through running an array carbon fiber chopping tests with grooved and plain backings, and by examining the worn blades produced during these tests, this work endeavoured to provide a better understanding of rotary carbon fiber chopping as a whole. 


\section{Chapter 3}

\section{EXPERIMENTAL SETUP}

\subsection{Apparatus}

\subsubsection{Rotary fiber chopper}

The rotary fiber chopper used to conduct these experiments was the same unit that was used in the previous work by Adamovsky and Alexander $[2,3]$. This unit was a modified Chopcot fiber chopper set up to more closely mirror the design of the largescale fiber chopper used on Dieffenbacher's D-SMC line at the Fraunhofer Project Centre in London Ontario. The chopper was driven by an electric motor connected to a variable frequency drive. Keyed directly to the motor output shaft was the blade roll half of the fiber chopping setup. A face plate was attached to the motor housing, and the backing roll, press roll, and fiber tow routing eyelets were connected to this aluminum face plate. A 3-D model of this chopper can be seen in Figure 2.3, and in Figure 3.1 is a picture of the entire setup, including fiber spool and spindle and the dust containment fume hood.

The motor drive was set to a constant frequency of $15 \mathrm{~Hz}$ for all tests; this corresponded to an output shaft rotation speed of 454 RPM (4540 chops per minute), or a fiber chopping rate of about 1.8 metres of carbon fiber per second. This speed was chosen based on the approximately $2 \mathrm{~m} / \mathrm{s}$ typical full-scale operation speed of the industrial chopper unit during material production with comparable fibers, but was reduced slightly to yield an easy-to-remember conversion of 2500 chops per 5.5 minutes. Further supporting this speed choice was an article which examined thin-edged blade wear during glass fiber chopping and found an optimal speed for reduced blade 


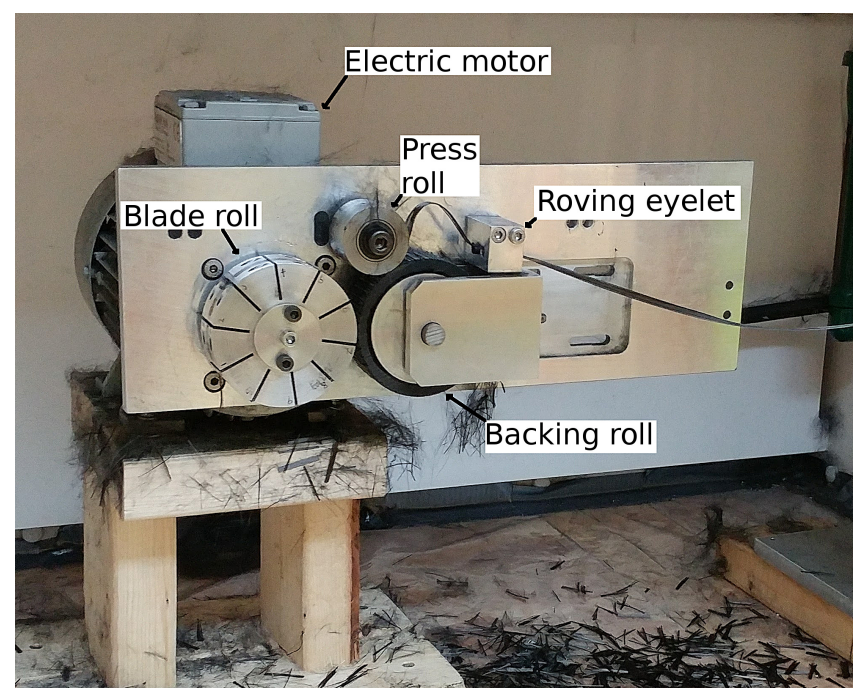

FiguRE 3.1: Annotated picture of actual fiber chopping setup used wear of approximately $1.9 \mathrm{~m} / \mathrm{s}$ [29]. Though the applicability of this research to rotary carbon fiber chopping is unknown due to the inherent differences between these two types of fibers, the chosen value was relatively close to both this experimentally determined "optimum" and to real-world production speeds.

The aluminium blade roll portion of the chopping setup could hold a maximum of 10 blades spaced at approximately 1 inch intervals around its circumference; these blades were swapped once each during an extended wear test to yield 20 specimens each worn increasingly more, ranging from 2500 chops to a maximum of 117,500 chops. Blades were indexed to the same protrusion distance out of the blade roll by attaching them while a machined key sat butted against the base of the blade holder groove. Each blade was secured by two small set screws which were hand-tightened to securely hold the blades against the wall of the blade groove. The blade roll was mounted to the motor shaft in a "high-blade" configuration; i.e. the wall of the blade groove applied pressure to the backside of the blades during rotary chopping operation. This was done to reduce damage to the blades, as early calibration tests showed high rates of blade breakage if the blades did not have a solid support during chopping. 
The backing rolls were press-fit onto the aluminium roll holder, which was unpowered and rotated freely about a steel shaft on a low-profile needle roller bearing. This backing roll sub-assembly was affixed to the roll holder yoke, and the entire assembly could be shifted towards or away from the blade roll assembly. A clamping force between the two rolls of approximately $100 \mathrm{~N}$ was used during each test.

The entire rotary chopper and fiber feed setup was contained within a laboratory fume hood connected to an exhaust system. This was deemed necessary due to the amount of dust and airborne fibers generated during fiber chopping and the dangers posed by carbon fiber dust to both electrical systems and human health. The continuous carbon fiber tows were pulled through a guide eyelet and into the chopper by friction between the blade roll and backing as well as between the backing roll and the press roll. The chopped fibers were allowed to fall downwards into a collection bin which was emptied every 2500 chops ( 5.5 minutes). The machine was briefly stopped during each of these intervals to change blades and/or empty the collection bin; however, no significant effects from stopping and starting the machine were expected due to the relatively low frequency of stoppage (48 stop-start cycles per 120,000 chops).

\subsection{Materials}

\subsubsection{Carbon fibers}

The carbon fibers used for all experiments were PYROFIL ${ }^{\mathrm{TM}} 15 \mathrm{~K}$ fibers. See Appendix 2 for a data sheet on fiber properties. Sized fibers were used to replicate typical chopped fiber production conditions, and given that polymer sizing agents typically comprise less than $2 \%$ of total carbon fiber tow mass, the effects of sizing on the blade wear results were expected to be negligible. 


\subsubsection{Blades}

Thin, M2 tool steel cutting blades were used for the experiments. These blades are of the same material and geometry as the "baseline" blades used in the works by Adamovsky and Alexander [1-3]. A drawing of the blade dimensions can be seen in Figure A1.1 in Appendix 1. The blades had a total thickness of 0.010 inches or approximately $0.25 \mathrm{~mm}$, and a manufacturer-stated Rockwell hardness of between 63 and 66 HRC. The blade tips had a double-bevel grind geometry, with a grind angle of $9^{\circ}$ and a hone angle of $16^{\circ}$. These blades were used to maintain some continuity between this work and the previous theses, and were also chosen due to the highly visible wear response seen when using thin steel blades for carbon fiber chopping. While blades made of harder materials have been shown to last longer [2], steel blades are considerably less expensive, plus, for the purposes of this study, greater magnitudes of wear were easier to detect and quantify with lower-powered microscopes and equipment.

\subsubsection{Backing rolls}

The backing rolls used in the experiments were polyurethane rubber of varying hardness: 80, 90, and 95 Shore A durometer. These harnesses were checked with a standard tire durometer, with actual durometer values measured at 84, 90, and 97A. The outer diameters of these rolls were precisely machined to match with the outer diameter of the blade roll, $76.07 \pm .1 \mathrm{~mm}$. The 23 to $25 \mathrm{~mm}$ wide backing roll sections were press-fit onto a fixture and machined on a lathe to ensure the rotational speeds of the blade roll and backing roll would be matched during cutter operation. This setup can be seen in Figure 3.2.

For the tests with intentionally-profiled backing rolls, grooves were machined into the polyurethane rolls using a vertical mill. A 1/32 inch carbide fluted end mill 


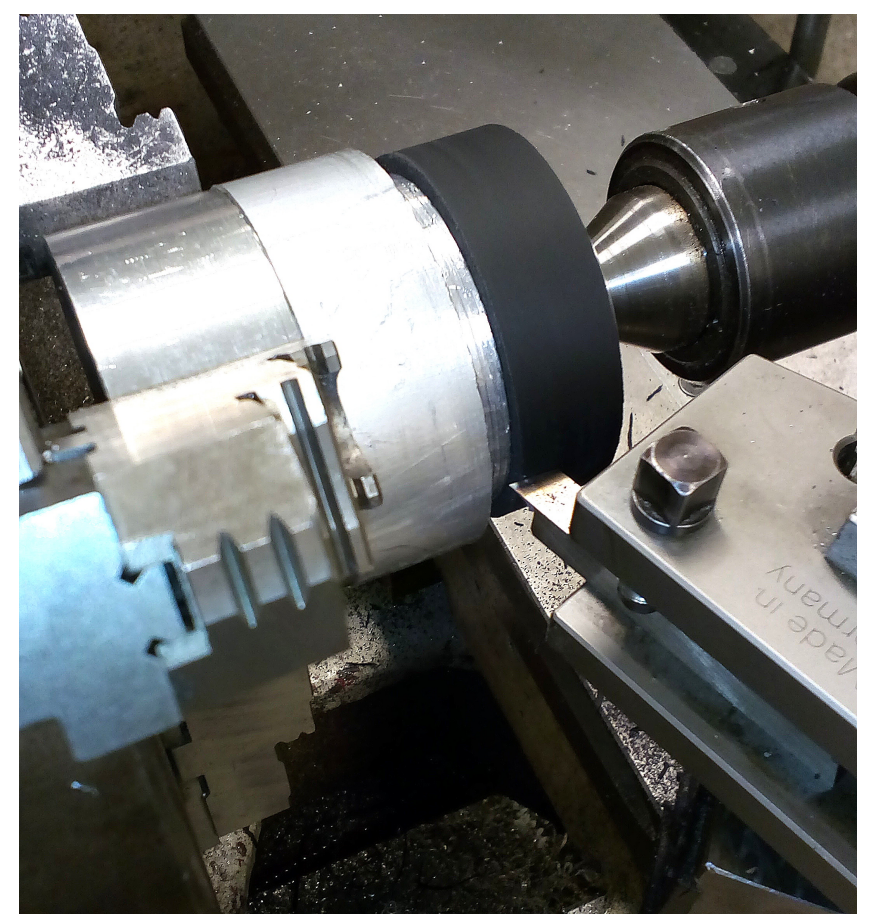

FiguRE 3.2: $25 \mathrm{~mm}$ backing roll section on lathe fixture Ready for cutting to required outside diameter

was used to cut the grooves of varying depth and width. After being turned to the proper diameter, the backing roll blanks were mounted on a fixture affixed to the vertical mill cutting table. See Figure 3.3 for a picture of the groove machining setup and Figure A1.2 in Appendix 1 for technical drawings of the groove cutting fixture and its components.

High spindle speeds ( $>2500$ RPM) were required to cleanly machine the fairly soft polyurethane materials, as at lower speeds the softer polyurethane had a tendency to flex around the cutter instead of being cut properly. In total, 50 grooves were cut in each backing roll; this number was chosen based on observations from the work by Alexander [3], and to increase the probability that blades would mesh with the grooves consistently. Note that the issue of blades failing to mesh with backing roll grooves does not apply to the full-scale chopping unit on the D-SMC line as the large unit uses a helical layout for its blades such that there is always a blade in contact 


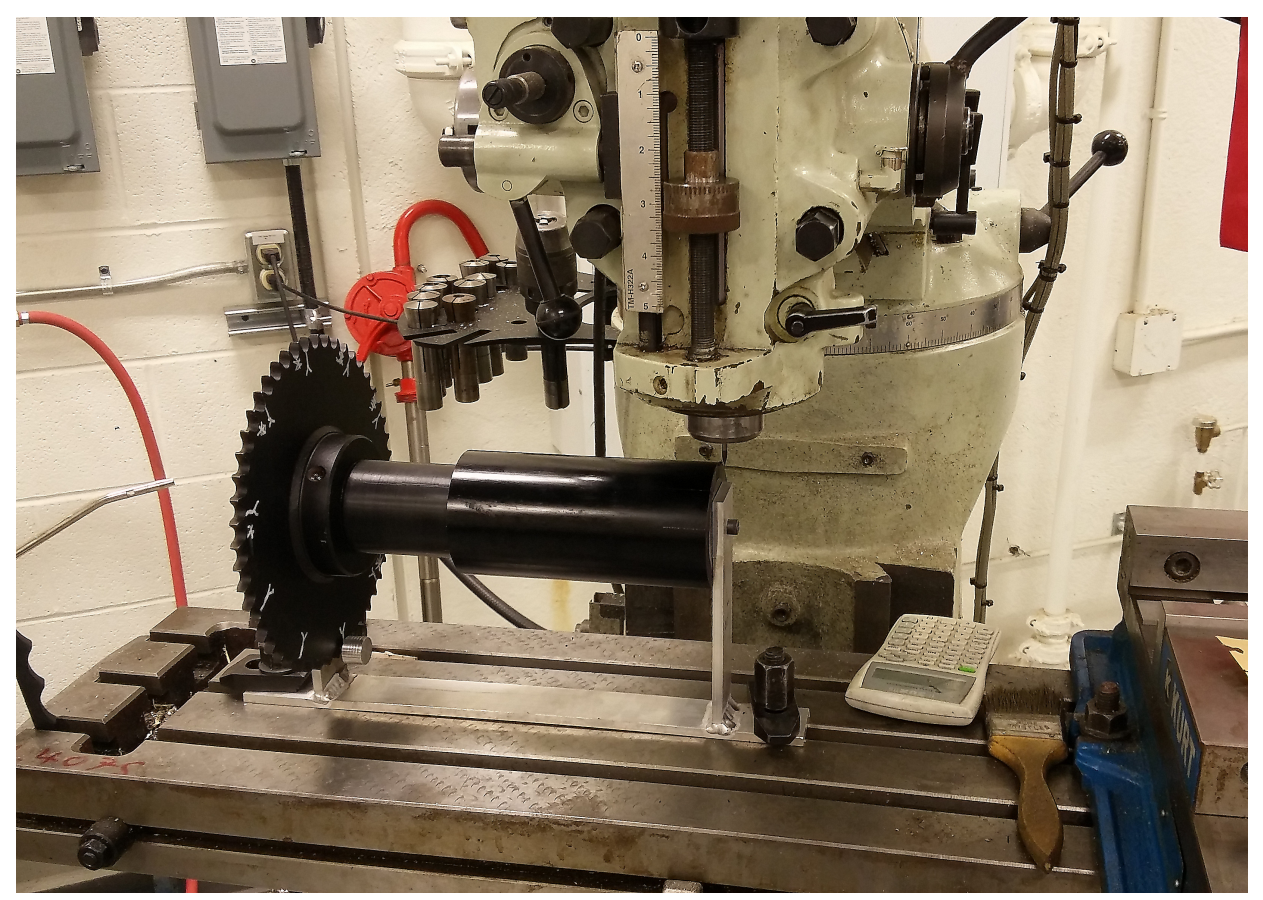

FIGURE 3.3: Backing roll blank and machining fixture mounted on vertical mill with a point on the backing roll. This ensures that blades are consistently aligned with grooves in the backing roll, as can be seen in Figure 3.4.

\subsection{Procedure}

\subsubsection{Experiments}

Each experiment was an extended wear test to simulate the lifespan of a blade chopping carbon fibers for SMC production. To obtain an array of data points, from $2.5 \mathrm{~K}$ chops up to $117.5 \mathrm{~K}$ chops, each blade was swapped once during testing. Worn blades were collected at $2.5,5,10,15,20,25,30,35,45,55,65,75,85,90,95,100,105,110$, 115, and 117.5 thousand chops per blade. Tests were run in a stop-and-go fashion, stopping briefly every $2.5 \mathrm{k}$ chops to empty the fiber collection bin and, if necessary, to swap blades. 


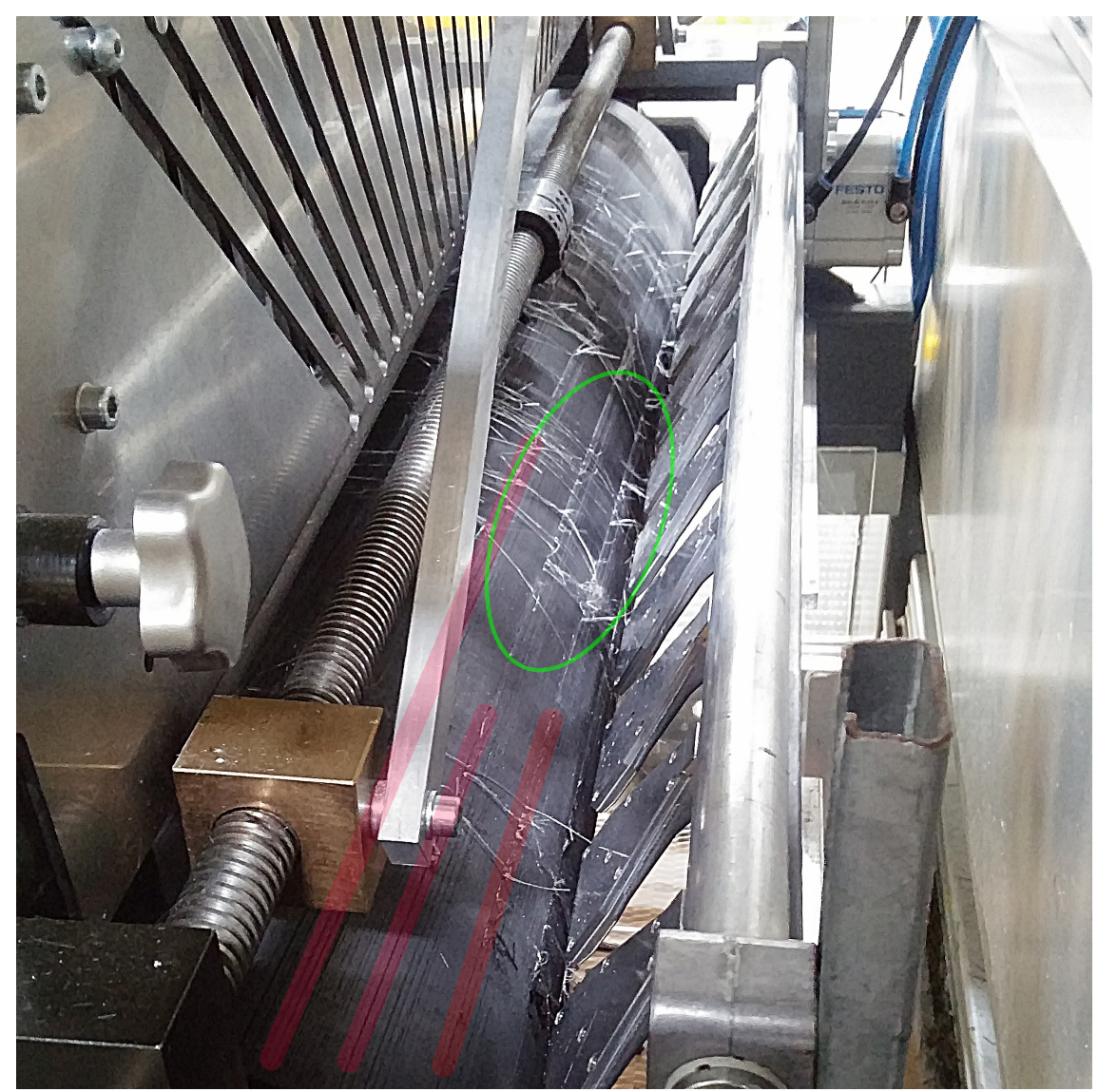

Figure 3.4: Naturally-formed helical grooves in full-size SMC fiber chopper backing A portion of the grooves are highlighted in red, with the entire grooves continuing across the backing. The white fibers (highlighted in green region) are unchopped ductile fibers that became trapped in these grooves during an experimental production run

The shorthand names for each test in Table 3.1 can be interpreted as follows:

- C denotes control test with plain backing,

- 1, 2, and 3 denote the PU roll hardness (80, 90, 95 Shore A respectively),

- $\mathrm{S}$ denotes $0.80 \mathrm{~mm}$ square end mill used to machine grooves,

- Sw denotes "wide" grooves machined by two passes of the $0.80 \mathrm{~mm}$ square end mill, and

- D denotes "deep" grooves (machined to a depth of $1.75 \mathrm{~mm}$ versus $1 \mathrm{~mm}$ ). 
TABLE 3.1: Configuration of conditions for each experiment

\begin{tabular}{cccc}
\hline Test number & $\begin{array}{c}\text { Backing hardness } \\
\text { (Shore A) }\end{array}$ & $\begin{array}{c}\text { Groove width } \\
(\mathbf{m m})\end{array}$ & $\begin{array}{c}\text { Groove depth } \\
(\mathbf{m m})\end{array}$ \\
\hline \hline C1 & $80 \mathrm{~A}$ & $\mathrm{~N} / \mathrm{A}$ & N/A \\
C2 & $90 \mathrm{~A}$ & N/A & N/A \\
C3 & $95 \mathrm{~A}$ & N/A & N/A \\
Sw2D & $90 \mathrm{~A}$ & 1.60 & 1.75 \\
S1D & $80 \mathrm{~A}$ & 0.80 & 1.75 \\
Sw3 & $95 \mathrm{~A}$ & 1.60 & 1.00 \\
S3D & $95 \mathrm{~A}$ & $1.0^{*}$ & $1.5^{*}$ \\
\hline
\end{tabular}

The "C" tests were used to set an experimental baseline of wear rates with which the grooved test results could be later compared. The varying groove parameters in the following tests were based off observations of naturally-formed grooves in the works by Adamovsky and Alexander and grooves formed during the three control tests. Figure 2.8 shows the groove profile seen in the previous theses, which is very similar to the naturally-formed major grooves that developed during the control tests. A comparison of all three control test backing rolls can be seen in Figure 3.5.

The grooves for the final test (denoted S3D, dimensions marked with an asterisk) were not machined in, but rather allowed to form naturally by running the chopper with fresh blades but no carbon fibers. The dimensions are marked with an asterisk as they are not exact, but rather a rough approximation based on measurements from the broken-in roll before new blades were swapped in and the S3D test began. Exact measurements of these groove dimensions were impossible to obtain using contact methods as the PU backing would deform when contacted, and cross-sections for optical measurement could not be obtained without damaging the backing roll.

The goal of these experiments was to attempt to replicate the grooves seen forming naturally in the backing rolls and harness their observed chopping force reducing abilities to reduce wear during high-volume rotary chopping. 


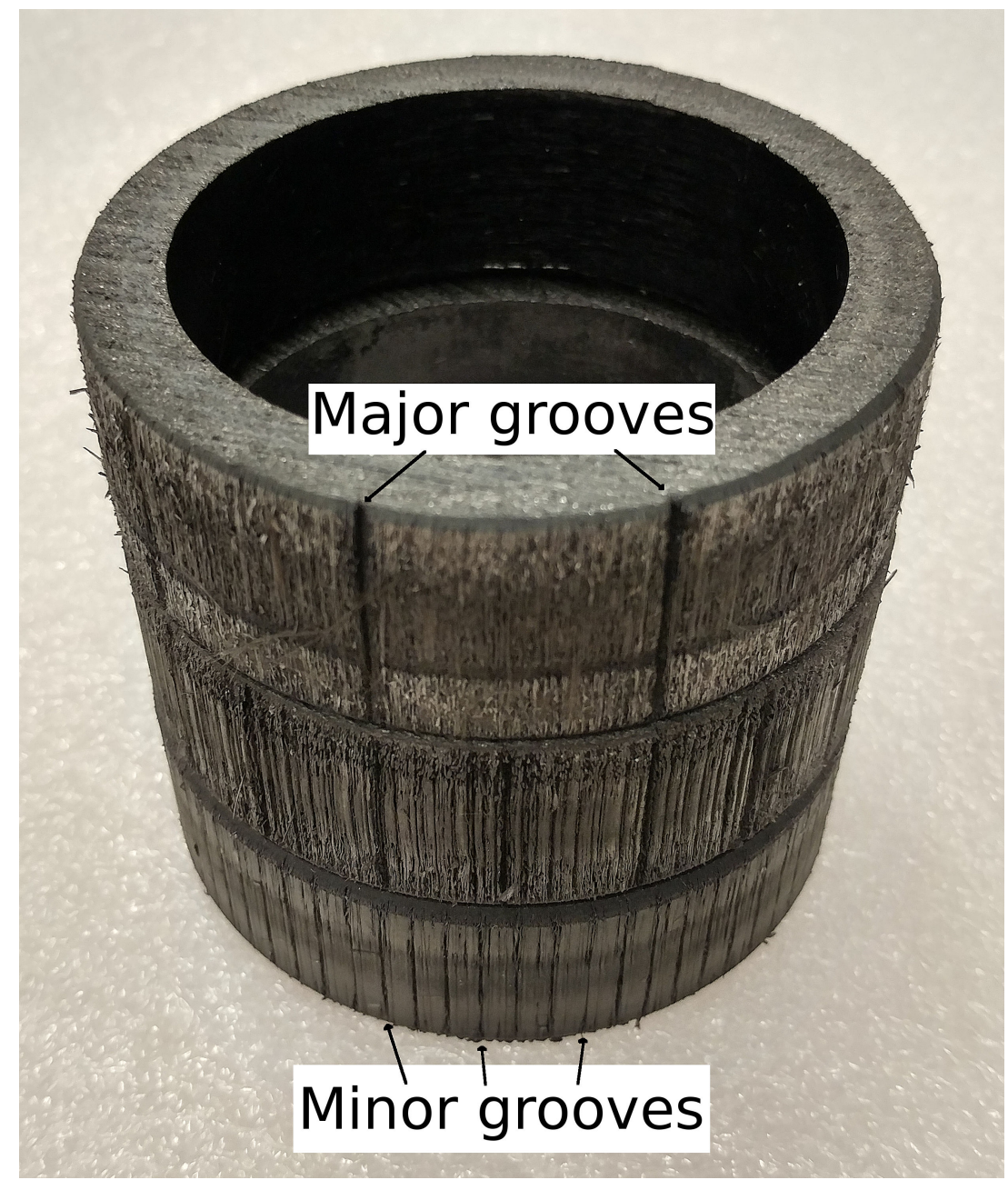

FiguRE 3.5: Side view of all control test backing rolls stacked (C3 on top, C1 on bottom)

\subsubsection{Measurement}

The primary wear metric used to quantify the magnitude of wear at each interval for the various backing configurations was blade tip worn distance, measured from the worn region of each blade when butted against a flat datum edge. While mass loss is a typical metric for measuring wear, issues encountered with blade chipping and breakage during tests and while removing blades from the chopper made this impossible. Similarly, the chopped carbon fiber collection method did not allow abraded metal 
particles to be collected, so worn distance was chosen as the primary wear metric to be measured. A crescent-shaped worn region (such as those seen in Figure 2.4) formed on the blades where the majority of abrasion from the carbon fibers took place, so the maximum distance between this worn region and a flat datum edge could be measured to yield a maximum blade wear value. This crescent-shaped worn region was expected due to the nature of the chopper setup and of carbon fiber tows, as it was assumed that one point on the blade would see the highest frequency of chops during the test, leading to uneven abrasion of the cutting edge and the formation a worn crescent and peak wear point. This method of measurement had the benefit of being non-destructive, so the blades remained whole for further analysis. Figure 3.6 shows an example of how the blade worn distance was measured by examining the blades butted against a flat datum surface.

Pictures were taken of the worn region, and measurements were extracted using open-source GNU Image Manipulation Program photo editing software. The linear distance (in pixels) between the edge of the worn crescent and the datum edge was measured for the front and back face of each blade. Several measurements were taken within the worn region, with the maximum value kept as the worn distance. This measurement was converted into mm based on the calibrated resolution of the microscope camera. Both the front side and back side worn distances were measured, and the mean value of the two was taken to represent the blade wear.

Along with worn distance values from the blade side-views, high-magnification composite images of the blade edges were also captured using an Olympus BH-2 binocular microscope. While the Zeiss microscope clearly showed the highly abraded blade regions as darker sections than the surrounding ground region, even under maximum magnification they just appeared to be areas which were worn smooth. While the maximum magnification for the Zeiss microscope was 50x, it was clear that a higher-powered scope was needed to better characterize the wear patterns 


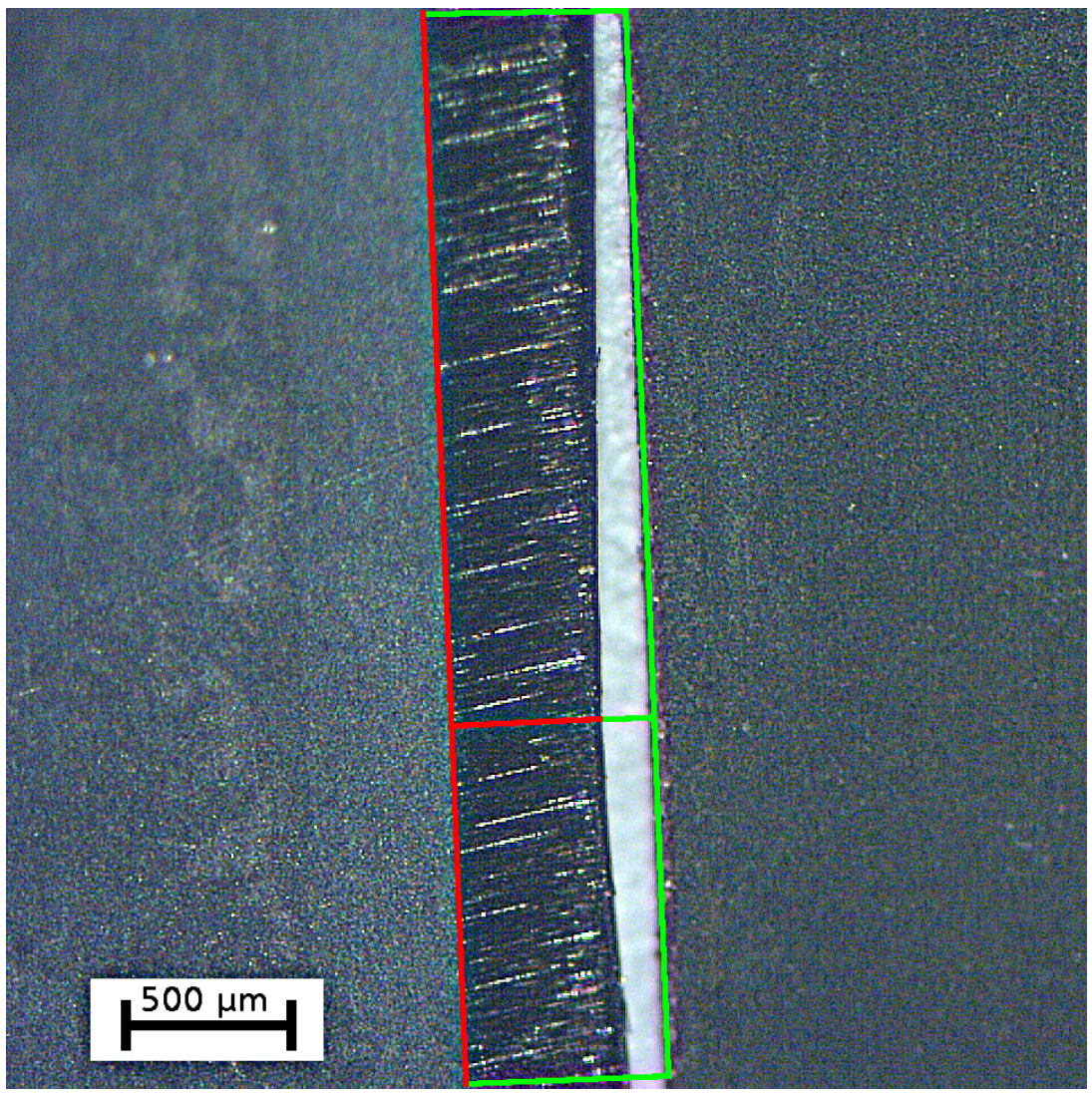

FiguRE 3.6: Measured micrograph of blade worn region - captured using a Zeiss Stemi 2000-C stereo microscope

on the blade sides. The blades were first cleaned in an ethanol solution, then the maximum worn regions on both the front and back faces were examined under 400x magnification. Due to the changing angles of the blade grind, hone, and rounded tip regions, an enhanced depth-of-field (EDF) image processing algorithm was used to combine a number of images at varying focus levels into one composite image which showed the entire worn region from minimal wear to the tip edge in clear focus. Pictures were taken using a 9 MP OMAX A3590U camera and ToupView v3.7 image capture software.

Cutting edge rounding was also examined, and the worn regions of the blades were investigated under high magnification. To examine cutting edge rounding, crosssections of blades were cut at the maximum wear point using a wire-EDM machine. 
The peak wear points were identified and marked on the blades during side-view measurement. The cut faces were polished using several increasingly-fine grades of sandpaper, from 1000 to 2500 grit, to smooth the surface and remove any rust and debris which accumulated after the cutting process. Since the area of interest was only the tip radius, not the blade microstructure, no further polishing or etching of the cross-sections was performed. The cut blades were then mounted upright using modelling clay with the cross-section facing upwards, and the surface was examined using the same Olympus microscope and OMAX camera combination as was used for the high-magnification side-view analysis. Again, EDF composite images of the tip cross-sections were generated from several pictures captured at different focus levels to ensure the entire blade tip was in focus for later image processing.

\subsubsection{Data analysis}

Data analysis was first and foremost performed by measuring the blade worn distances and tabulating the results. The plots generated from these experimental results detail the wear progression of blades during their typical production lifespans. For the side view worn distances, measurements consisted of the pixels between the edge of the worn blade and the edge of the datum edge. Open-source GIMP image processing software was used for micrograph preparation and measurement. To get these values, a mild "unsharp mask" filter was first applied to the images to boost the contrast between blade edges and the neutral background. The parameters for this filter were Radius $=0.1$ and Amount=1.0. After this, worn distance was measured at several spots within the worn region to ensure the peak was found, with the maximum wear value recorded. Scaling of the images was calculated manually based on the measured size of a datum blade and related to the images on a per-pixel basis. This scaling process was repeated before each microscopy session to account for any changes to the microscope setup, as the lower-magnification microscope used for these measurements 
was located in a shared lab space. In Figure 3.6 the red lines denote the grind region of the blade, while the green lines were used to measure the worn distance. Actual measurement lines were only 1 pixel wide; they have been thickened for illustration purposes in Figure 3.6. Measurement from the beginning of the ground region of the blade to the maximum worn region was attempted but abandoned due to variability in the way the blades were ground; reliable measurements could not be obtained as some blades had a larger ground region than others.

For all pictures taken with the Olympus BH-2 microscope a 40x Olympus MPlan40 objective lens was used, corresponding to a calibrated image resolution of $13.5 \mathrm{px} / \mu \mathrm{m}$. The high-magnification EDF composite images of the blade sides were combined into large images comparing the magnitude of wear on the front and back faces of the blades. The disparity between the magnitude of wear on the front and back faces was examined, as were the defining wear features present under varied conditions.

More extensive analysis was performed on the blade tip cross-section pictures to quantify the blade tip radii and magnitude of cutting edge rounding. These images were imported into GIMP photo editing software and a Gaussian blur filter was applied to smooth the edges of the blade. The blur radius used was $50 \mathrm{px}$ as this provided an adequate middle-ground between filtering edge noise and preserving the overall blade profile, and the Infinite Impulse Response (IIR) formula was used as this is better suited to photographs [9]. This was done to get an approximation of the blade tip profile while eliminating interference from shadows, scratching, and other discontinuities around the perimeter of the cross-section. The contrast setting of the blurred image was then maximized and the image brightness adjusted until the outline of the blade tip matched with the dimensions of the original image. These images were then exported for further analysis using MATLAB.

To measure the minimum radius of the blade tips, a MATLAB script was used 
to extract the blade profile as a series of coordinates. The images were imported into MATLAB and converted to a binary black-and-white format, as this is required for the boundary detection algorithm used. The boundary of the blade tip was extracted using the bwtraceboundary function. A simple function was then developed to find the minimum y-value of the blade tip (the trace y-values were inverted) and two inflection points on either side of this minimum value where the slope of the profile line begins to decrease. The radius of curvature was found from a circle running through these three points. Figure 3.7 shows the various steps taken to get from the original image to the extracted boundary trace and tip radius.

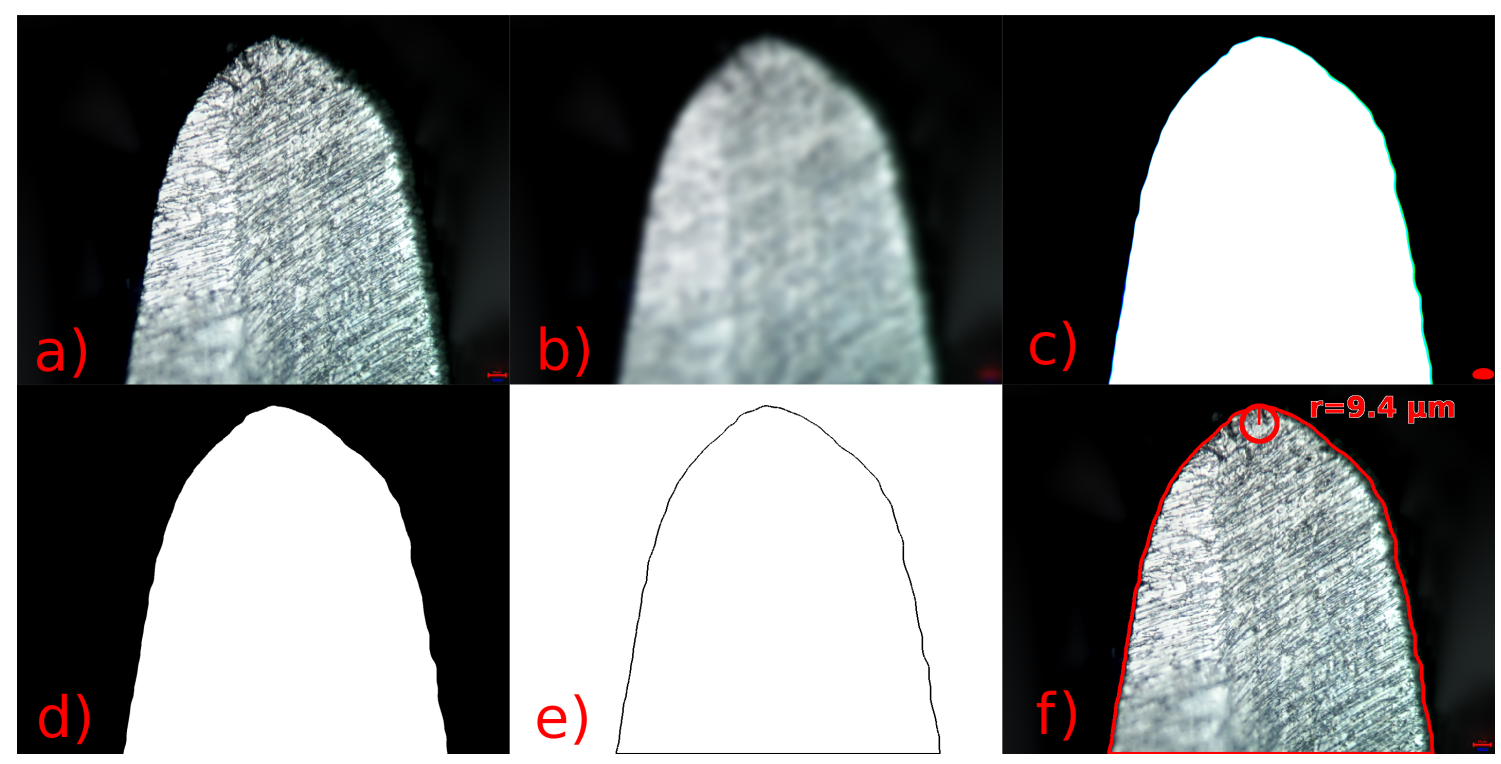

FiguRE 3.7: Steps in the blade tip minimum radius extraction method

a) Original micrograph,

b) micrograph after Gaussian blur,

c) blurred micrograph with maximum contrast,

d) binary black and white image from MATLAB,

e) boundary extracted in MATLAB,

f) boundary and calculated tip radius superimposed onto original blade micrograph

The blade tip cross-section images were also used to measure wear based on tip worn distance as compared to an unused blade. The blades were aligned based on width at the bottom of the combined cross-section image to create a composite 
image using the sharp blade as the tip, then progressively-worn blades were aligned on top of this combined blade to make a side-by-side image for comparison between the blades. A line was projected across horizontally from the tip of the sharp blade, and the vertical distances from this line to the tips of the worn blades were measured. An example of this method with enlarged lines can be seen in Figure 3.8.

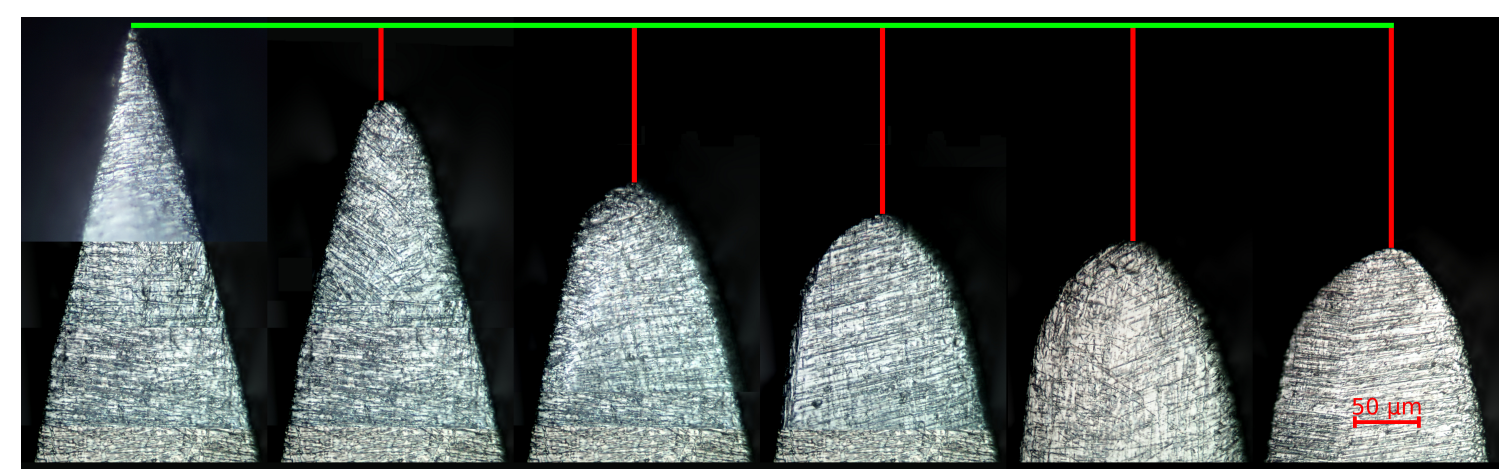

FiguRE 3.8: Blade tip worn distance measurement method

For a final comparison method, the worn blade tip outlines from the $\mathrm{C} 1$ control test were superimposed over the aligned images of the Sw2D and S3D blade tips, highlighting differences in both wear magnitude and worn blade geometry. These outlines were extracted in the same way as the individual tips for radius measurement but instead the combined image of all blades aligned was used. This was then superimposed over the other aligned blade images, using the as-received sharp blade to align the outlines. Both sides of the cross-sections were examined, denoted as "front to left" or "front to right" depending on orientation. These can be found in subsection 4.3.1 in the Results section. 


\section{Chapter 4}

\section{RESUlts}

\subsection{Blade Wear Measurements}

\subsubsection{Front and rear face worn distances}

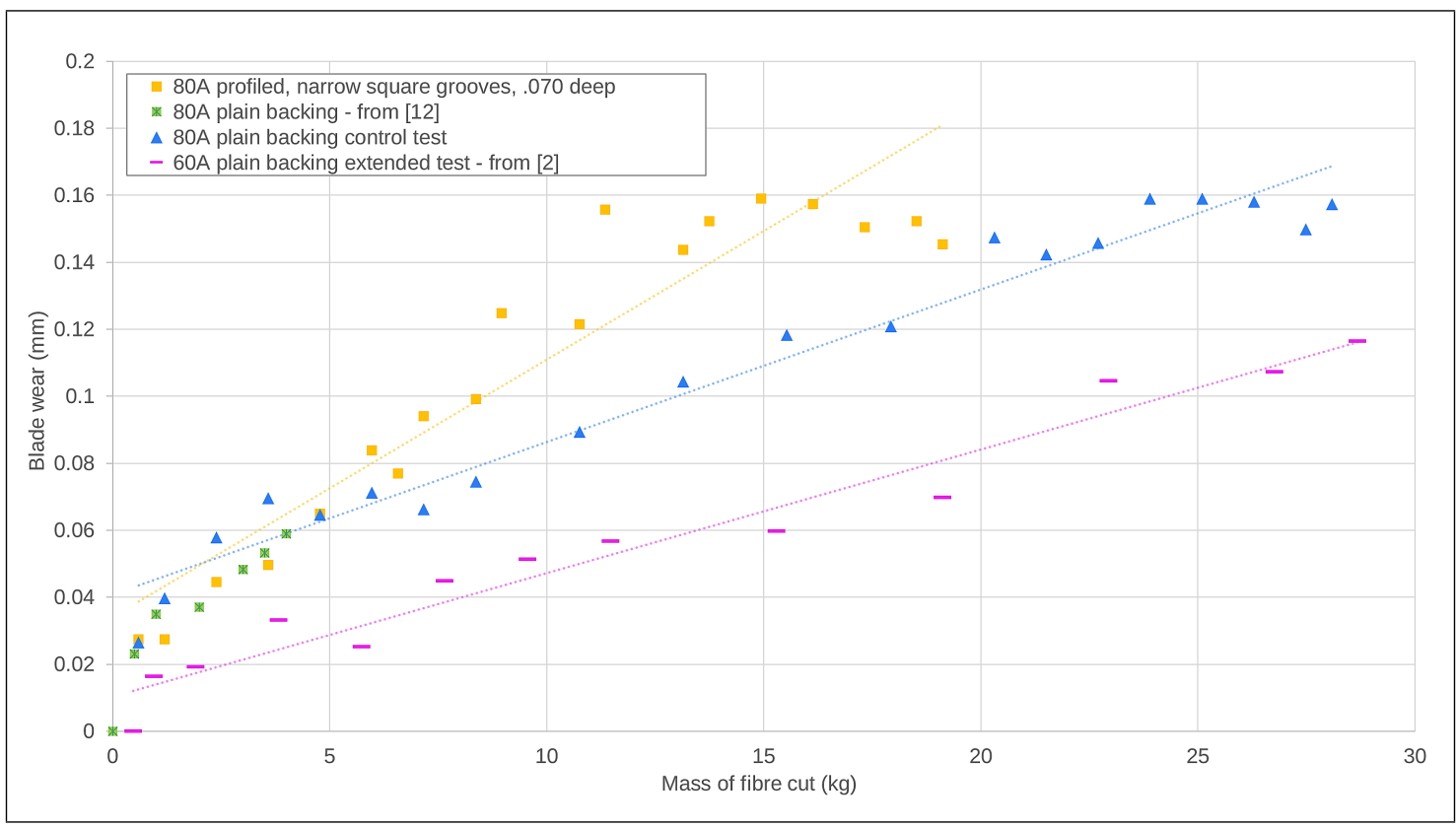

FiguRE 4.1: Blade wear versus mass of chopped fiber for all 80A durometer test runs Also contains some data from Adamovsky [2]

The grooved 80A durometer test (S1D) was one that had to be stopped before the 120,000 chops goal was reached as it often failed to chop the fiber tow fully starting around 75,000 chops (approx. $18 \mathrm{~kg}$ chopped fiber). The 80A results are compared here to the 60A extended wear test performed by Adamovsky [2], which showed much lower overall wear and slightly lower wear rate. Limited data from the 80A plain backing test performed by Adamovsky is also included, which tracked well 
with the $80 \mathrm{~A}$ results collected in the present work, although that test was ended after 50,000 chops of 12K fiber (approx. $5 \mathrm{~kg}$ total chopped fiber weight).

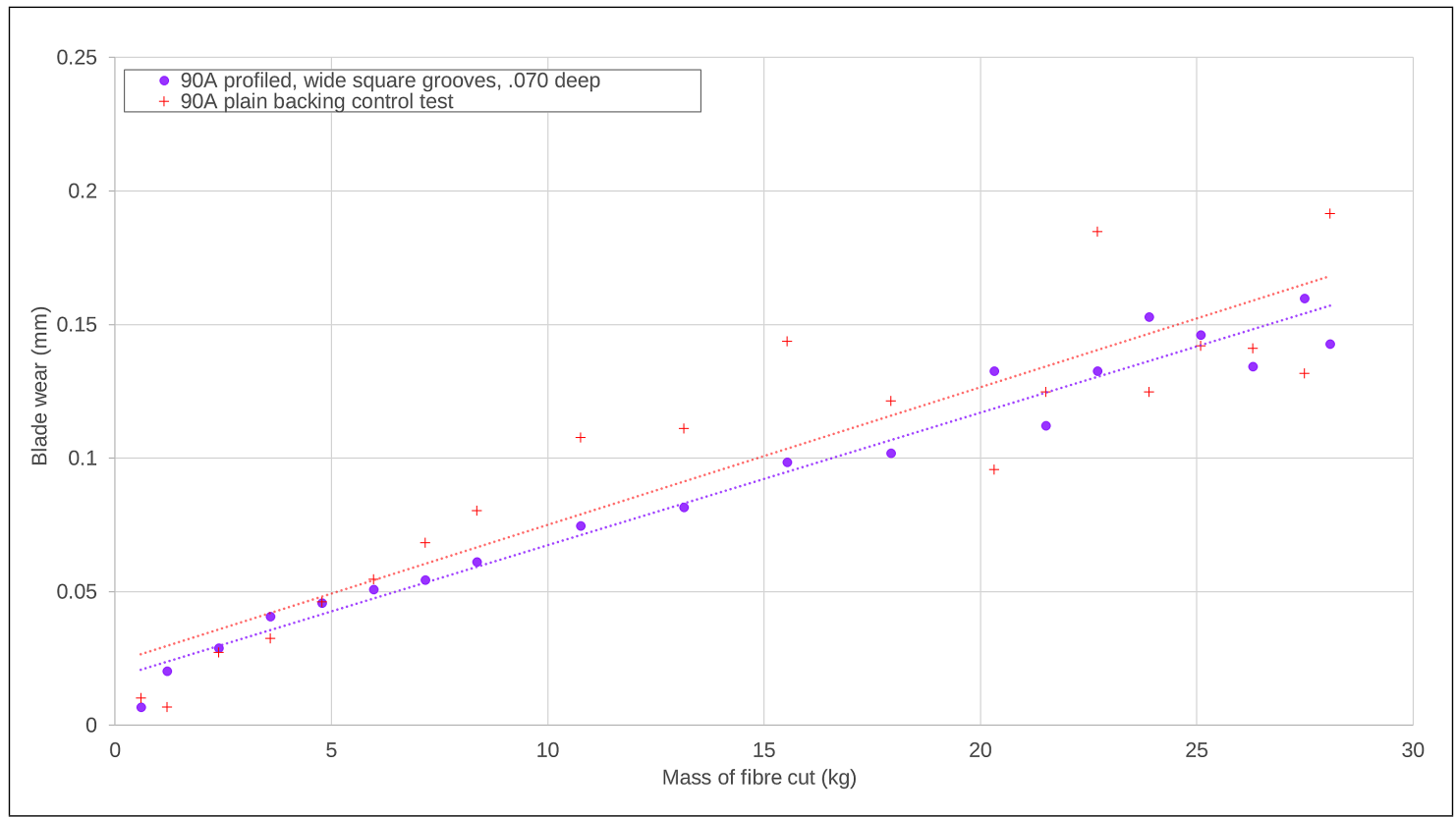

FiguRE 4.2: Blade wear versus mass of chopped fiber for all 90A durometer test runs

The grooved 90A backing test (Sw2D) saw only a slight improvement over the $90 \mathrm{~A}$ control test wear rate, although the control test had higher peaks and a higher overall magnitude of wear. 


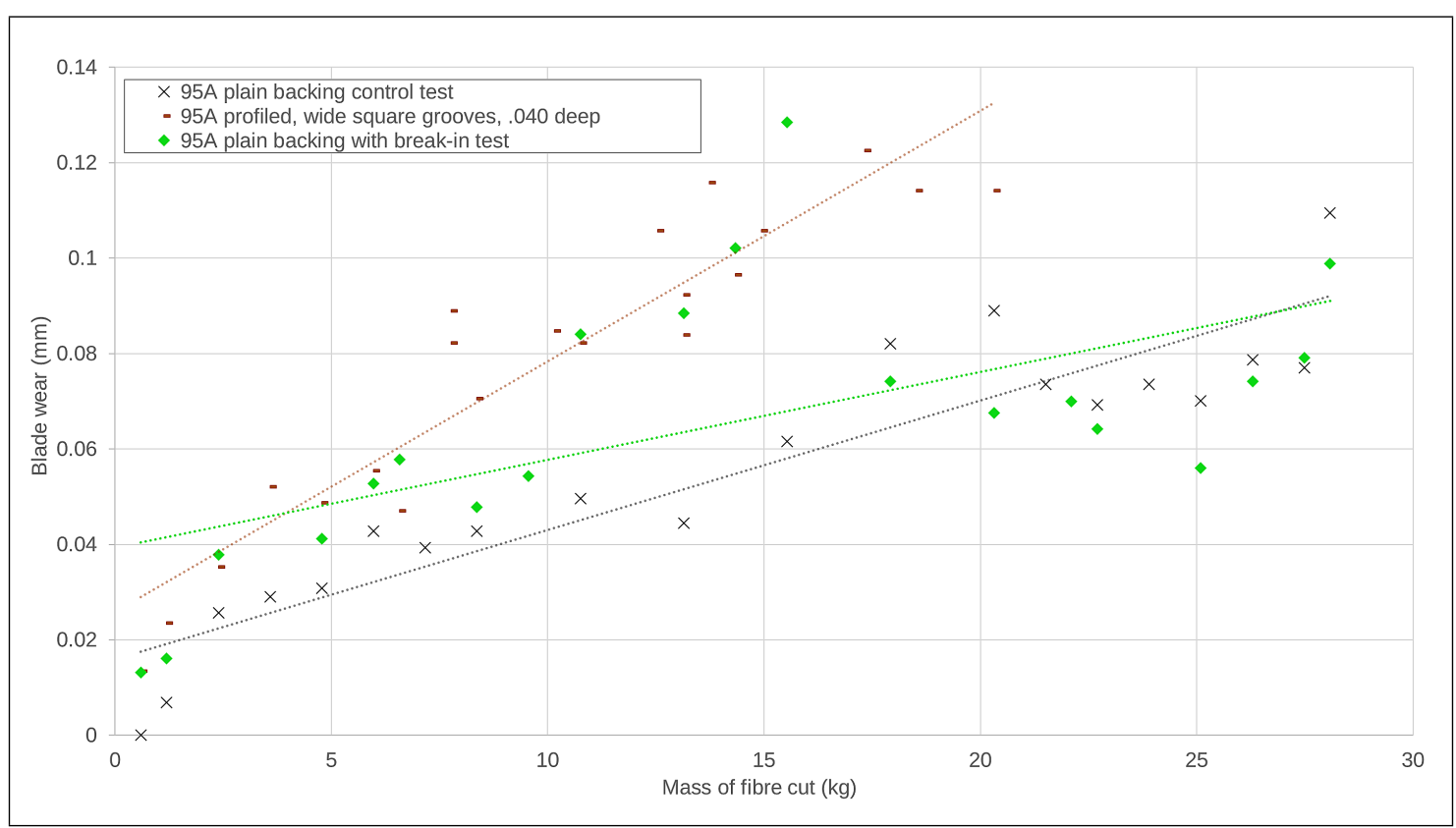

Figure 4.3: Blade wear versus mass of chopped fiber for all 95A durometer test runs

The 95A tests (Figure 4.3) yielded the most surprising results, as they consistently showed lower wear rates than other test conditions. The best performing tests were the $95 \mathrm{~A}$ plain backing rolls, both with a break-in period (test S3D) and plain (C3). These showed the lowest wear rates and lowest overall magnitude of wear, while the 95A grooved test (Sw3) performed on-par with the 90A grooved test.

In all of these plots, linear fits are applied to the data to yield trendlines for comparison purposes. These linear models are not intended to represent the actual wear progression or model the process; rather, they are provided as a visual aid allowing easy comparison between the overall wear trends of the different test conditions. It should be noted that both linear and logarithmic trendlines were applied to the data sets, but linear was chosen as, despite how the data sets may appear, it produced higher average fitness values $\left(\mathrm{R}^{2}\right.$ and the logistic $\mathrm{R}^{2}$ equivalent in Microsoft Excel) than logarithmic. 


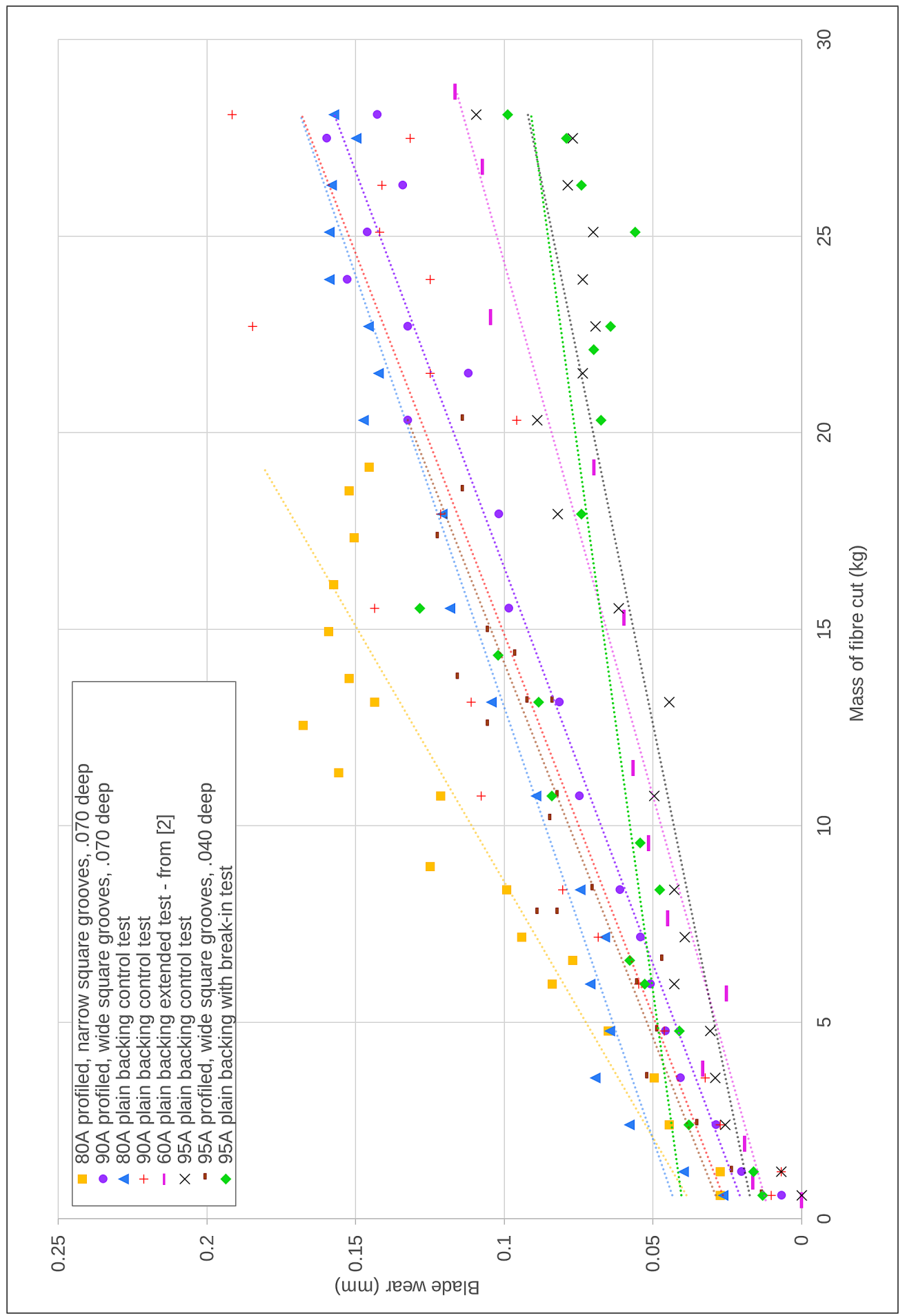

Figure 4.4: Blade wear versus mass of chopped fiber for all test runs Also contains limited data from Adamovsky [2] 


\subsubsection{Blade wear based on tip measurement}

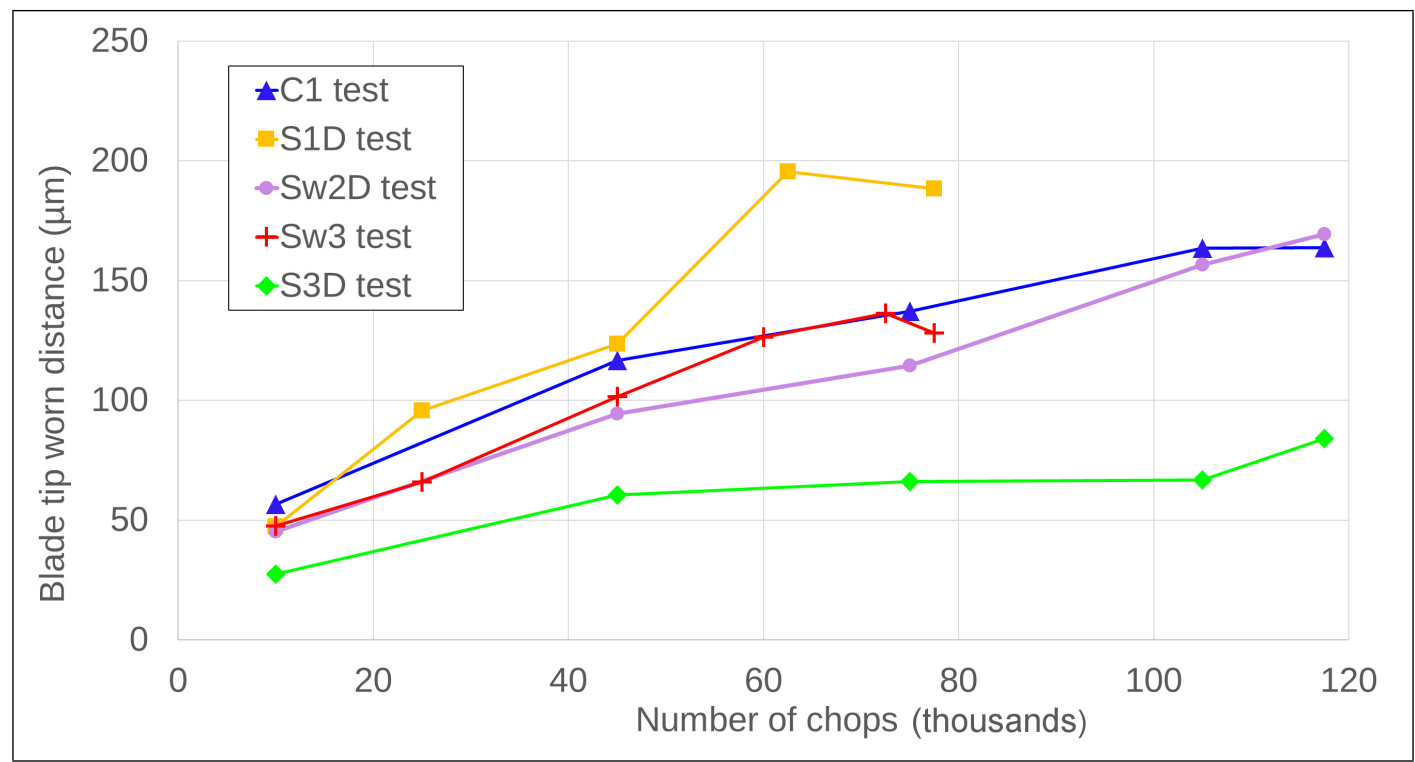

FIGURE 4.5: Plot of blade tip worn distances measured from cross-sections

The blade tip worn distance wear measurements collected from the cross-sections showed similar patterns to the side-view wear values. Again, the S3D had the lowest overall wear and wear rate, the Sw2D, Sw3, and C1 tests were all within a similar range, and the highest wear was seen during the S1D test. 


\subsection{WEAR PATtERNS}
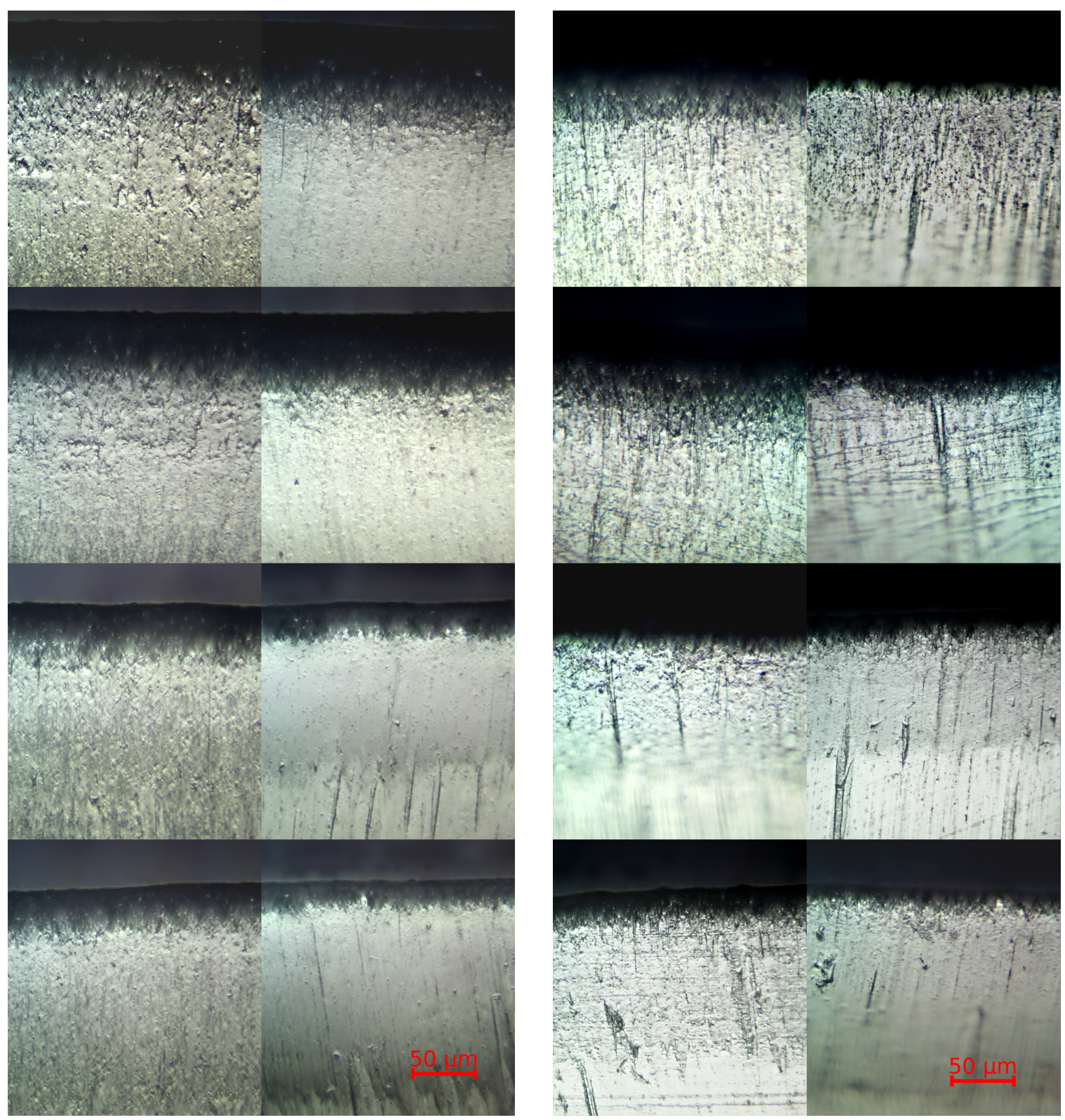

(A) Test C1 (L: front, R: back)

(B) Test C2 (L: Front, R: back)

Figure 4.6: Comparison of maximum wear regions for tests $\mathrm{C} 1$ and $\mathrm{C} 2$ From bottom: 20k, 35k, 65k, 115k chops

The overall trend seen on all blades was that the size of the worn region on the blade edge (distance from tip to end of visibly abraded area) increased steadily along 
with number of chops.

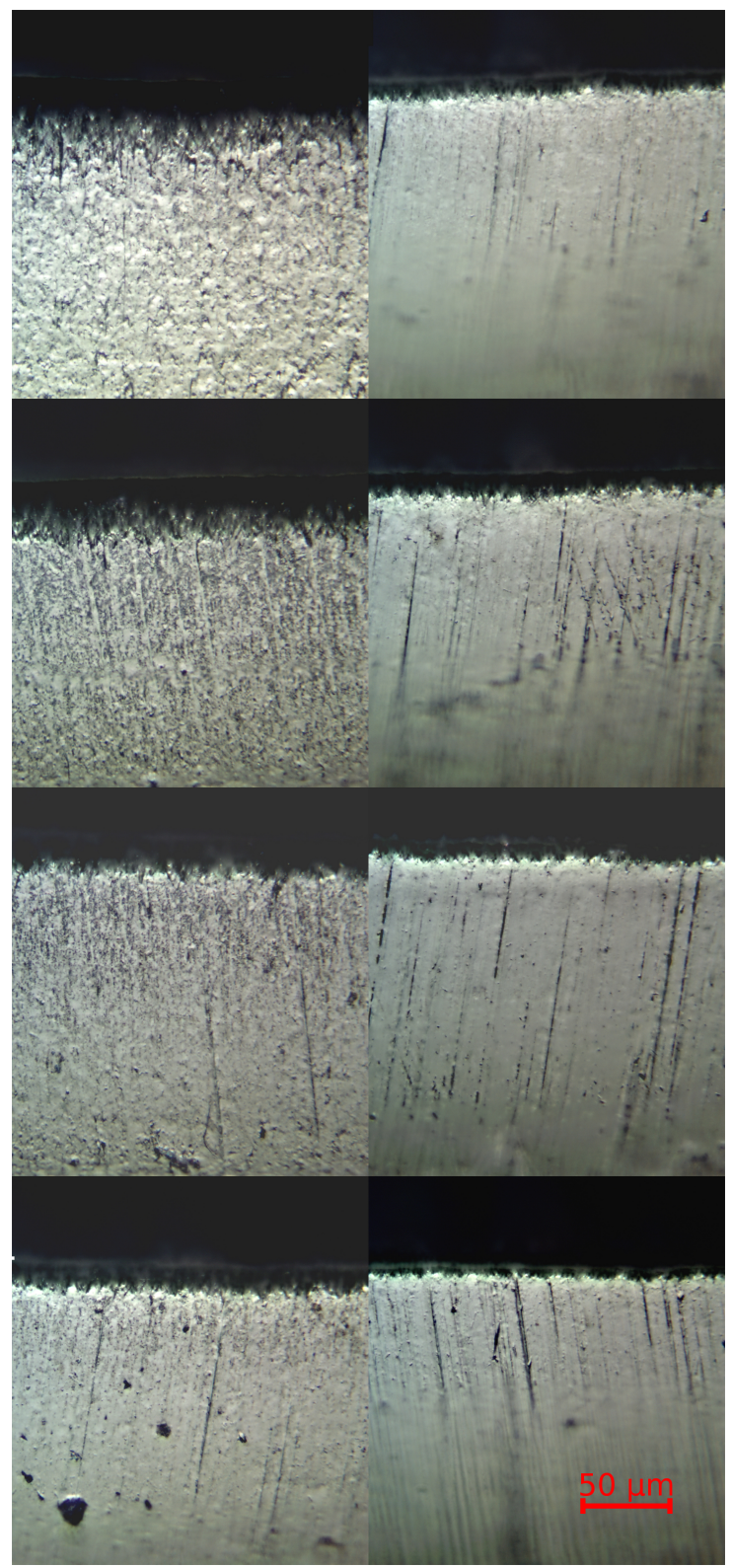

(A) Test C3 (L: front, R: back)

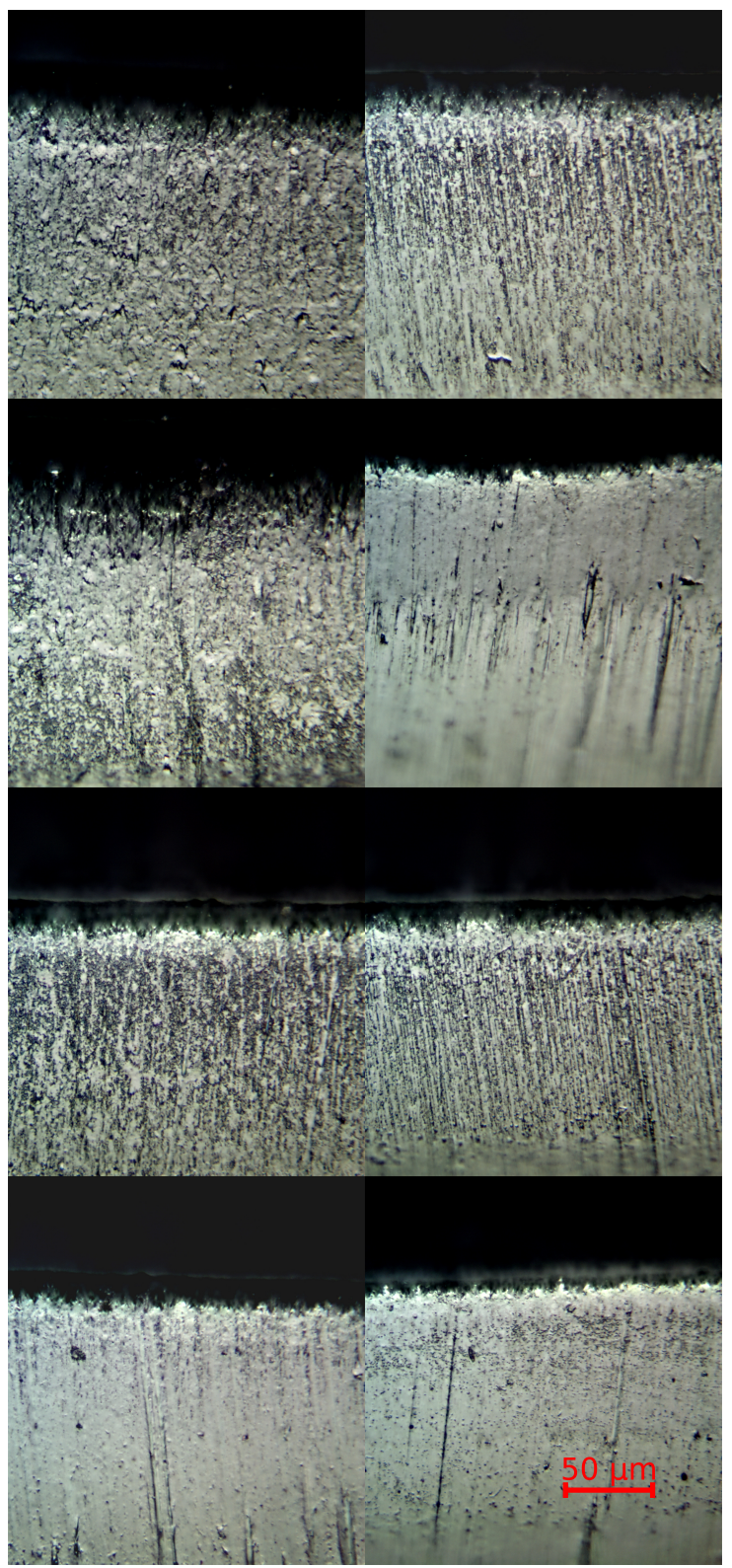

(в) Test S3D (L: front, R: back)

Figure 4.7: Comparison of maximum wear regions for tests C3 and S3D From bottom: 20k, 35k, 65k, 115k chops

Between the 3 control tests plus the S3D test, C1 showed the greatest abraded region size on both front and back faces. 


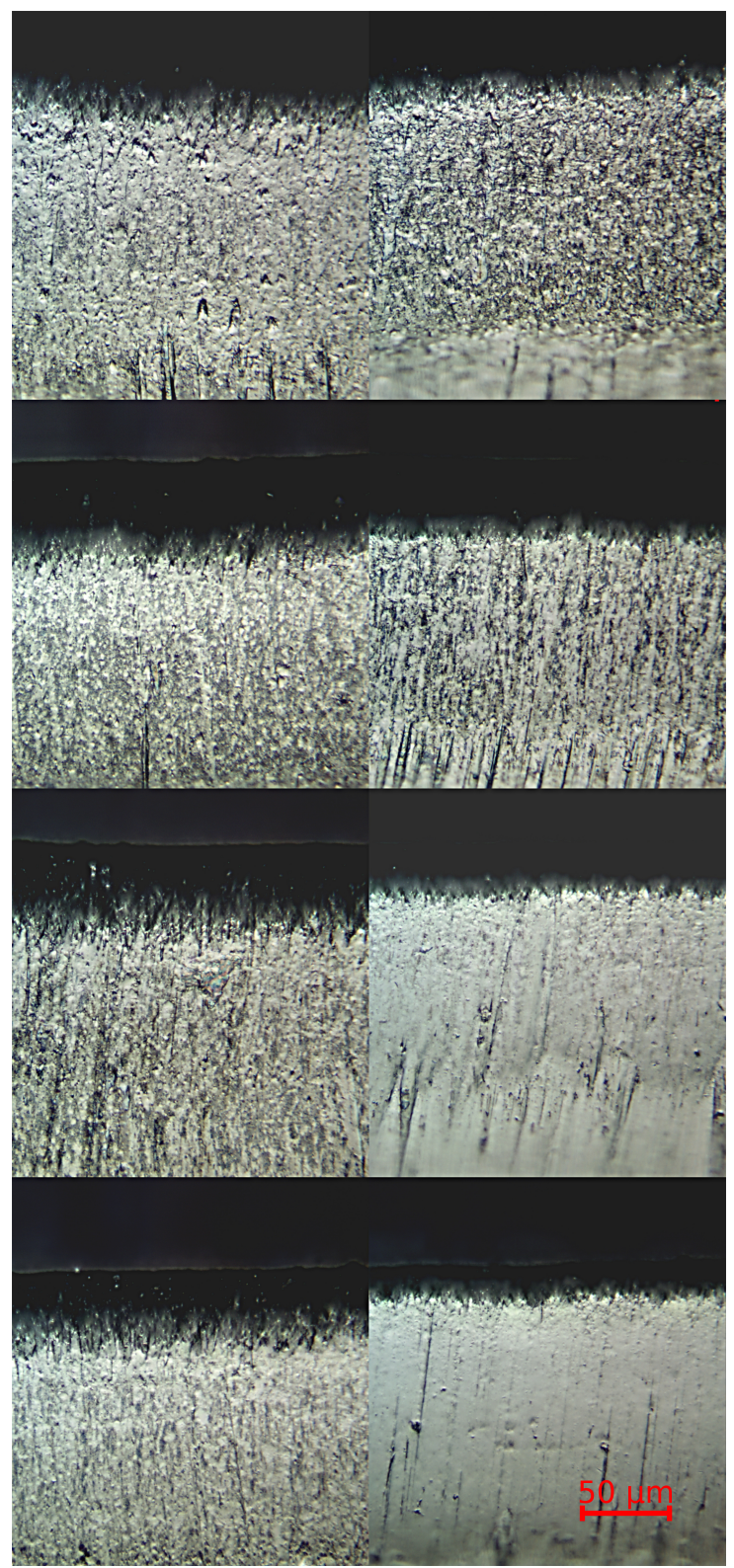

(A) Test S1D (L: front, R: back)

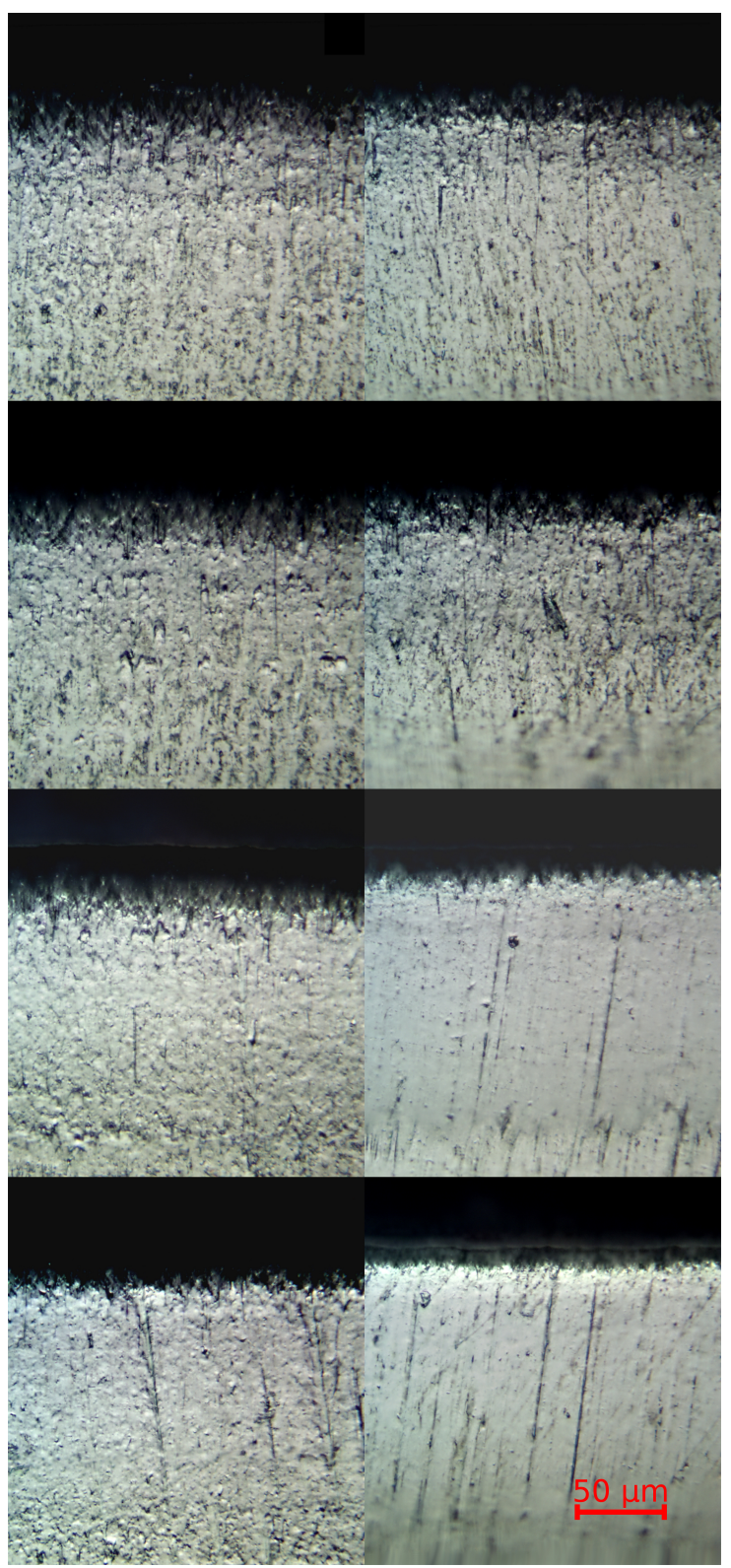

(B) Test Sw3 (L: front, R: back)

Figure 4.8: Comparison of maximum wear regions for tests S1D and Sw3 Subfig. (A), from bottom: 20k, 35k, 57.5k, 80k chops Subfig. (B), from bottom: 20k, 35k, 57.5k, 85k chops

The difference in wear between front and back faces is most apparent in test S1D, which was also the worst-performing test condition. In the majority of side-view micrographs, striations can be seen where the blade was ground during production; 
these remained visible on nearly all back-face micrographs, with better performing conditions maintaining these striations on the front face as well for the entirety of the experiment.
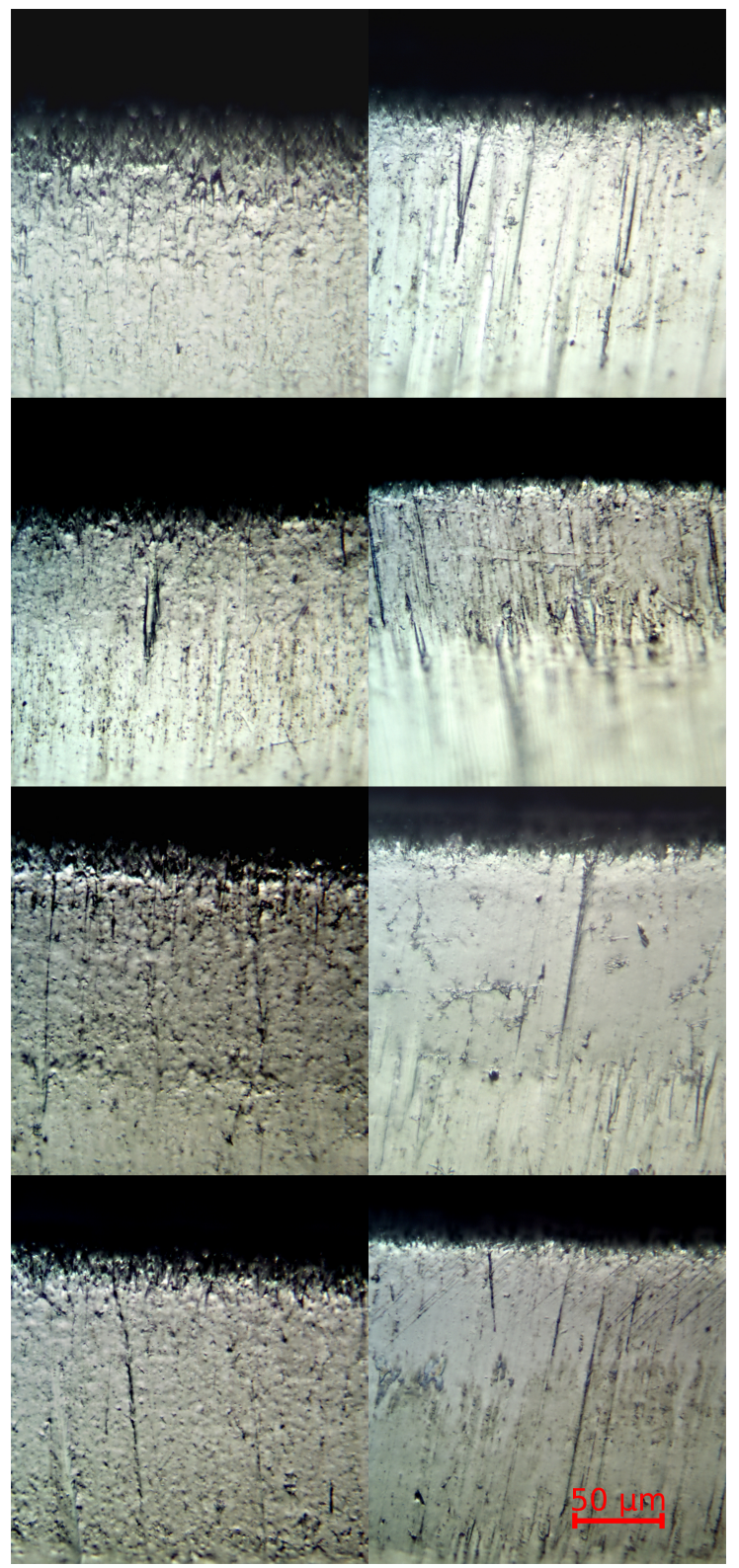

Figure 4.9: Maximum wear regions for test Sw2D (L: front, R: back) From bottom: 20k, 35k, 65k, 110k chops

In nearly every image featured in this section, the worn region on the front face of each blade was larger than the worn region on the back face; however, the 
the differences between the size of abraded regions and the severity of wear varied considerably between tests. This is elaborated on in the next chapter.

\subsection{Cutting Edge Rounding}

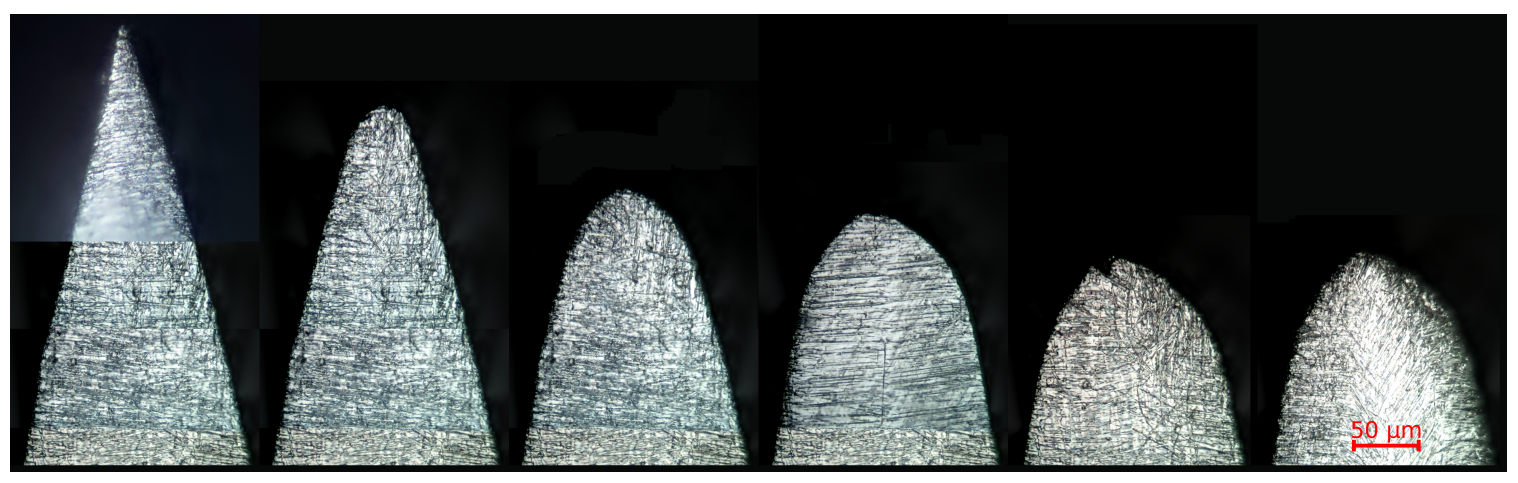

Figure 4.10: C1 test blade tip rounding, front face to left From left to right: as received, 10k, 45k, $75 \mathrm{k}, 105 \mathrm{k}, 117.5 \mathrm{k}$ chops

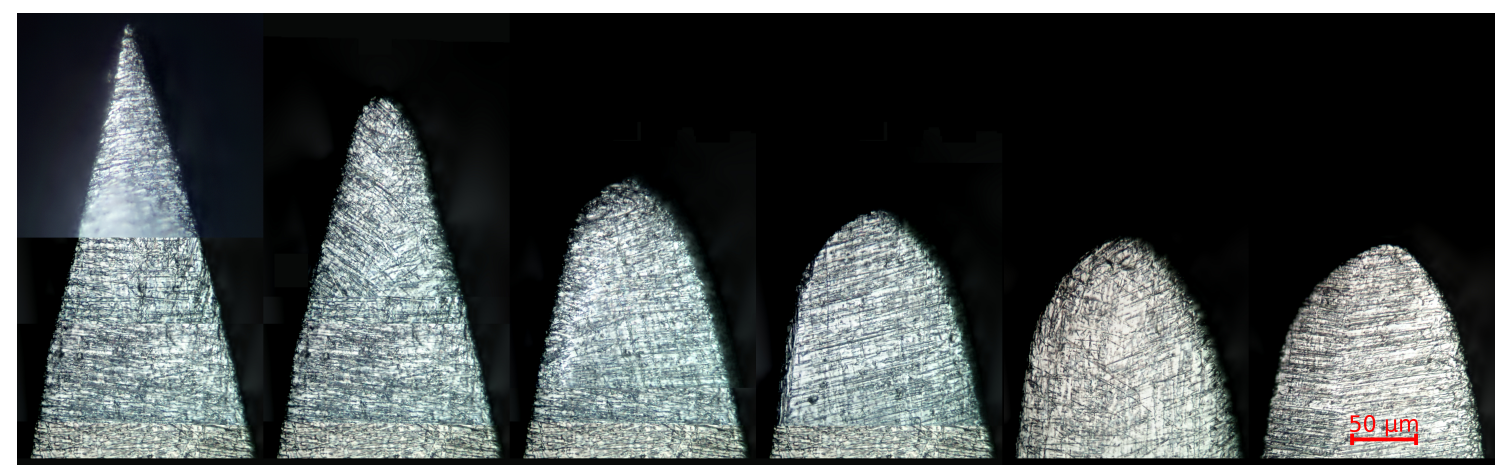

FiguRE 4.11: C1 test blade tip rounding, front face to right From left to right: as received, 10k, 45k, 75k, 105k, 117.5k chops

Aside from the magnitude of wear, differences in the wear progression of the blade tip profile can also be seen. While the $\mathrm{C} 1$ test showed wear further along the front faces than back faces, more mass removal occurred on the back face, thus skewing the blade tip towards the front edge. 


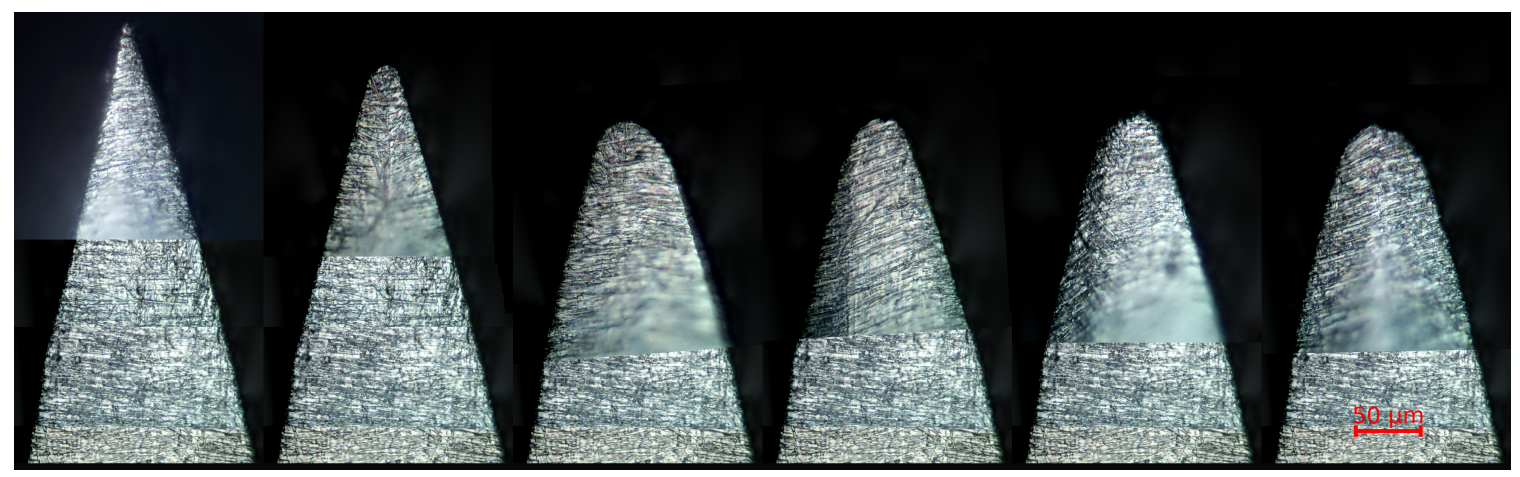

Figure 4.12: S3D test blade tip rounding, front face to left

From left to right: as received, 10k, 45k, 75k, 105k, 117.5k chops

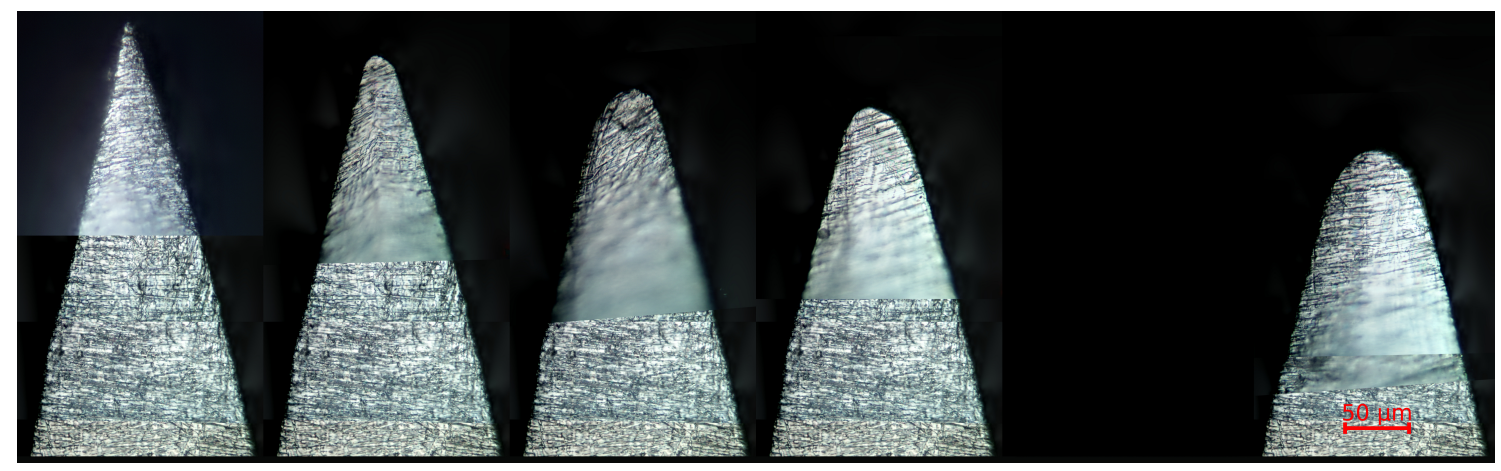

Figure 4.13: S3D test blade tip rounding, front face to right

From left to right: as received, $10 \mathrm{k}, 45 \mathrm{k}, 75 \mathrm{k}, 117.5 \mathrm{k}$ chops

The S3D test did not show a consistent pattern in worn tip geometry, aside from having lower overall wear. Note that the 105k chop blade, front face to right, was damaged during sample preparation so it is not included here. 


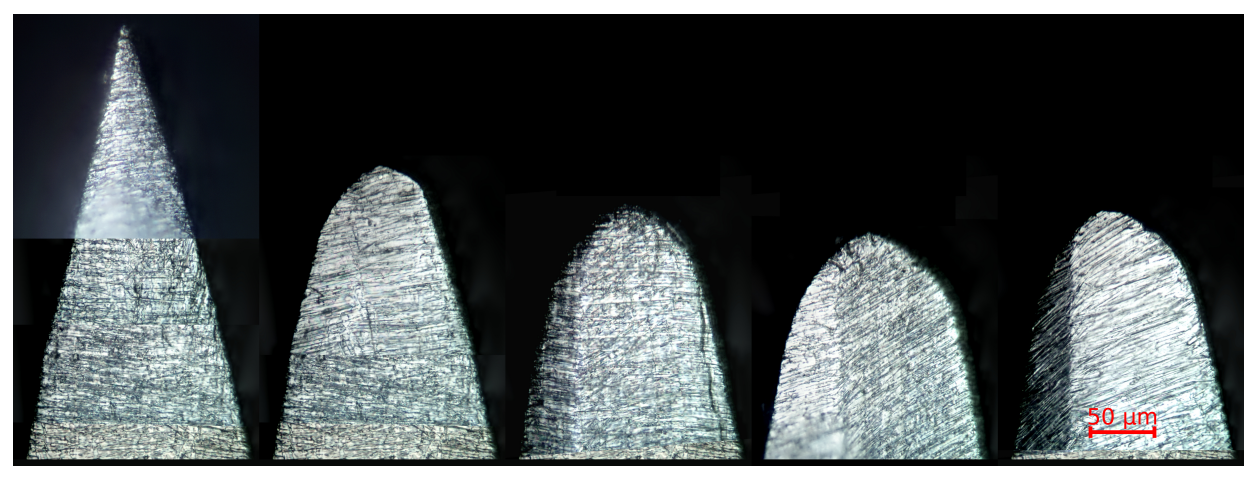

Figure 4.14: Sw3 test blade tip rounding, front face to left From left to right: as received, $45 \mathrm{k}, 60 \mathrm{k}, 72.5 \mathrm{k}, 77.5 \mathrm{k}$ chops

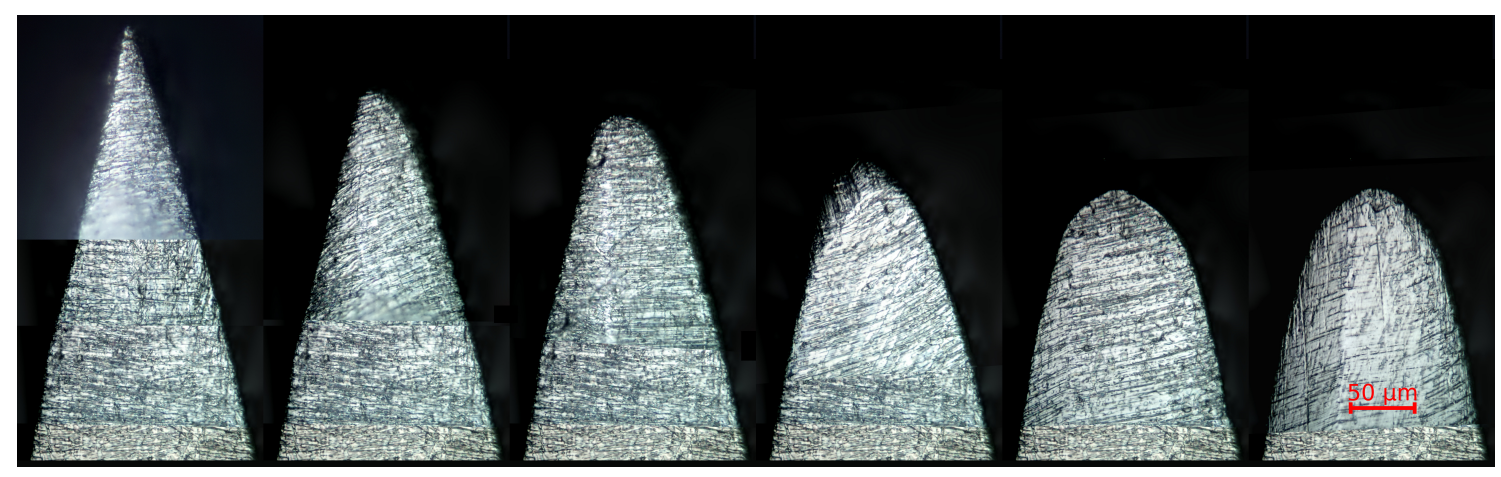

Figure 4.15: Sw3 test blade tip rounding, front face to right From left to right: as received, 10k, 25k, 45k, 60k, 77.5k chops

The Sw3 blades showed a similar pattern to the $\mathrm{C} 1$ blades, with wear further down the front face than the back, but with a large region of removed material on the back face of the tip. Due to some blades becoming unusable during sample preparation, some of the front-to-left and front-to-right blades are at different wear levels. 


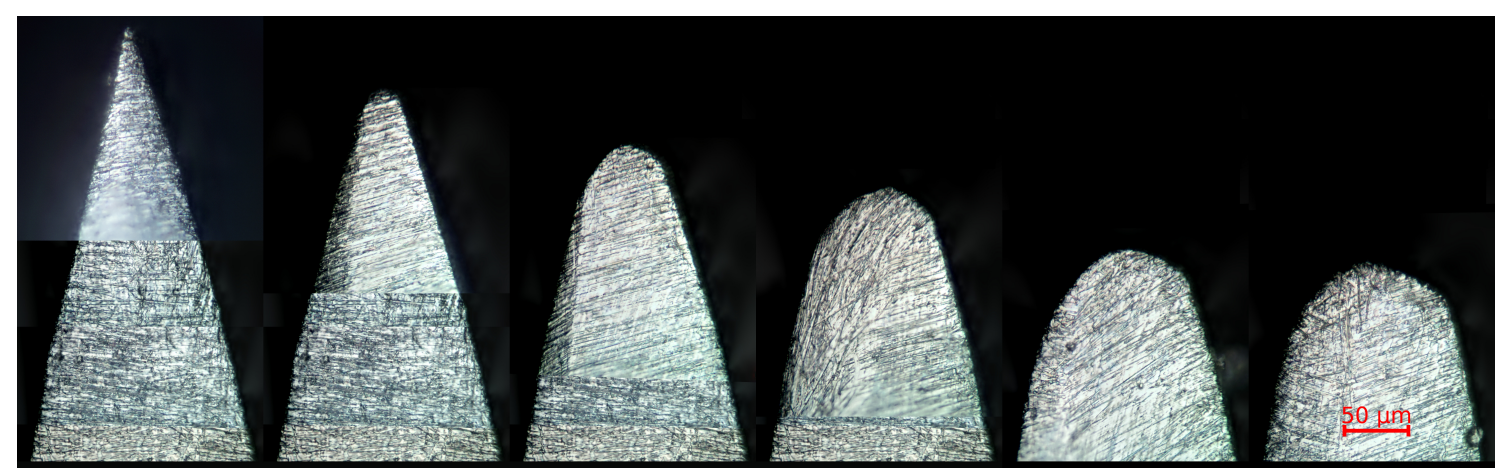

Figure 4.16: Sw2D test blade tip rounding, front face to left

From left to right: as received, 10k, 45k, 75k, 105k, 117.5k chops

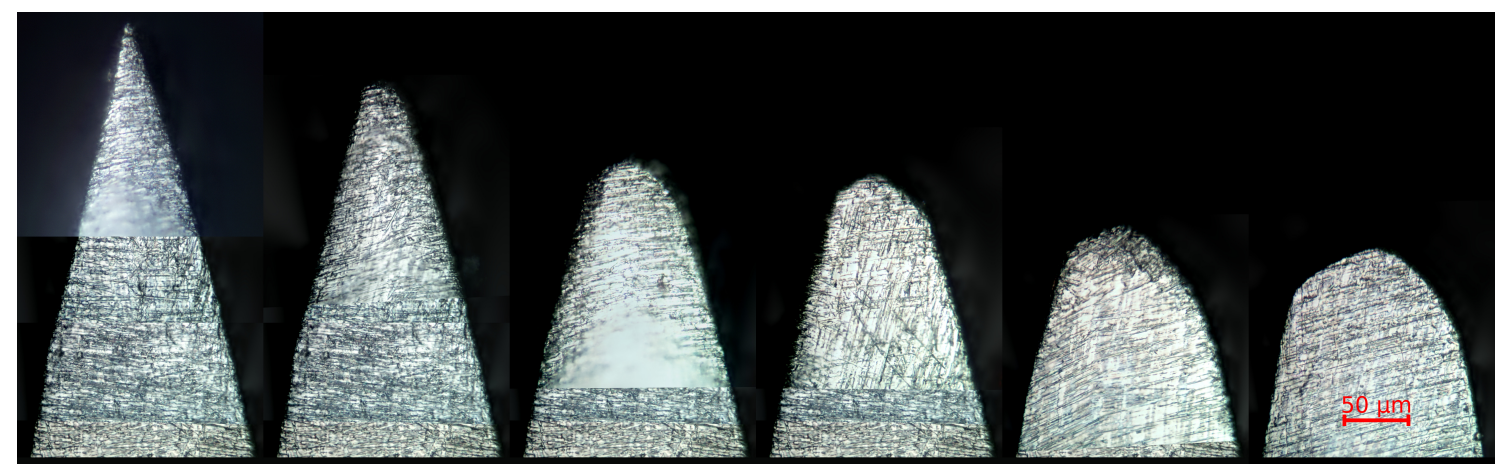

Figure 4.17: Sw2D test blade tip rounding, front face to right From left to right: as received, 10k, 45k, 75k, 105k, 117.5k chops

These blades again show a similar wear pattern to $\mathrm{C} 1$ and the other grooved tests, although they had the highest average and overall cutting edge rounding values, as seen in Figure 4.20. While the $\mathrm{C} 1$ and S1D tests produced more pointed blade profiles (and lower CER values), the Sw2D blades were more smoothly rounded. 


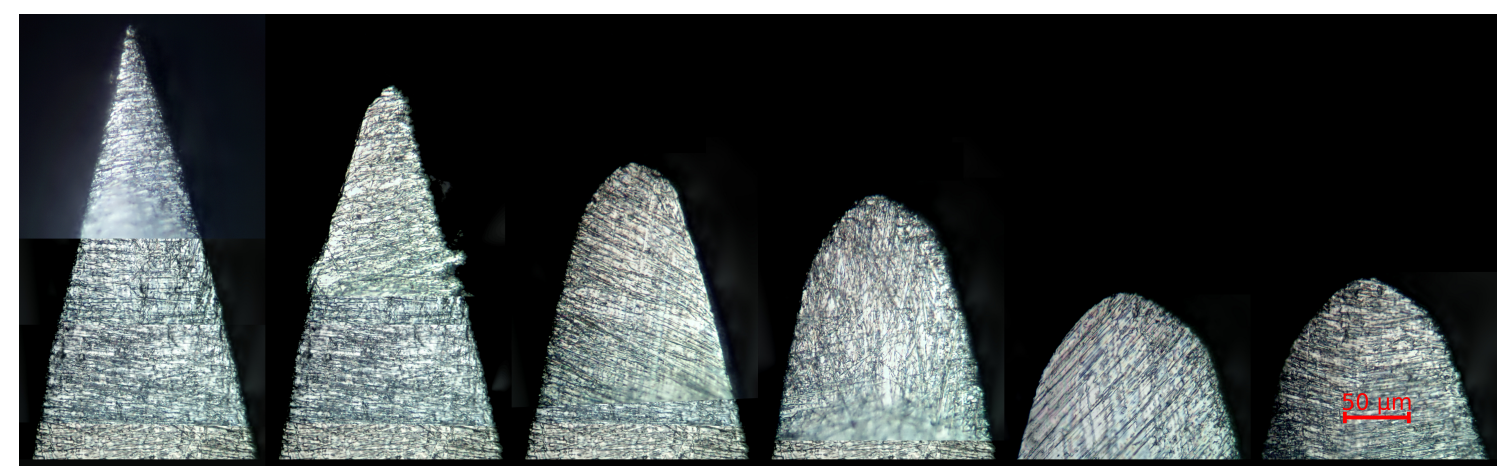

Figure 4.18: S1D test blade tip rounding, front face to left

From left to right: as received, 10k, 25k, 45k, 62.5k, $77.5 \mathrm{k}$ chops

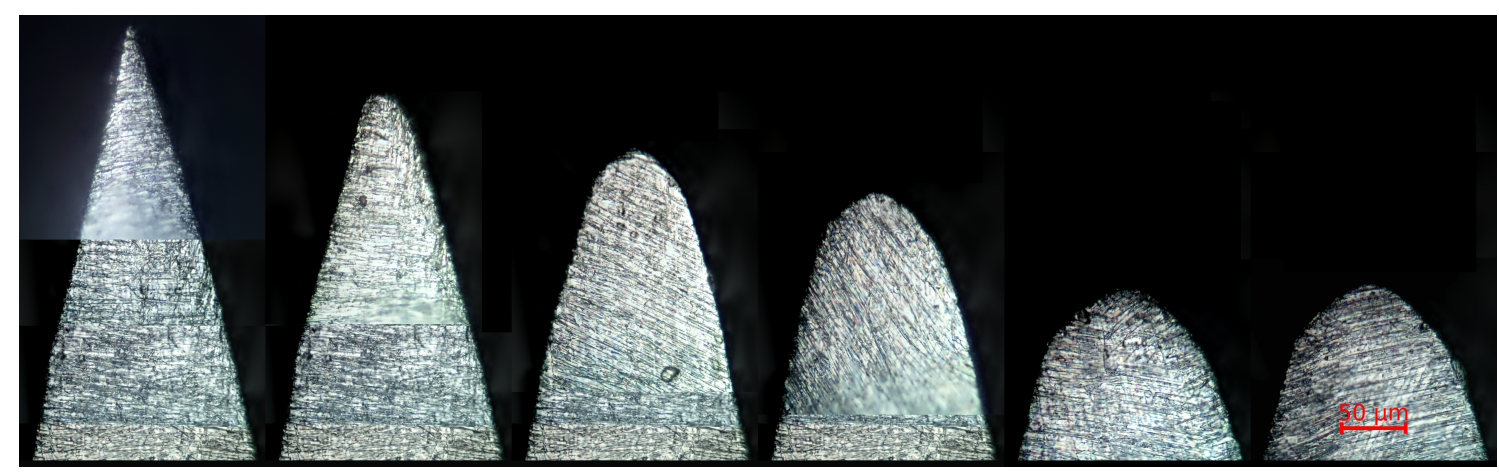

Figure 4.19: S1D test blade tip rounding, front face to right

From left to right: as received, 10k, 25k, 45k, 62.5k, $77.5 \mathrm{k}$ chops

The S1D test conditions led to blade tips rounded similarly to the $\mathrm{C} 1$ test, although with a higher magnitude of blade wear after fewer chops. Again, the front face wore smoothly but deeper down the blade, while the wear on the back face was confined to a smaller region but was equally or more severe.

All of the grooved tests seemed to show similar wear patterns, with only the S3D test (95A backing with break-in period) showing a different wear pattern. While the other various grooved tests showed significant wear and shared differences in abrasion between the front and back faces, the S3D had greatly reduced wear and had no clear pattern defining front and back face wear. 


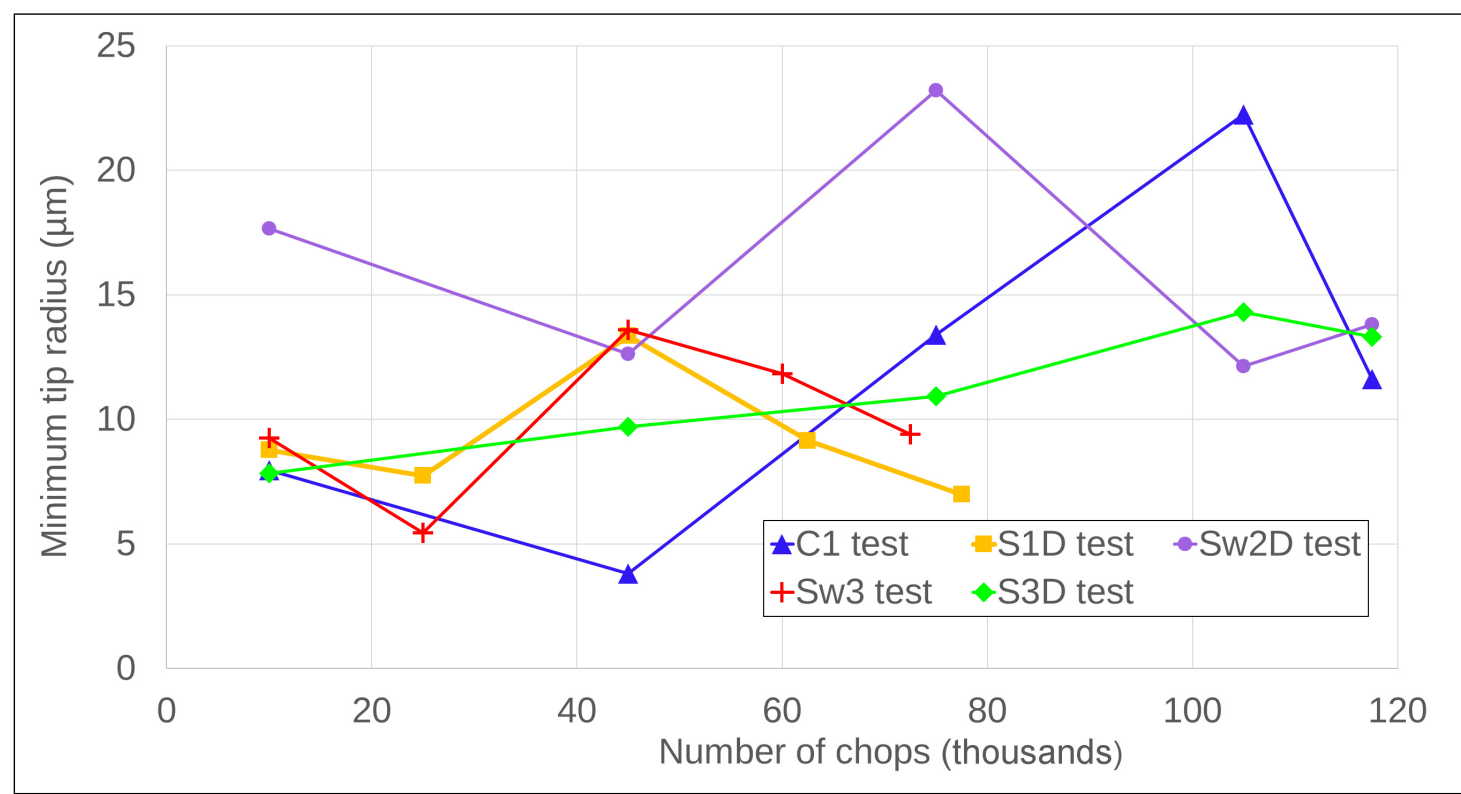

FIgURE 4.20: Plot of minimum tip radius versus number of chops for select blades

Although efforts were taken to ensure that noise was filtered from the images before the profiles were generated and minimum tip radii extracted, the results for blade tip rounding showed no clear trend. The S3D test (best performing condition) did return results as expected, increasing rather linearly as the number of chops increased, but the other test conditions did not follow this trend. 


\subsubsection{Comparison of worn blade outlines}

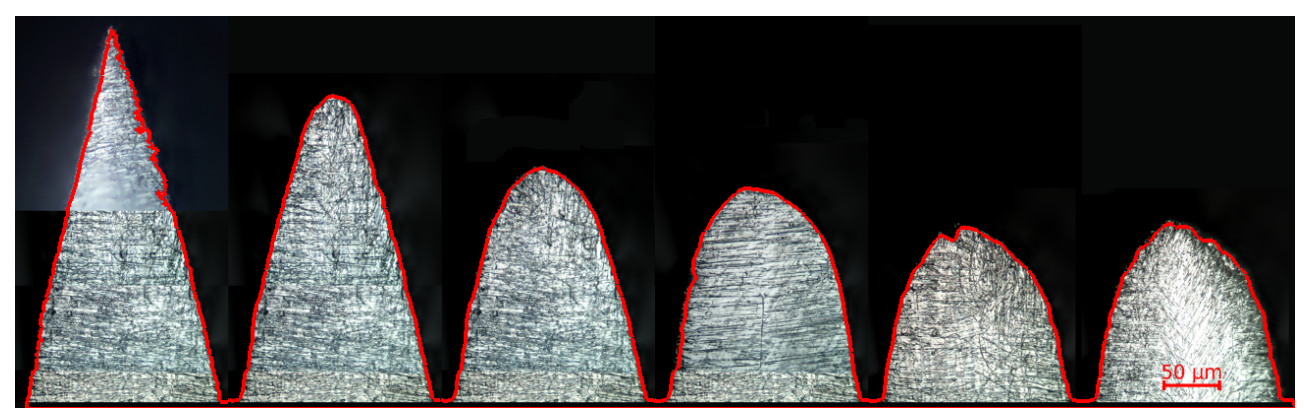

Figure 4.21: C1 tips with C1 blade outlines overlay, front faces to left From left to right: as received, 10k, 45k, 75k, 105k, 117.5k chops

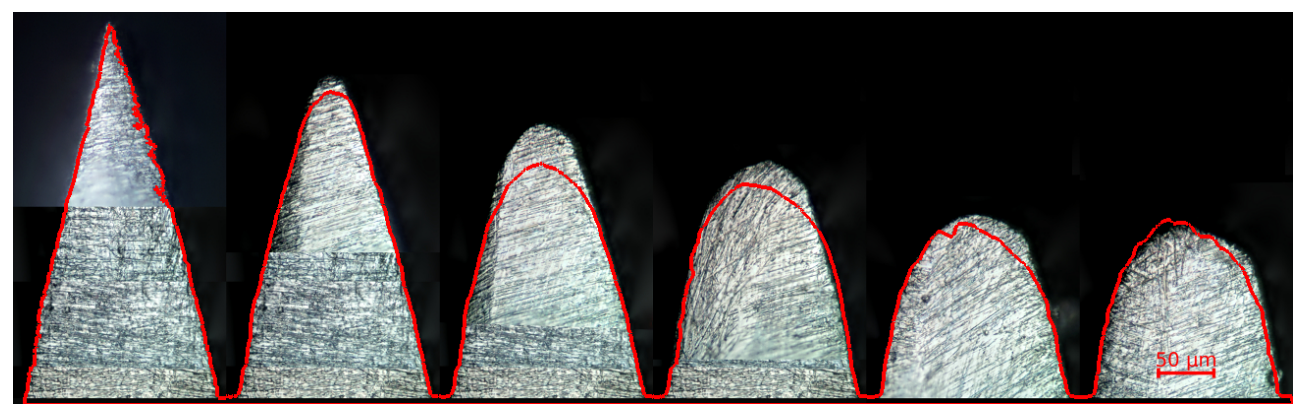

Figure 4.22: Sw2D tips with C1 blade outlines overlay, front faces to left From left to right: as received, 10k, 45k, 75k, 105k, 117.5k chops

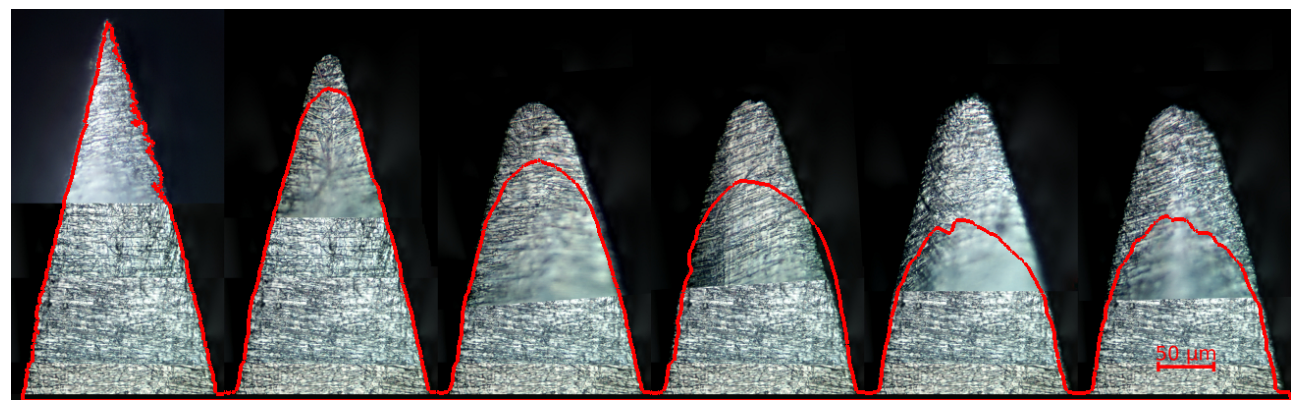

Figure 4.23: S3D tips with C1 blade outlines overlay, front faces to left From left to right: as received, 10k, 45k, 75k, 105k, 117.5k chops 


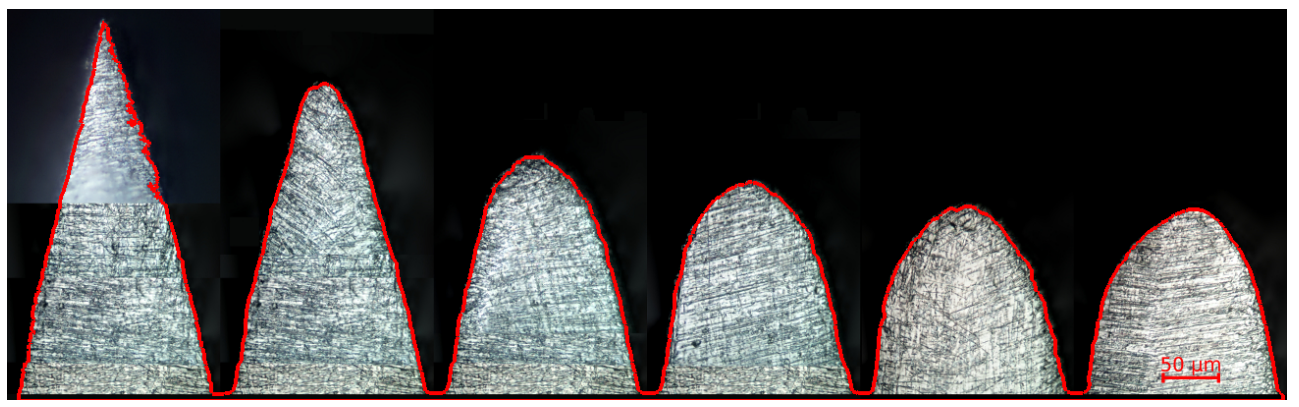

Figure 4.24: C1 tips with C1 blade outlines overlay, front faces to right From left to right: as received, 10k, 45k, 75k, 105k, 117.5k chops

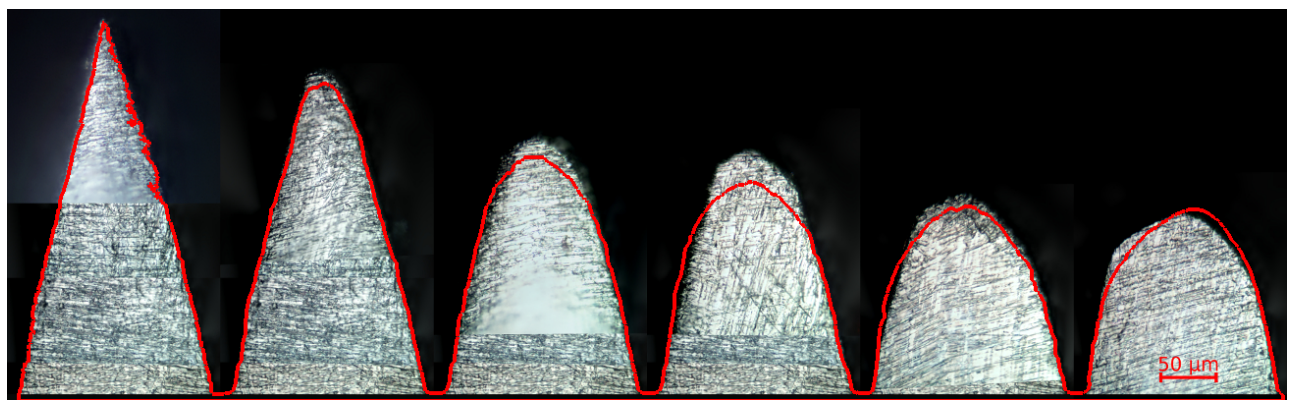

Figure 4.25: Sw2D tips with C1 blade outlines overlay, front faces to right From left to right: as received, 10k, 45k, 75k, 105k, 117.5k chops

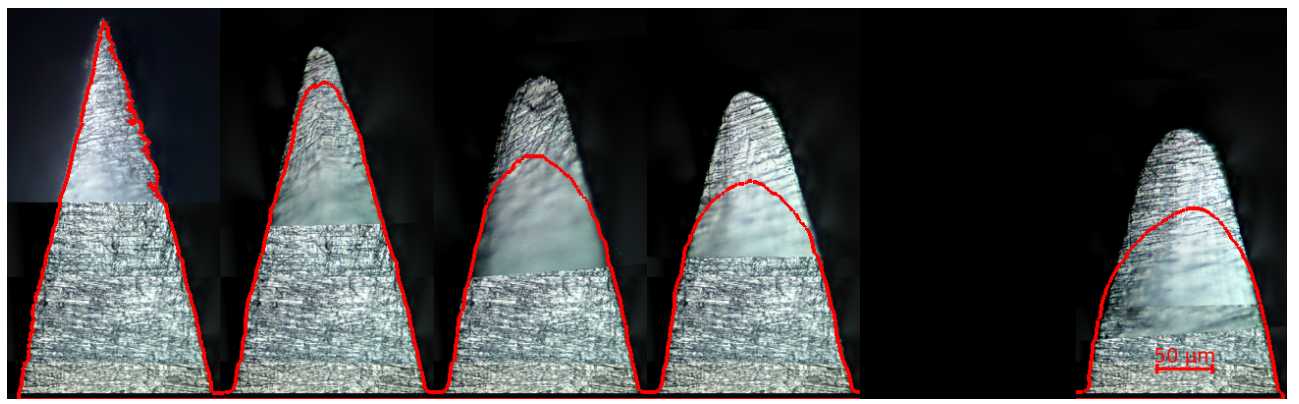

Figure 4.26: S3D tips with C1 blade outlines overlay, front faces to right From left to right: as received, 10k, 45k, 75k, 105k, 117.5k chops

The final comparison of blades is between the three sets of blade cross-sections that lasted a full 120k extended wear test. The C2 and C3 blade cross-sections were not cut due to time constraints; however, the $\mathrm{C} 1$ test is an adequate baseline for 
comparison as it most closely resembles the setup of a large-scale chopper. Overlaying the $\mathrm{C} 1$ outline as generated during MATLAB analysis clearly shows the similarities and differences between these three test conditions.

The major difference between the Sw2D tips and the C1 outline is between the front and back face wear patterns. While both show a smoothly-sloping wear pattern on the front faces, the back faces of the Sw2D blades show a more horizontal worn region and a very abrupt transition between the worn and unworn surfaces. The C1 blades also come to a sharper point, whereas the Sw2D blades have a more rounded profile up until the end of the worn region on the back face.

For the S3D blades, the major difference is the magnitude of wear. Even from the 10k chops level, the wear on the S3D blades is seen to be much lower than on the $\mathrm{C} 1$ blades, and throughout the test this disparity continues to grow due to the low wear rate seen during the S3D test. While some of the S3D blades did seem to have a smoother front face than back, they do not all follow any clear pattern. 


\section{Chapter 5}

\section{Discussion}

\subsection{Blade Wear Measurements}

\subsubsection{Front and rear face worn distances}

The primary wear metric, side-view worn distance, shows some distinct patterns in wear rate based on backing material and groove geometry. The most readily apparent trend in wear rates as chopping parameters changed is the inverse relationship between backing hardness and wear rate, as the softest material used (nominally 80A durometer) led to the highest wear rates during both control tests and grooved tests, whereas the hardest (95A durometer) consistently had the lowest wear rates seen. The 95A durometer control and narrow-grooved tests conducted were on par with or exceeded the performance of the baseline 60A durometer backing used by Adamovsky and Alexander $[2,3]$; however, no other combination of groove parameters and backing hardness show an improvement in wear rates as compared to the previous works. See Table 5.1 for the side view wear rates as determined from the slopes of the linear trendlines. As for the worst-performing condition, the 80A durometer square-grooved test (S1D, yellow in Figure 4.4) had the highest wear rate of any test; indeed, the blade wear was so high that the test had to be stopped after it was only two-thirds complete as some blades were failing to consistently chop fibres. Another test (Sw3, the $95 \mathrm{~A}$ roll with wide, shallow grooves) also had to be stopped, but this was due to degradation of the backing roll to such an extent that the fibre tows could not bend far enough to sever. This is likely due to the fibre tows being unable to reach their critical severing bending radius, as identified by Xie et al. [28]. 
TABle 5.1: Performance measures from Figure 4.4 (ordered by wear rate)

\begin{tabular}{ccc}
\hline Test number & $\begin{array}{c}\text { Wear rate } \\
(\mathbf{m m} \text { wear } / \mathbf{k g} \mathbf{C F})\end{array}$ & $\begin{array}{c}\text { Median wear } \\
(\mathbf{m m})\end{array}$ \\
\hline \hline S1D & .007683 & .1232 \\
Sw3 & .005251 & .0839 \\
C2 & .005142 & .1095 \\
Sw2D & .004953 & .0901 \\
C1 & .004547 & .1114 \\
C3 & .002708 & .0616 \\
S3D & .001841 & .0659 \\
\hline
\end{tabular}

The wear rates in Table 5.1 are computed as the slopes of the linear trendlines applied to the various data sets. Again, though the linear model may not be the best suited method for describing the actual wear progression, using the slope allows each test's performance to be quantified and compared with an objective metric.

\subsubsection{Blade wear based on tip measurement}

Similar results were seen when blade wear was measured using the blade tip crosssections. The averaged wear results from the left and right sides of each blade were within a range of approximately $30 \mu \mathrm{m}$ from the values measured from the front faces, so the overall trends remain the same. This suggests that the side view worn distance measurement method is preferable to cutting cross sections - provided blade tip profile is not required - as this way reliable wear results can be obtained in a non-destructive manner.

\subsection{Wear Patterns}

Significant differences in the wear patterns present on the front and back faces of the blades are apparent, suggesting that abrasion happens differently on each side of the 
cutting blade. The most readily apparent difference is between the wear magnitude on the front and back faces. This was first identified during side view wear measurement, as dark regions indicative of high wear could be seen along the edges of the worn blades; upon closer examination, a pattern of larger dark regions on the front faces of blades than the backs was identified. An example of these dark discoloured regions seen in low-magnification micrographs can be seen in Figure 5.1.

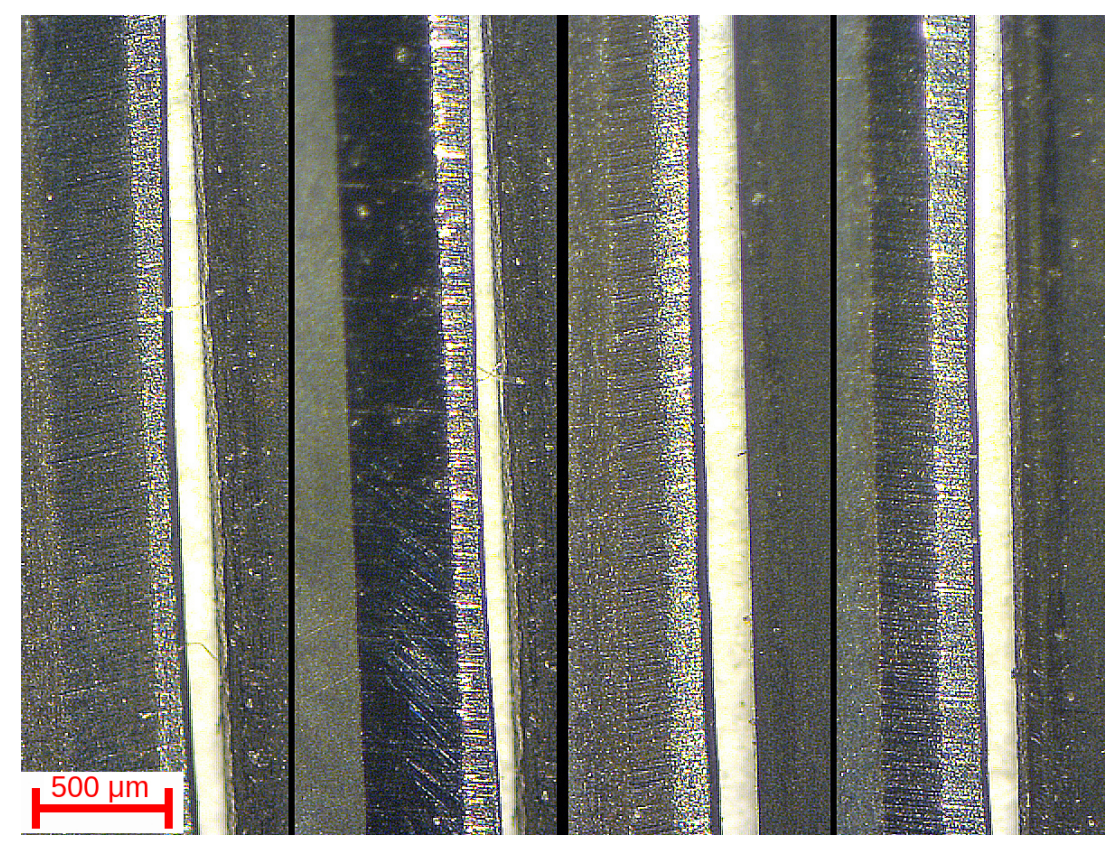

FigURE 5.1: S1D low-power micrographs, comparing dark regions on front and back From left to right: $35 \mathrm{k}$ front, $35 \mathrm{k}$ back, $80 \mathrm{k}$ front, $80 \mathrm{k}$ back

This disparity between front and back faces presents even clearer in the highmagnification images, and from examining the blade micrographs side-by-side the general trend is that the worn regions on the back faces are roughly half as large as the worn regions on the fronts. This near-50-percent difference can be seen on a large majority of the blades examined under high magnification. Of the aligned blade pairs featured in the Results section, 27 of 28 show the front face wear greater than the back face wear (only S3D-65k shows the two equal), and 22 of 28 show the worn region on the back face as half the size of the front face wear or smaller. Though not included in the composite images here, all of the $2.5 \mathrm{k}$ chop side-view micrographs 
also showed the worn region on the front face to be at least twice as large as on the back.

Another observation suggesting that a disparity between front and back face wear exists is the wear on the front and back face of the blade where the grind begins (i.e. the transition between the flat, non-ground face of the blade and the sharpened cutting edge). For all blades examined, by the maximum chopping duration (either 117.5k or $80 \mathrm{k}$ ) the front face of the blade shows some mild wear even as far down as the start of the sharpened region. By comparison, the back faces do not show any wear where the grind begins. Figure 5.2 is a labelled image showing the typical front face wear pattern, with the regions of interest labelled, while Figure 5.3 shows several examples of this seen during different tests, with the corresponding back faces for comparison. Likewise, Figure 5.4 shows this on a single blade under high magnification, highlighting the absence of visible wear from the back face.

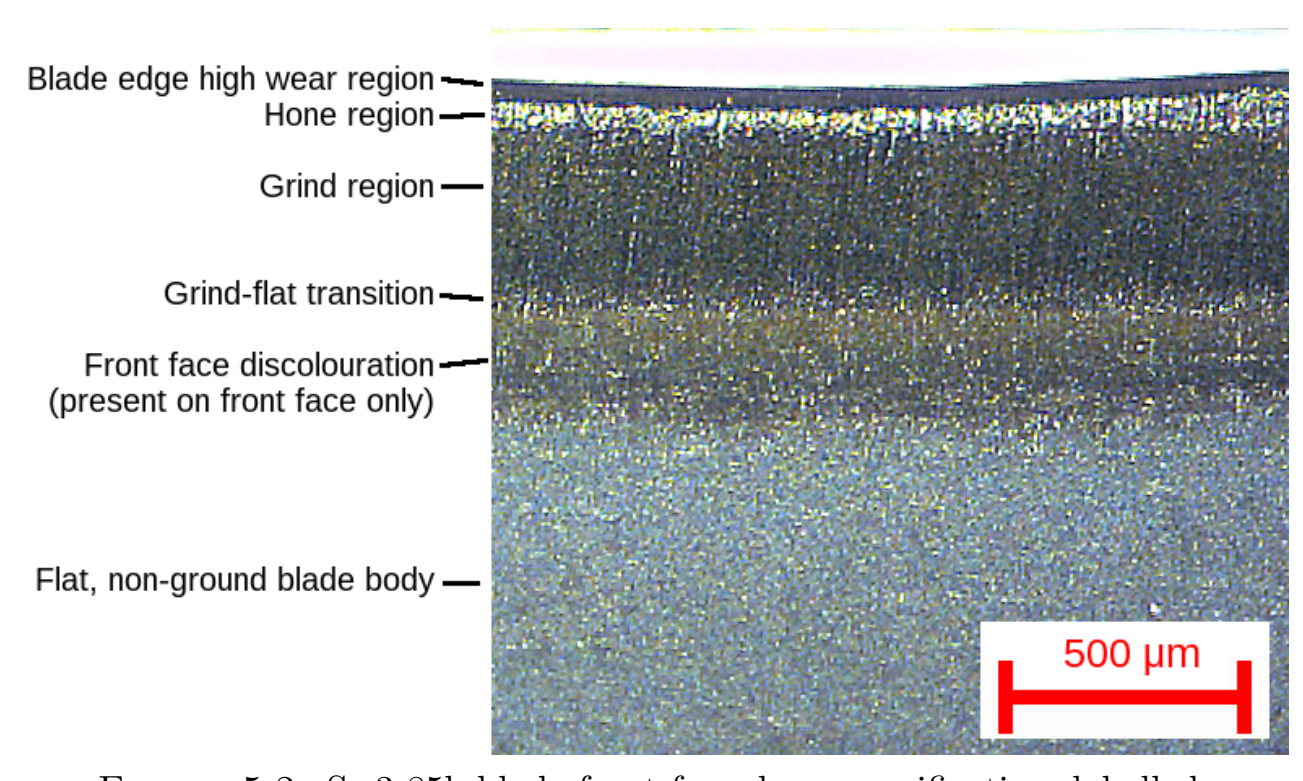

Figure 5.2: Sw3 85k blade front face, low-magnification, labelled

Overall, the wear pattern differences between front and back faces suggest that, regardless of backing roll hardness or profile, the general blade wear trend during 


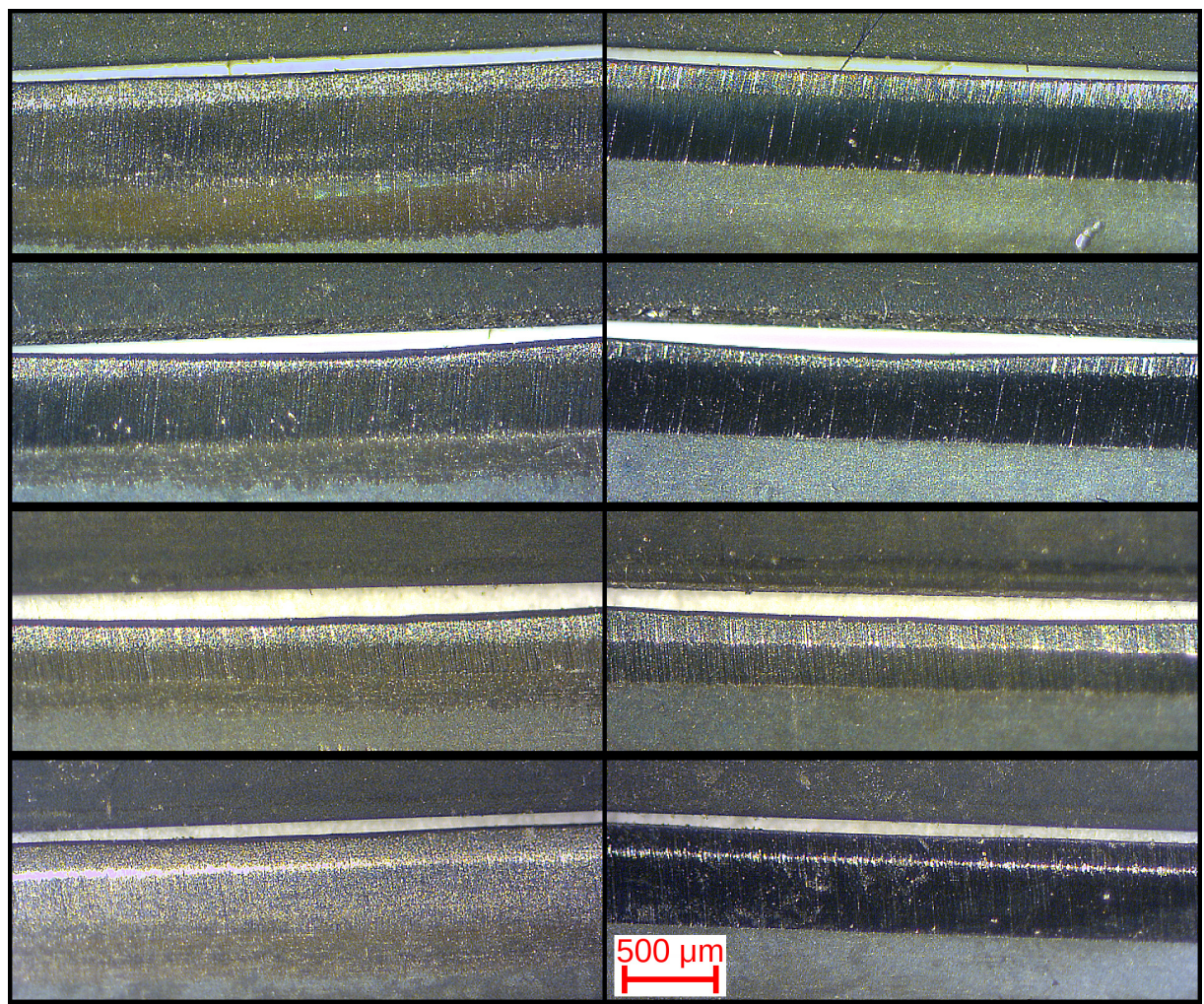

FigURE 5.3: Front (left) and back (right) grind regions wear, low magnification From top: S3D 115k, Sw3 77.5k, S1 80k, C3 115k

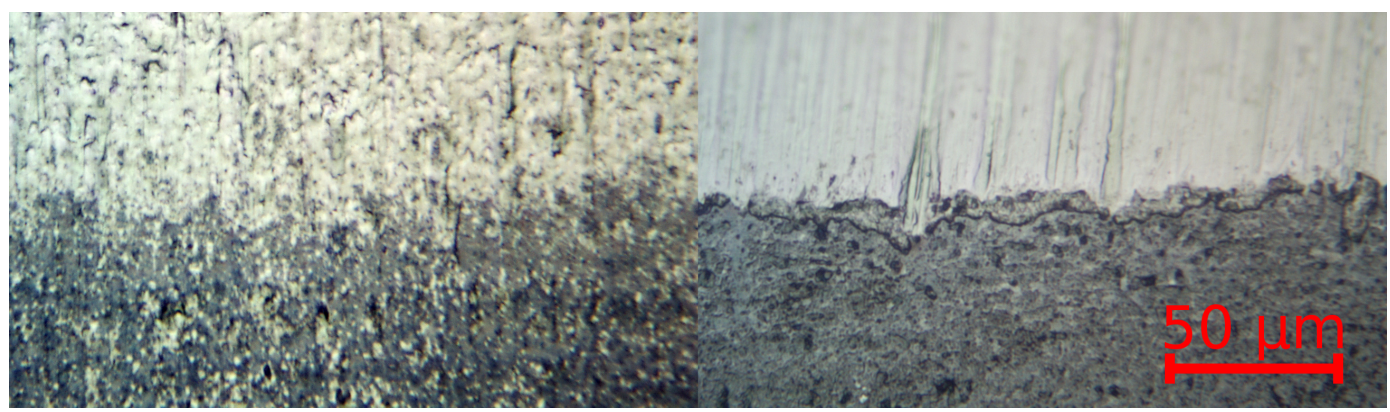

Figure 5.4: Front and back (L and R) of C3 115k

rotary chopping remains constant. The front face of the blade experiences more wear spread along the length of the blade, whereas the back face wear occurs closer to the blade tip area. 


\subsection{Cutting Edge Rounding}

\subsubsection{Tip radii}

While the results for blade wear based on tip worn distance measurement for both the side-view and cross-section methods were similar and followed the same patterns, the minimum tip radius values did not follow a clear trend. The number of samples that were cut and examined was fairly low since this process was labour intensive, so extensive statistical analysis of the trends was impossible. Figure 5.5 shows a comparison of CER and tip wear values on the same plot for the three full-length tests examined. Overall, only the S3D test showed the expected CER trend of constantly increasing tip rounding as number of chops rises; this may have been due to the low magnitude of wear on these blades as compared to the others examined, as Shen et al. suggested that blades first undergo a CER wear phase during the early stages of abrasion, followed by a more severe rake face wear phase as abrasion becomes more extensive [23]. It is plausible that the S3D blades (which experienced the least wear) remained in this steady CER-dominated wear regime, whereas the other severely worn blades entered into the next wear regime and thus yielded unreliable CER values. More research is required to confirm the relationship between CER and overall wear.

The CER measurement method used could have contributed to the inconsistent CER results, as no standardized method for measuring yet exists. The cross-section cuts yielded a complex blade tip profile with noise around the edges; when this was smoothed using a Gaussian blur filter, noise still remained. During the blurring and conversion to a pure black-and-white image, some distortion of the tip geometry may have occured. 


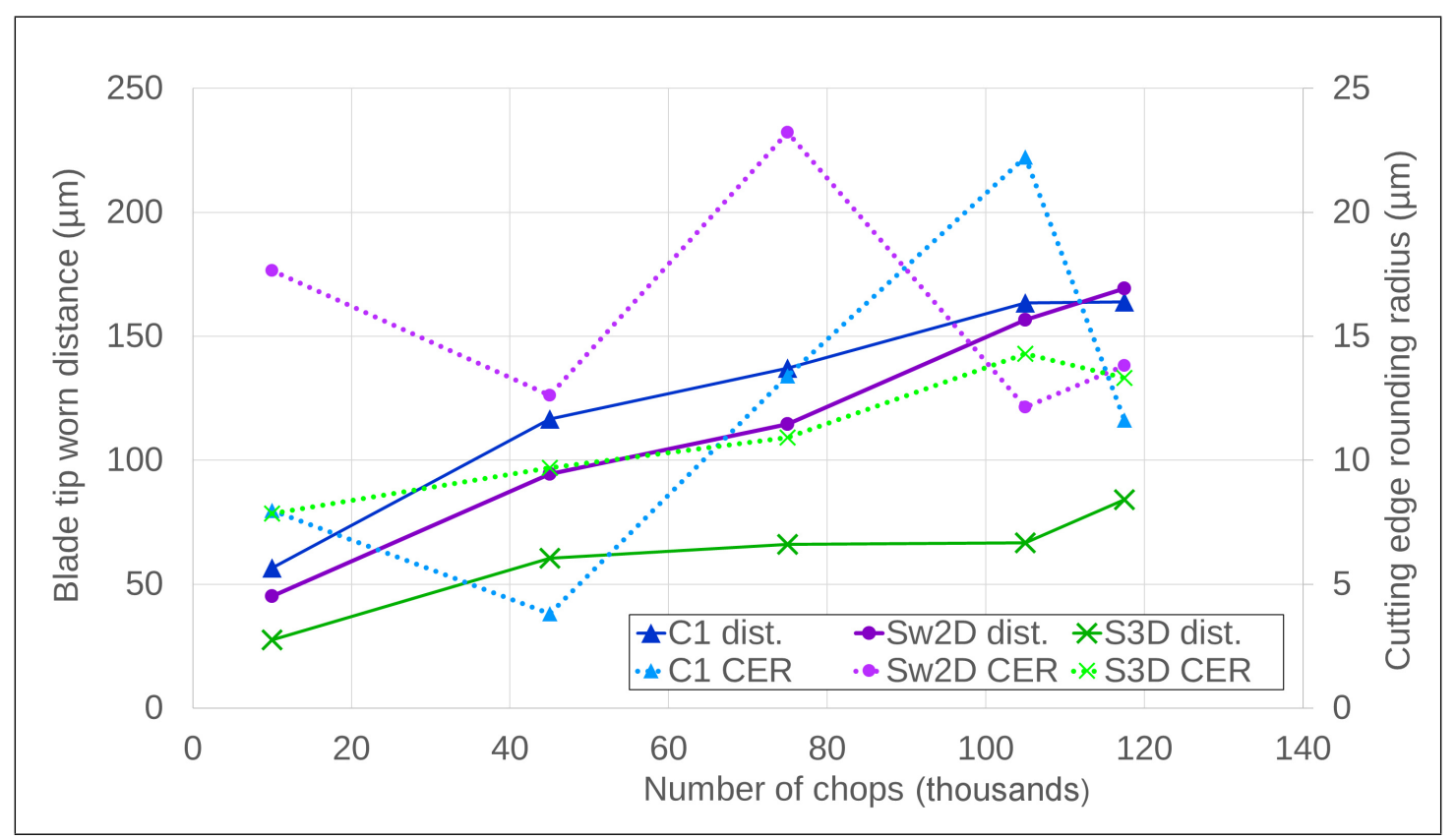

FIGURE 5.5: Combined tip wear and cutting edge rounding plot

Worn distance ("dist.", solid lines) and CER (broken lines)

\subsubsection{Cross-section profiles}

The cross-section profiles provide very valuable insights into the progression of wear under different conditions and the physical phenomena responsible for cutting blade wear. The majority of the blades examined showed similar front and back face wear patterns, with the typical worn blade profile shown in Figure 5.6.

The typical profile seen echos the observations from the high-magnification side view micrographs, with the front face of the blades seeing more wear than the back. In the side view micrographs, both the extent of front and back face wear and the wear severity as you approach the blade tip differ; the cross-section micrographs show this difference clearly, with a longer worn region on the front side and a fairly long transition between no wear, mild wear, and severe wear. Conversely, the back side transition is much more abrupt, with a large area of mild or no wear below the transition zone and severe wear above.

Typically, the smaller worn region on the back face of the blades also appears 


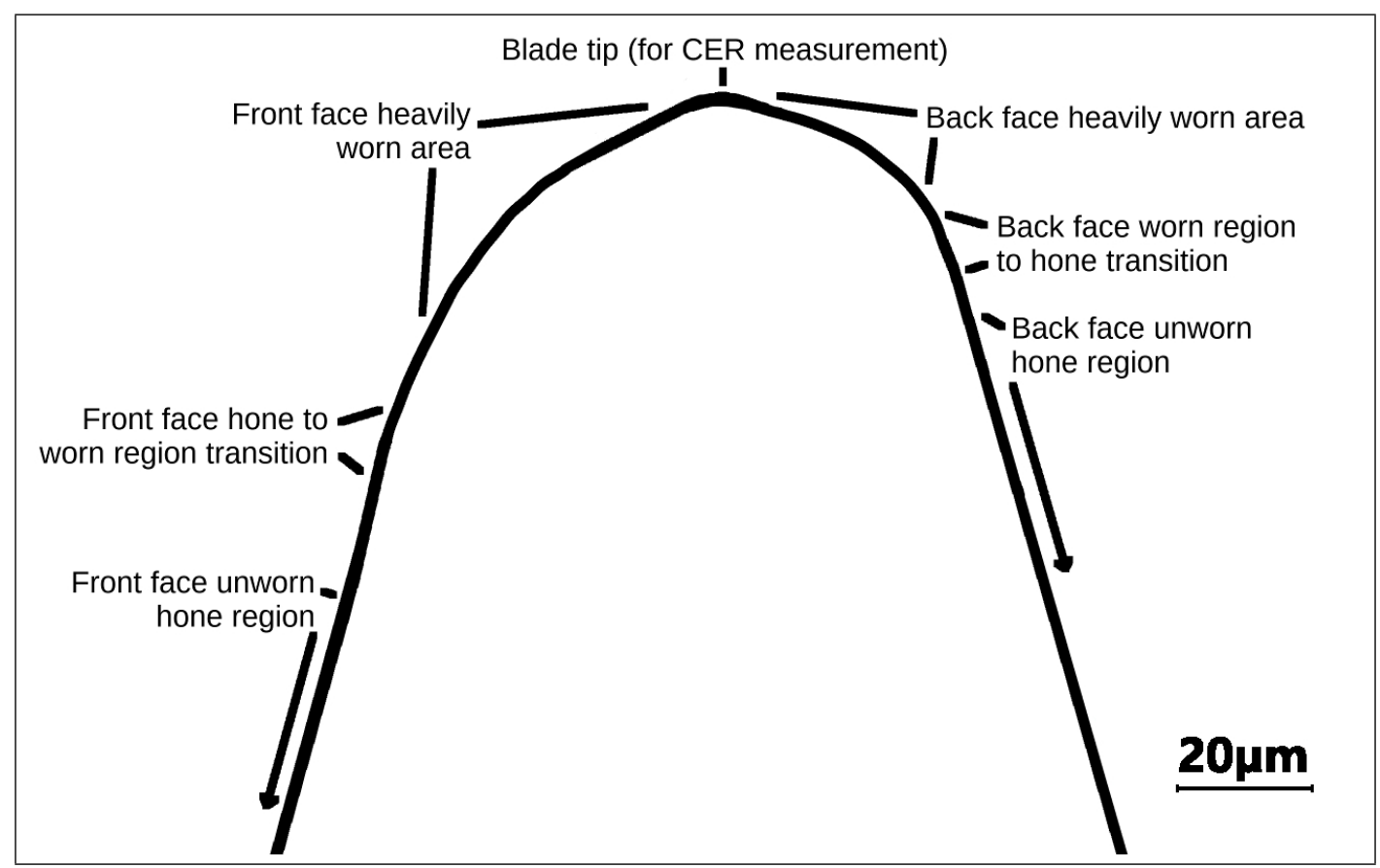

FiguRE 5.6: Typical cross-section profile for a worn blade (around 45k chops)

Front face to left

to be more horizontal than the front face, while the blade peak (effective tip) location remains nearly centred on the blade except during the initial wear period (approximately within the first $30 \mathrm{k}$ chops). All of the blade cross-sections examined except for the S3D test show similar wear patterns, although the similarities manifest at different levels as both S1D and Sw3 had to be stopped around 80k chops. These all showed a smaller, heavily abraded region on the back side of the blade, with a smoother, rounded front face. S3D was the outlier for the blade tip profile observations since it had far lower wear overall and showed no clear pattern of profile and wear differences.

Although more cross-sections would be needed to make a definitive conclusion, the available data suggests that blades which had better performance and more reliable meshing with their backing roll also saw less back face blade wear; this manifests in a highly-horizontal back face in the Sw2D test and as overall low wear in the S3D 
test. Conversely, the C1, Sw3, and S1D tests had more steeply worn back faces; this connection is discussed further in the next section (section 5.4).

\subsubsection{Comparison of worn blade outlines}

The most striking difference between the blade tip wear patterns is difference in wear magnitude between the $\mathrm{C} 1$ and S3D tests; while the values seen in Figure 4.5 quantify this well, the direct comparison of a poor-performing test (C1) and a well-performing test (S3D) highlights the impact that the backing roll and its profile can have on chopper blade wear.

The overlay comparison of the C1 outlines on Sw2D profiles Figure 4.22 clearly shows how the chopping parameters affect blade wear patterns, as both followed a similar wear progression but differences in profile developed. By the 117.5k chop level, both tips were worn to a similar extent, but the back face of the Sw2D blade had wear confined to a much smaller length. The front face of the blade was smoothly rounded with considerable wear across its extent while the back face wear was confined to a near-horizontal zone near the blade tip.

\subsection{Front and Back Face Wear Mechanism}

As a pattern of uneven front and back face wear is present in the vast majority of blade outlines and can be seen on most side-view micrographs too, it indicates that some differences in abrasion exist on the front and back faces of the blades. Overall, the wear on the blades is thought to be caused by an abrasive interaction between the blade tip, backing, and fiber ends as the tow is severed. This abrasive action seems to be caused by the chopped fiber ends raking across the front and back faces of the blades. Gouges across the severely worn portion of the blade tip present in 
a "peaks and valleys" pattern, with the gouges measuring approximately $7 \mu \mathrm{m}$, the diameter of a single carbon fiber. Figure 5.7 shows a single blade with these features highlighted. These gouges and the "peaks and valleys" pattern occurs on the vast majority of blades examined, and is present from the $2.5 \mathrm{k}$ chop wear interval onward (see Figure 5.8 for $2.5 \mathrm{k}$ chop blades).

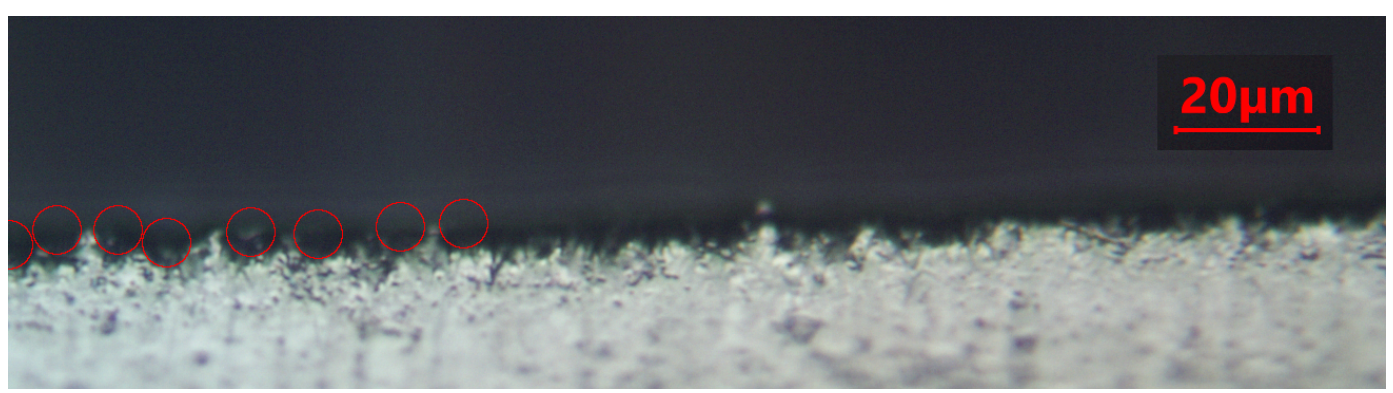

FiguRE 5.7: S3D 20k back face, non-EDF image, with several gouges highlighted $7 \mu \mathrm{m}$ circles (single fiber diameter)

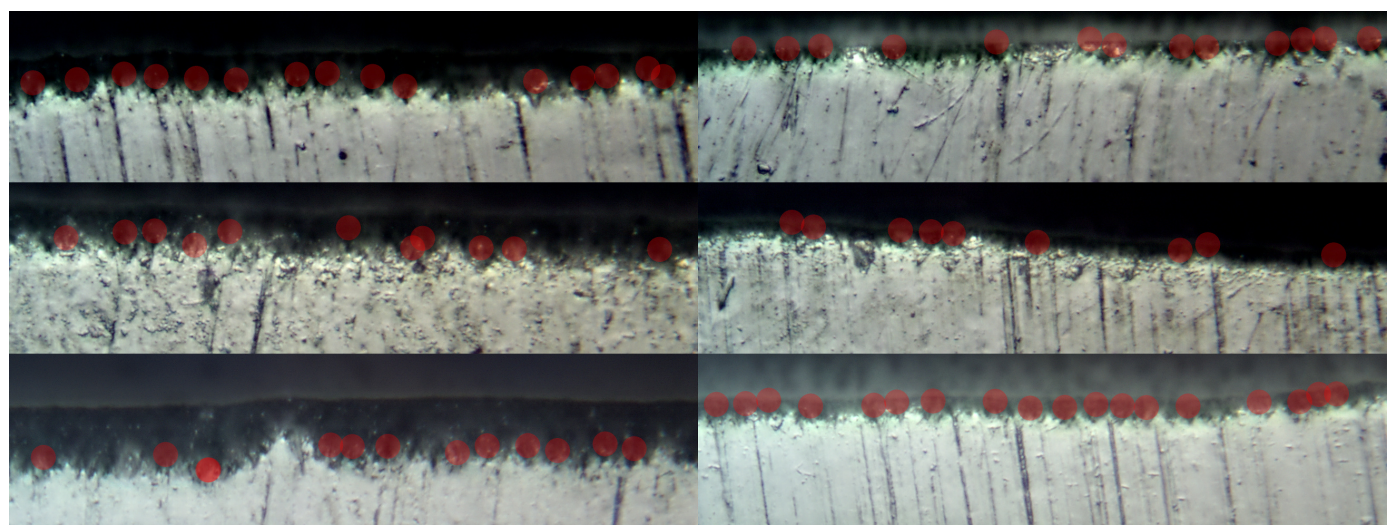

FiguRE 5.8: Front (left) and back (right) faces with gouges highlighted From top: S3D 2.5k, Sw2D 2.5k, C1 2.5k; $7 \mu \mathrm{m}$ circles (single fiber diameter)

These gouges are most prominent in the heavily-worn to unworn region transitions on the front and back sides of the blades (as defined in Figure 5.6); they also tend to be more prominent or easier to observe when the overall size of the worn region is lower (i.e. on back faces and at a lower number of chops). As the wear progresses, random dimpling or cratering of the surface begins to appear, starting just below the transition zone and extending further down the blade face as the test 
progresses. Figure 4.6 shows the appearance of this dimpling in the $\mathrm{C} 1$ test back face wear progression, with no clear dimpling seen at the $20 \mathrm{k}$ wear level; by the $35 \mathrm{k}$ level it has become noticeable, and by 65k chops the onset of severe wear below the transition zone can be seen.

The prevalence of grind lines on the front and back faces of worn blades is another piece of evidence suggesting that wear occurs differently on the front and back faces, as many blades show grid lines (clearly defined on unused as-received blades) with no or minimal wear on their back faces. Conversely, on the majority of blades these grind lines were worn off the front face by halfway through a $120 \mathrm{k}$ chop test. A greater magnitude of wear occurs on the front faces of the blades, and it occurs further down the blade face than wear on the back.

\subsubsection{Blade wear physical explanation}

Given the above pieces of evidence, a four-stage breakdown of the fiber tow chopping process can be used to explain why the various wear features and differences exist. During all of these stages the blades and backing are moving in unison with the same rotational speed; Figure 5.9 outlines the process graphically for a grooved chopping condition. The first stage of chopping, initial contact with the fiber tow, is when the blade first touches the tow; in grooved chopping, the tow is taut across the groove and the blade begins to press into the carbon fibers, while in standard flexible-backed chopping this is when the blade initially begins to press the tow into the backing material. The second stage is when the blade begins to sever the tow and the fiber tow ends rake across back of blade while the partially-severed roving ends rake across front. This is where abrasion begins to occur, but the blade is moving away from the severed tow end while the roving gets trapped between the blade and the backing (either in a temporary indentation or against the front face of a groove), so the tow 
ends make a fairly brief contact with the back face in a small area, while the roving ends are in contact with the front face of the blade for far longer. The third step is when full chop of the tow occurs, either before or as the blade reaches a fully horizontal position; the full blade plunge into the backing with the roving trapped between the front face and the backing causes the roving to rake along a large portion of front surface, including the transition between the grind region and flat front of the blade (the region of interest in Figure 5.3). During this stage, the back face is typically no longer in contact with the tow, as the tow end is either loose in the groove or the blade has pulled away from it during the plunge stage. The fourth and final stage is as the blade pulls out of the backing along with roving, with the roving still contacting the front face of the blade as pull-out occurs. This likely also causes additional wear on the front face until the roving is finally freed and can fall away from the chopper assembly.

This process adequately explains the various wear features that appear across different blades. The difference in front face and back face wear seen on nearly every blade examined is due to both the relatively brief contact the severed tow ends have with the back face of the blade as compared to the front face, as well as the trapping of the severed roving piece between the backing roll and the front face of the blade for the majority of the chopping process. While the back of the blade makes contact for a short while, the front of the blade is in constant contact with carbon fibers during the plunge, chop, and pull-out phases. Likewise, this explains the wear at the grind-flat transition seen exclusively on front faces, as the blade plunges into the backing or grooves past this transition point and carbon fibers become trapped between the backing and blade face. This does not happen on the back face as the blade is moving away from the tow end, plus some elastic deformation of the backing groove/indentation in the direction of blade travel may also contribute to keeping the tow end and blade back face separated. 


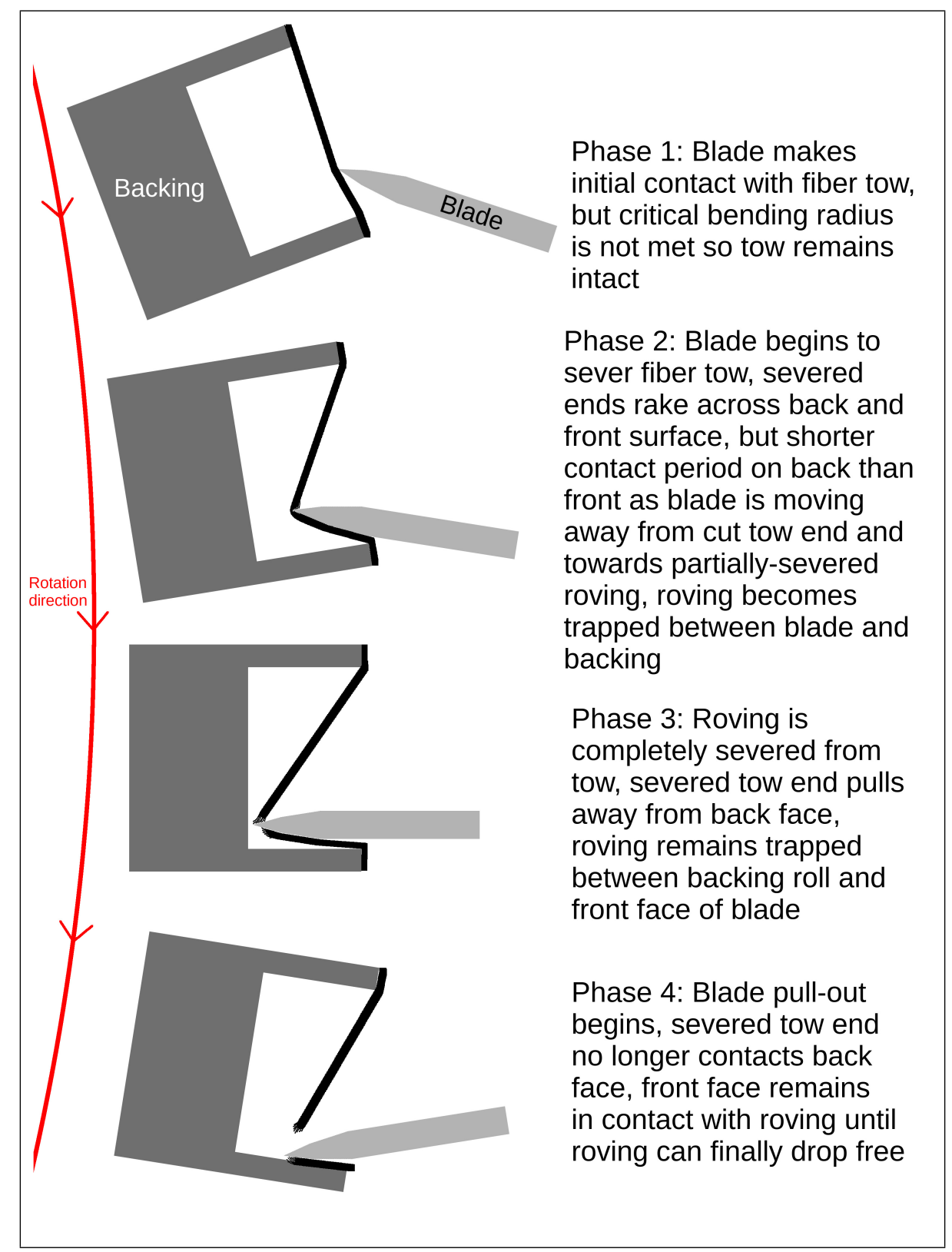

Figure 5.9: Four steps of the grooved fiber chopping process Dimensions for grooves are based on the Sw3 test

The non-grooved chopping process differs from the grooved process as there is more contact between the back face of the blade and the fiber tow. Figure 5.10 outlines the chopping process with a standard backing. Whereas the grooved chopping method seems to confine wear to the front face of the blades and reduce the force 


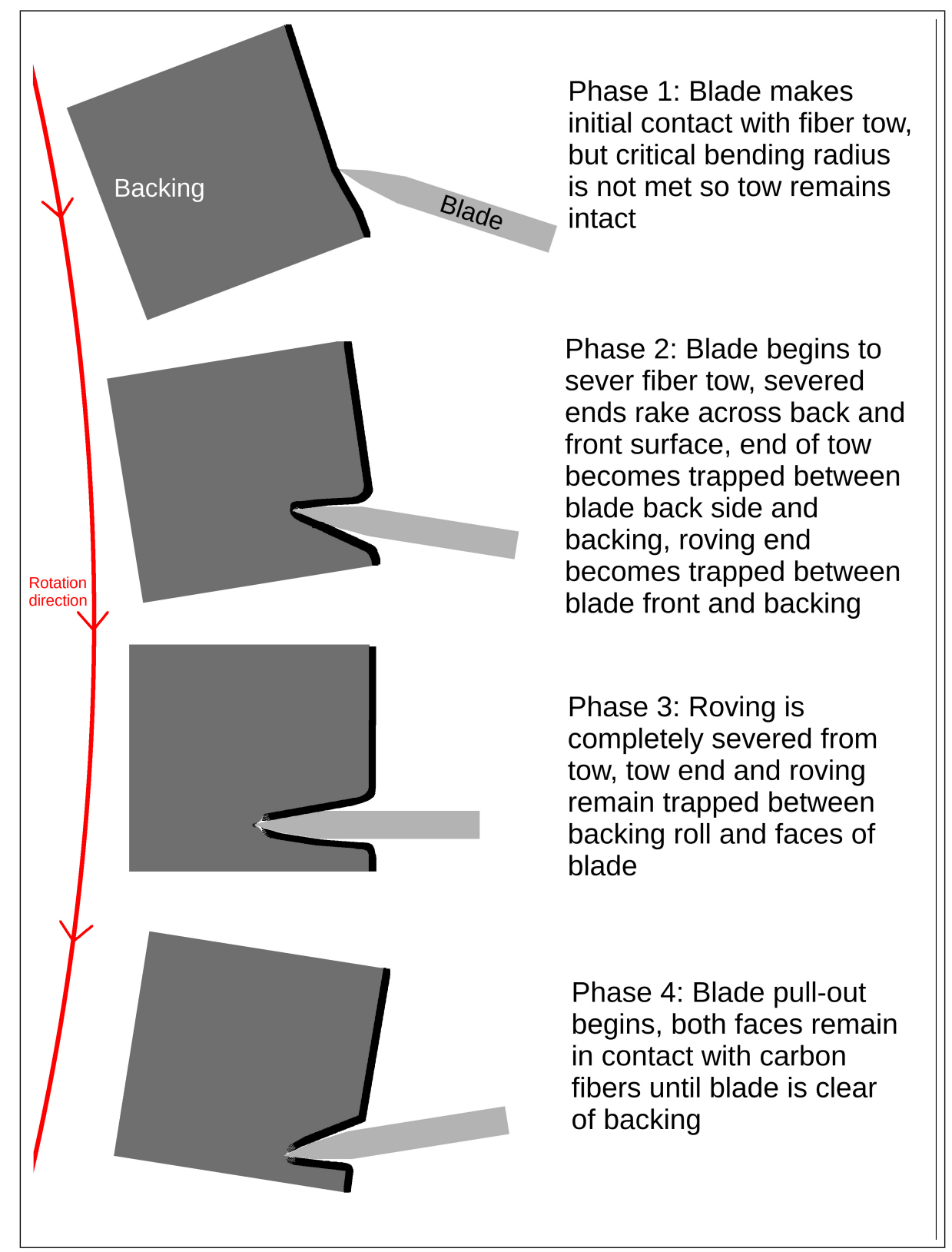

FiguRE 5.10: Steps in the non-grooved chopping process

required for blades to chop fibers, non-grooved chopping traps carbon fibers against both sides of the blade for the duration of the chop and subjects the blade to higher cutting forces. More abrasion further down the back face of blades chopping in nongrooved conditions presents in the form of worn down grind lines; comparing the back 
face grind lines on C3 and Sw2D 65k (naturally and intentionally grooved) with those on $\mathrm{C} 1$ and $\mathrm{Sw} 3$ (non-grooved and poor groove meshing) shows that the grooved tests preserved the back face better even though significant wear was seen on all of the fronts (see Figure 5.11). Thus, it seems likely that this difference in the chopping process is responsible for the major differences in front and back face wear and the slight improvements in overall blade wear seen during properly behaving grooved tests.

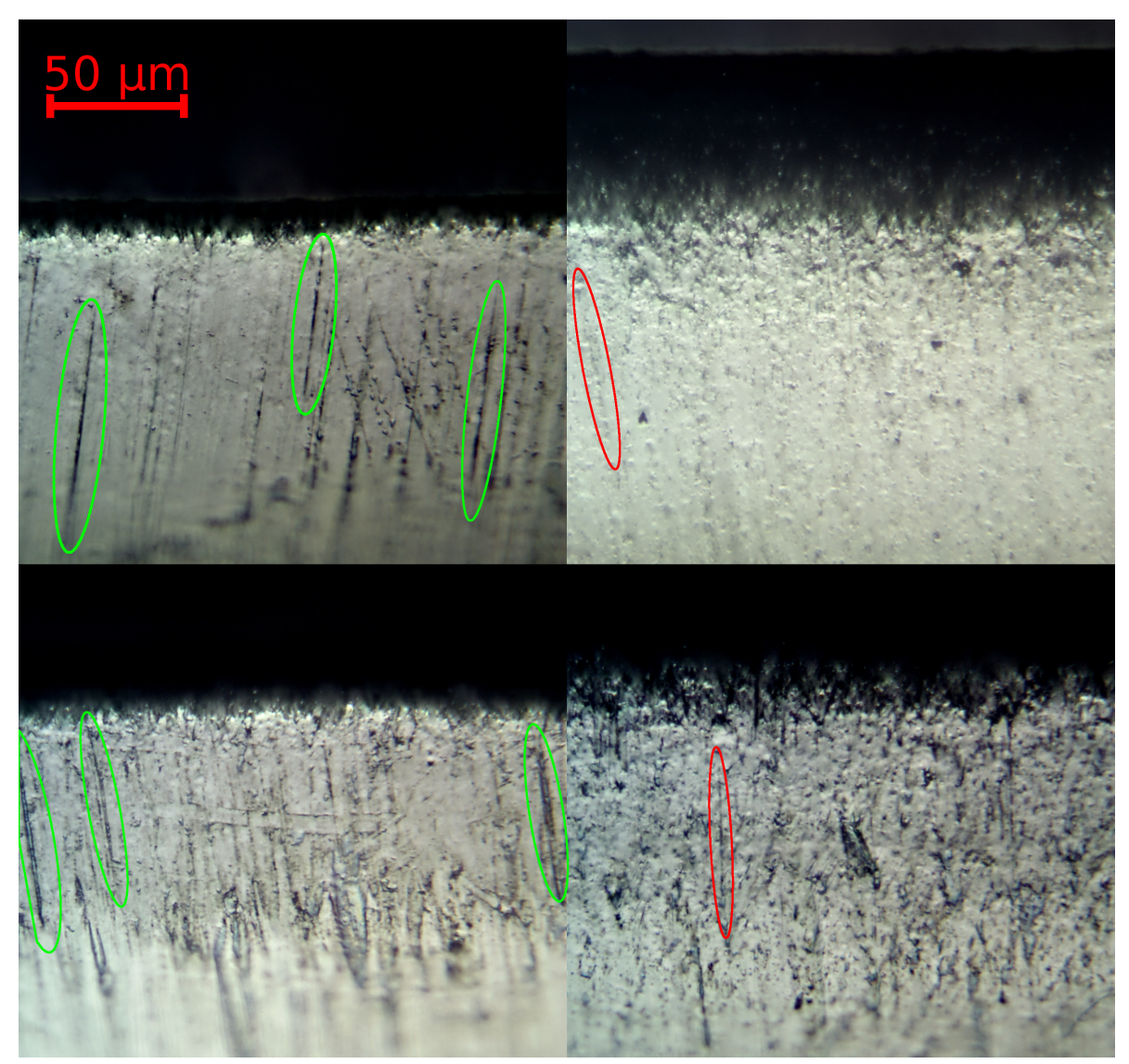

Figure 5.11: Comparison of grind lines on back faces Top: C3 65k (L), C1 65k (R) Bottom: Sw2D 65k (L), Sw3 57.5k (R)

Deep grinds highlighted in green, abraded grind lines in red 


\subsection{Wear Differences With Profiled Backings}

When the results are examined using the above explanation of the wear process, the effect that backing conditions had on wear can also be determined and related to the wear features observed.

The best performing tests, S3D and C3, performed well because they chopped consistently in the manner described above. The wear on these blades occurred almost exclusively on the front face, with the back faces of the blades looking almost unchanged as the number of chops increased. The Sw3 blades had worse wear than the other two 95A durometer-backed conditions, and these blades showed far higher back face wear as well. After approximately 25,000 chops the Sw3 results began to diverge from the other 95A durometer backing tests. This is likely because initially, the blades did mesh properly with the backing grooves and wear progressed as described above, but eventually degradation of the grooves led to a diameter mismatch between the blade roll and backing; in turn, this affected the meshing of the blades. With mismatched diameters, the backing could neither form natural grooves nor consistently align the machined grooves with the blades. This then caused the back faces of the blades to contact the fiber tow during a longer portion of the test, resulting in higher back face wear, more rounded blade tips, and worse overall performance.

The C2 plain and Sw2D grooved backings behaved similarly, although the C2 test showed a higher amount of back face wear than Sw2D and had slightly worse performance overall. The higher wear on the $\mathrm{C} 2$ blade was likely due to the lack of major groove formation during the test; the middle roll in Figure 3.5 is from the $\mathrm{C} 2$ test, which shows moderate-depth grooves but far more than the 10 expected from proper meshing. The grind lines on both the front and back of the $\mathrm{C} 2$ blades saw more severe abrasion earlier on in the test, indicative of mild abrasion further down the blade face; this suggests that more contact was made with carbon fibers along a 
larger portion of the blade face. The Sw2D blade cross-sections also showed that the worn area on their back faces was far smaller than on the fronts, presenting as more horizontal area with a rapid transition to the unworn grind region; these results are echoed by the side-view micrographs, which show a shorter worn region than on the C2 blades. All of these points suggest that the Sw2D blades wore differently than the $\mathrm{C} 2$ blades due to the presence of and proper meshing with the machined backing roll grooves.

Both $\mathrm{C} 1$ and S1 performed poorly, with S1 wearing so quickly that the test had to be stopped early. No major grooves formed in the $\mathrm{C} 1$ backing during this test, only minor grooves (see Figure 3.5), which indicates poor meshing between the blade roll and backing roll. The S1 test seemed to mesh properly, but it still experienced very high wear. Together both showed front and back face wear closer than any others. Even from 2.5k chops they showed significant abrasion on both front and back, with grind lines becoming visibly abraded at this point (see Figure 5.12), and both had severe abrasion on the front face as early as 20k chops. Although the high wear seen during the $\mathrm{C} 1$ plain backing test can be explained by the failure of the backing to develop major grooves for the blades to mesh with, the reason for the poor performance of the $\mathrm{S} 1$ test is still unknown. The $80 \mathrm{~A}$ durometer backing was the worst performing condition tested during these experiments, and it was also identified as the worst performing condition tested by Alexander [3], so it seems that this material should be avoided in actual production equipment. 


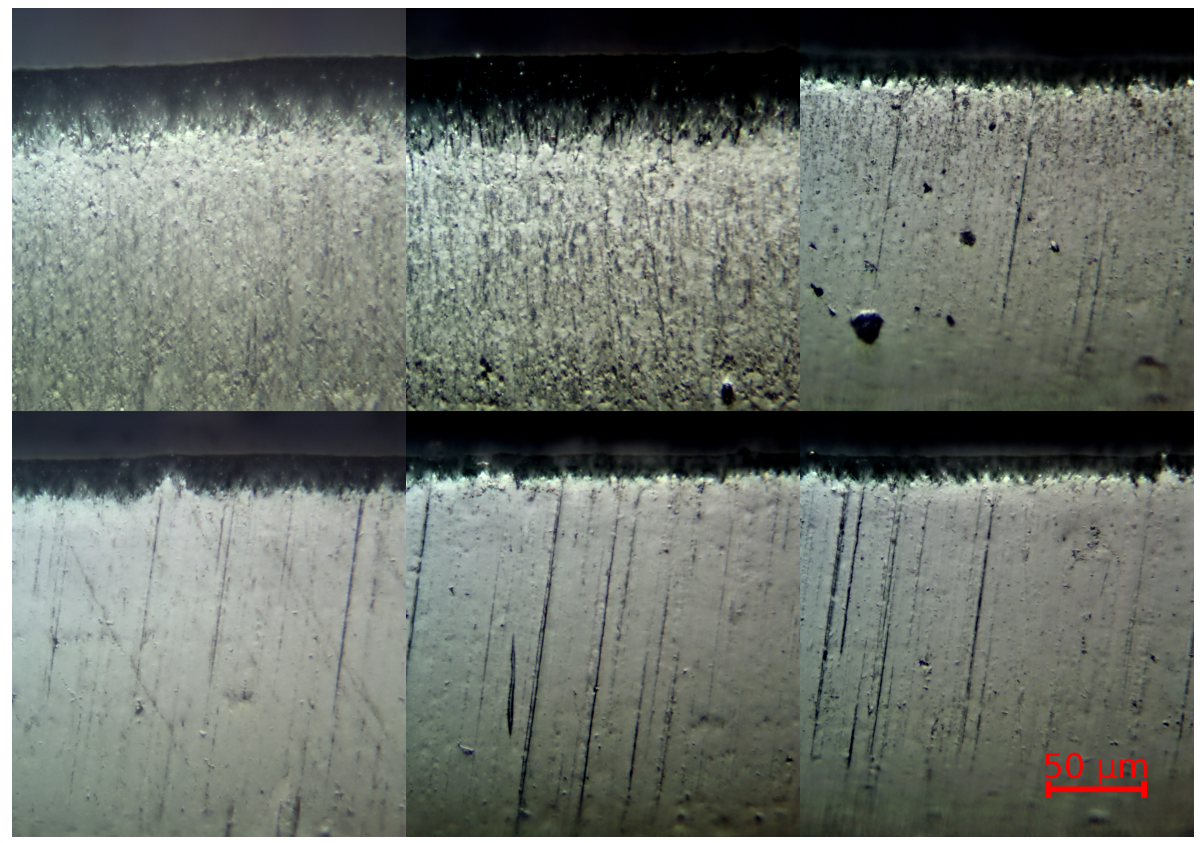

FiguRE 5.12: 2.5k and 20k chop front face wear for C1, S1, and C3 Top: C1 20k, S1 20k, C3 20k Bottom: C1 2.5k, S1 2.5k, C3 2.5k 


\section{Chapter 6}

\section{CONCLUSiOnS}

\subsection{Conclusions}

The goals of this work were to examine the effect of backing profile on blade wear during rotary carbon fiber chopping, and to determine if intentionally-grooved backing rolls are a feasible method for prolonging blade life during this chopping process. Over $180 \mathrm{~kg}$ of carbon fibers were chopped during the seven experiments; if the full-scale industrial chopper was running at a rate of 2 metres of fibre per tow per second, this is equivalent to roughly 250 hours of continuous operation. These tests simulated the wear progression across a blade's lifespan and determined how changes in the backing profile affected wear, both positively and negatively.

Several overall conclusions can be drawn from the results and analysis detailed in the previous sections:

- Backing rolls with a machined groove profile failed to improve blade wear as compared to non-grooved control tests; 80A durometer backing with machined grooves had the highest wear rate of any test, and the wear rate of the best performing test with machined grooves was more than $50 \%$ higher than the average for naturally grooved backings.

- Backings with naturally-formed major grooves performed best out of all conditions tested; 95A durometer backings which were allowed to form and mesh with their own grooves had the lowest wear rates, with a $65 \%$ reduction in wear rate as compared to the worst two conditions. 
- Meshing between blades and grooves is a key requirement for effective wear reduction; blades meshed properly and consistently with naturally-formed grooves, whereas backings with machined grooves saw damage indicative of inconsistent meshing.

- Patterns of differences in front and back face wear during grooved and nongrooved tests suggest that different wear mechanisms are responsible for blade wear when backing profile is changed; two physical explanations for these differences were proposed based on wear pattern observations.

\subsection{Future Work}

The implementation of a gear train or another method to ensure that both the backing and blade roll are constantly rotating at the same speed would be beneficial in future experiments using this small-scale chopper. The full-sized D-SMC chopper unit at the FPC does not have this issue of failing to mesh as it uses blades with a slight helical pattern, thus ensuring that a blade is always in contact with the backing. Ensuring perfect meshing between the backing and blade rolls would also allow harder materials, such as UHMWPE or another hard plastic, to be used as a grooved backing since with proper meshing the blades would never contact the backing.

A typical worn blade tip profile was identified based on cross-section observations of a number of blades, but a quantitative metric for relating tip profile and overall wear performance would be even more useful for understanding the relationships between backing, blades, rounding, and wear. Likewise, this knowledge of how the blade profile wears could be utilized to tailor blade geometry to specific chopping conditions, thus allowing less-expensive, softer blade materials to last longer during chopping. 
For further research into blade wear progression and the wear phenomena present during chopping, developing a method for indexing blades and targeting the same point on the same blade for analysis at various wear levels would also be useful. This would allow researchers to map exactly how a single blade wears rather than generating a composite from several different blades. A non-destructive method of measuring/mapping tip profile would be required for this, along with an indexing system to ensure blades are replaced exactly from where they were removed; alternatively, examining the blades without ever removing them from the blade holder would achieve this goal.

Similarly, running extended wear tests without any carbon fibers would provide insights into the role that backing alone plays in blade wear; i.e. what percentage of wear is due to the backing as opposed to the fibers. The general assumption in this work along with previous works $[2,3,23]$ is that the backing contributes minimally to wear, with the major contributor being the carbon fibers due to their hardness and abrasive nature; however, determining the wear contribution due to the backing alone may be useful for removing this from consideration in future simulation or analytical modelling work. 


\section{REFERENCES}

[1] Adamovsky, M., Alexander, R., Tutunea-Fatan, O. R., and Wood, J. T. (2017). "Instrumented linear cutting device for the analysis of fiber severing process". Proceedings of IMechE Part B: Journal of Engineering Manufacture. - accepted pending revisions.

[2] Adamovsky, M. F. A. (2015). "The Effect of Cutting Blade Geometry and Material on Carbon Fiber Severing as Used in High-Volume Production of Composites". Master's thesis, Western University, London, Ontario.

[3] Alexander, R. W. (2015). "The Effect of Backing Material on Carbon Fibre Severing for High-Volume Production of Composites". Master's thesis, Western University, London, Ontario.

[4] Bennet, S. C., Johnson, D. J., and Johnson, W. (1983). "Strength-structure relationships in PAN-based carbon fibres". Journal of Materials Science, 18(11):33373347.

[5] Bruderick, M., Denton, D., Shinedling, M., and Kiesel, M. (2002). "Applications of Carbon Fiber SMC for the Dodge Viper". Presented at the Second SPE Automotive Composites Conference.

[6] Campbell, F. C. (2010). "Structural Composite Materials". ASM International, Materials Park, Ohio 44073-0002. Chaper 2, pages 31-61.

[7] Cheah, L. W. (2010). "Cars on a diet: the material and energy impacts of passenger vehicle weight reduction in the US". PhD thesis, Massachusetts Institute of Technology, Cambridge, Massachusetts. 
[8] Dold, C., Heinrichs, M., Bochmann, L., and Wegener, K. (2012). "Comparison of ground and laser machined polycrystalline diamond (PCD) tools in cutting carbon fiber reinforced plastics (CFRP) for aircraft structures". In Procedia CIRP, volume 1, pages 178-183. 5th CIRP Conference on High Performance Cutting 2012.

[9] GNU Image Manipulation Program Team (2017). GIMP v2.8.20.

[10] Grafil Inc. (2010). PYROFIL TM TR50S 15K Typical Fiber Properties.

[11] Henning, F., Thoma, B., Hangs, B., and Keckl, C. (2016). "Large Scale Manufacturing of Composite Parts in Compression Molding". Presented at the New Developments in Sheet Metal Forming Conference, Stuttgart, 2016.

[12] Hoa, S. V. (2009). "Principles of the Manufacturing of Composite Materials". DEStech Publications, Inc., 439 North Duke Street, Lancaster, Pennsylvania 17602. Chapter 2, pages 45-98.

[13] Kaw, A. K. (2006). "Mechanics of Composite Materials, Second Edition". CRC Press, 6000 Broken Sound Parkway NW, Suite 300, Boca Raton, Florida 334872742. Chapter 1, pages 1-60.

[14] Koplev, A., Lystrup, A., and Vorm, T. (1983). "The cutting process, chips, and cutting forces in machining CFRP". Composites, 14(4):371-376.

[15] Liu, Y. and Kumar, S. (2012). "Recent Progress in Fabrication, Structure, and Properties of Carbon Fibers". Polymer Reviews, 52(3):234-258.

[16] Lu, L., Hou, Z., Zhang, F., Xie, Y., and Tang, Y. (2016). "Fracture analysis of a single polyacrylonitrile-based carbon fiber in rigid-fixing and flexible-fixing chopping processes". Textile Research Journal, 0(00):1-10. 
[17] Maegawa, S., Morikawa, Y., Hayakawa, S., and Itoigawa, F. (2016). "Mechanism for changes in cutting forces for down-milling of unidirectional carbon fiber reinforced polymer laminates: Modelling and experimentation". International Journal of Machine Tools $\&$ Manufacture, 100:7-13.

[18] Mallick, P. K. (2008). "Fibre-Reinforced Composites: Materials, Manufacturing, and Design - Third Edition". CRC Press, 6000 Broken Sound Parkway NW, Suite 300, Boca Raton, Florida 33487-2742. Chapter 1, pages 19-48; Chapter 5, pages 395-468.

[19] Mazumdar, S. (2016). "State of the Composites Industry" . Composites Manufacturing, Jan/Feb 2016:19-23.

[20] Minus, M. and Kumar, S. (2005). "The processing, properties, and structure of carbon fibers". JOM: Journal of the Minerals, Metals, and Materials Society, $57(2): 52-58$.

[21] Sakuma, K., Seto, M., Taniguchi, M., and Yokoo, Y. (1985). "Tool wear in cutting carbon-fibre-reinforced plastics". Bulletin of JSME, 28(245):2781-2788.

[22] Sakuma, K., Yokoo, T., and Seto, M. (1984). "Study on Drilling of Reinforced Plastics (GFRP and CFRP)". Bulletin of JSME, 27(228):1237-1244.

[23] Shen, Z., Lu, L., Sun, J., Yang, F., Tang, Y., and Xie, Y. (2015). "Wear patterns and wear mechanisms of cutting tools used during the manufacturing of chopped carbon fiber". International Journal of Machine Tools \& Manufacture, 97:1-10.

[24] Sugimori, Y., Kusunoki, K., Cho, F., and Uchikawa, S. (1977). "Toyota production system and Kanban system Materialization of just-in-time and respect-forhuman system". International Journal of Production Research, 15(6):553-564.

[25] Teti, R. (2002). "Machining of Composite Materials". CIRP Annals - Manufacturing Technology, 51(2):611-634. 
[26] Uhlmann, E., Sammler, F., Richarz, S., Heitmüller, F., and Bilz, M. (2014). "Machining of Carbon Fibre Reinforced Plastics". In Procedia CIRP, volume 24, pages 19-24. 5th Machining Innovations Conference.

[27] Witten, E., Kraus, T., and Kühnel, M. (2015). "Composites Market Report 2015". by Carbon Composites eV, page 6.

[28] Xie, Y., Lu, L., Hou, Z., Tang, Y., Miao, L., and Liu, X. (2016). "Fracture behavior of PAN-based carbon fibre tow in a chopping process on an elastic support". Fibers and Polymers, 17(8):1262-1268.

[29] Yang, C.-L., Sheu, S.-H., and Yu, K.-T. (2009). "The reliability analysis of a thin-edge blade wear in the glass fiber cutting process". Journal of Materials Processing Technology, 209:1789-1795. 
Appendix 1

Technical Drawings (see next page) 


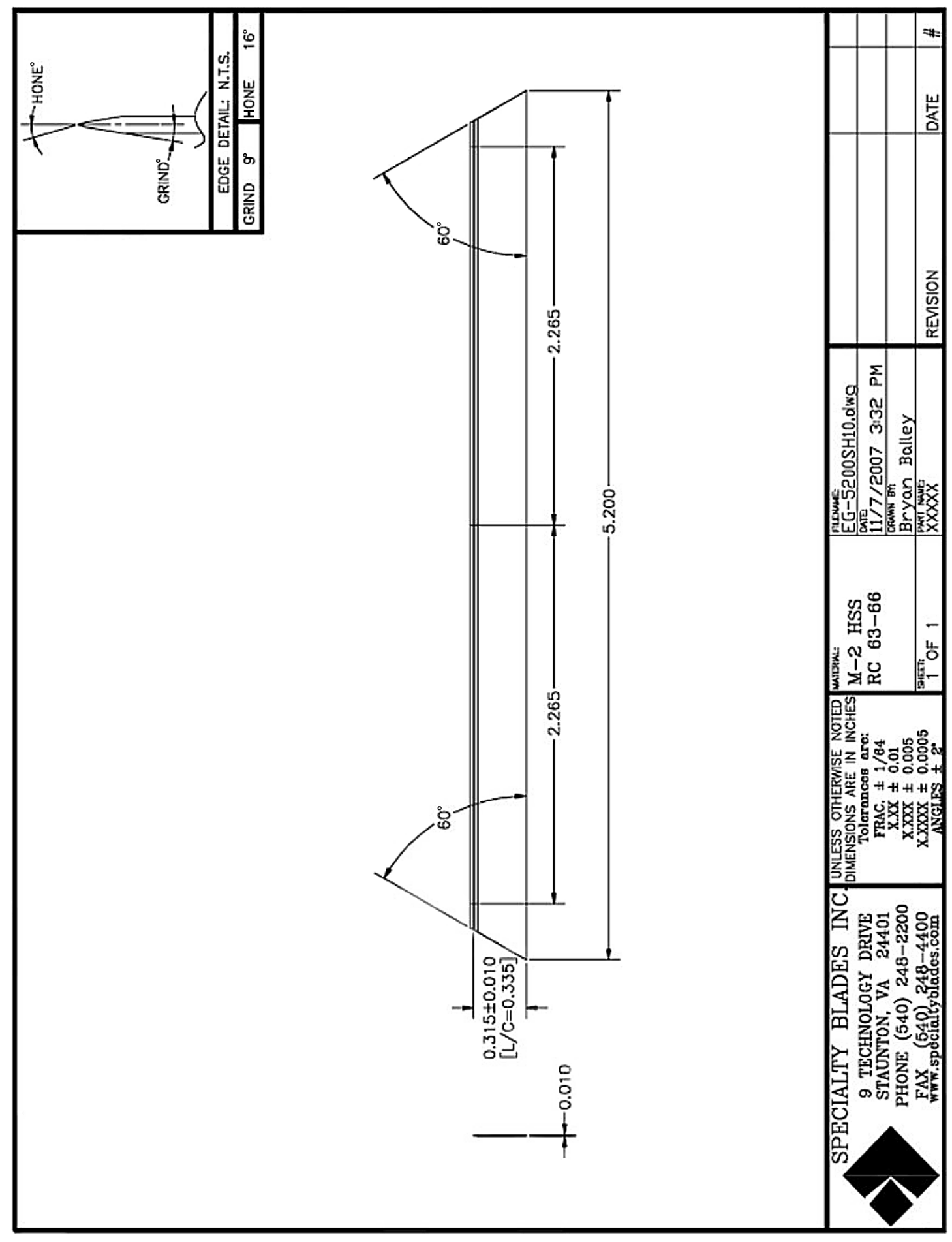

Figure A1.1: Baseline blade dimensions (blades were cut into $25 \mathrm{~mm}$ segments) 


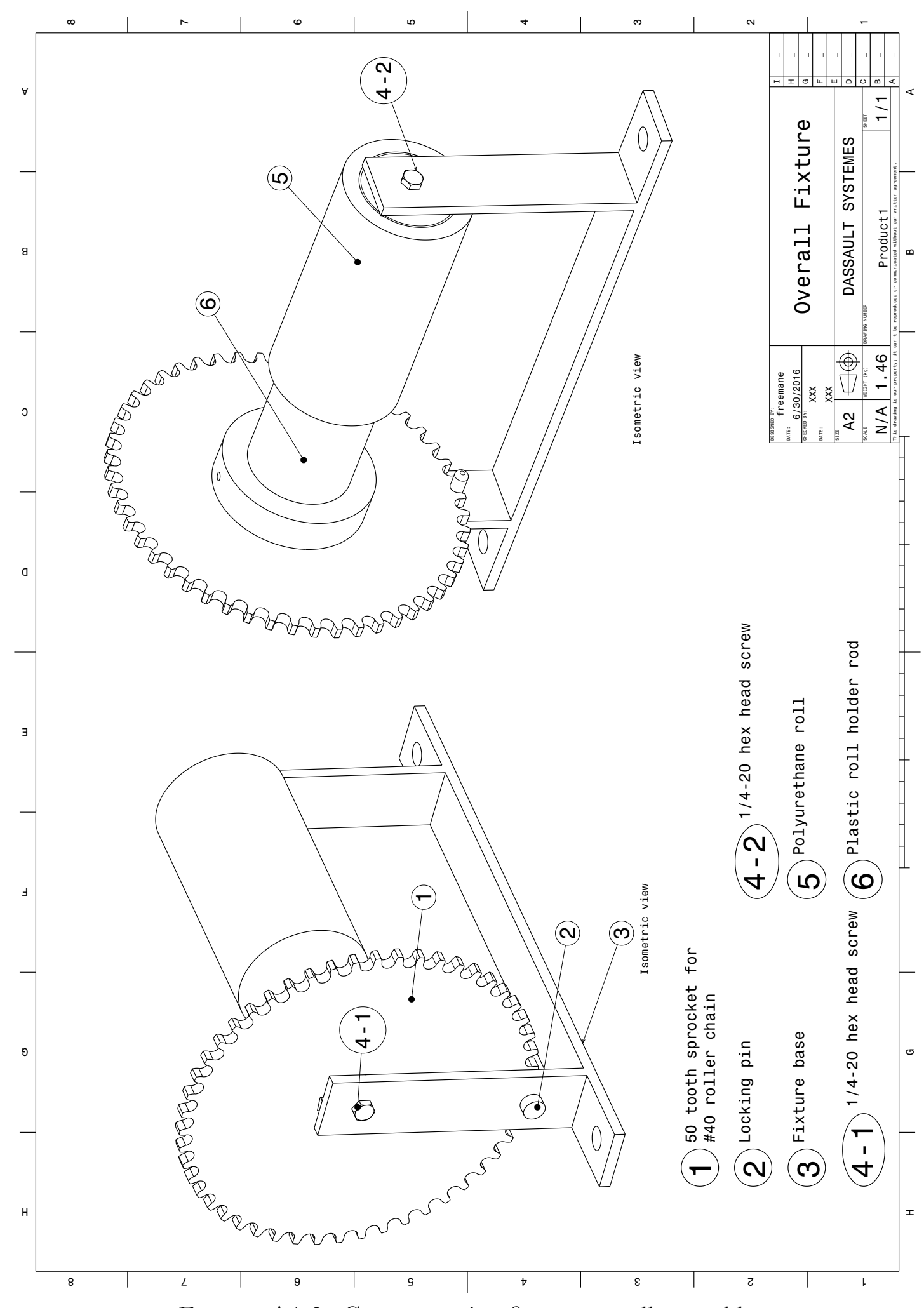

Figure A1.2: Groove cutting fixture overall assembly 


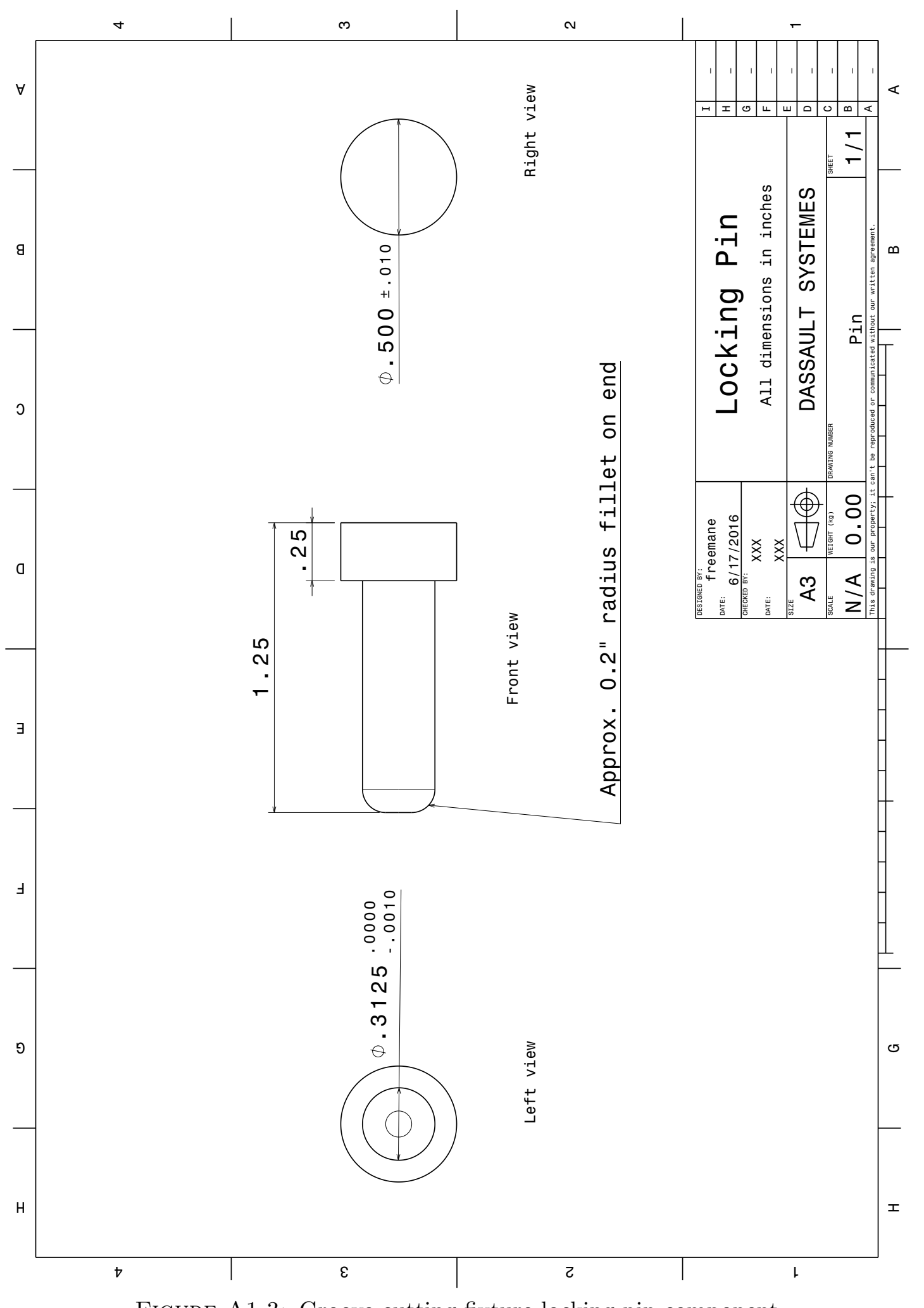

Figure A1.3: Groove cutting fixture locking pin component 


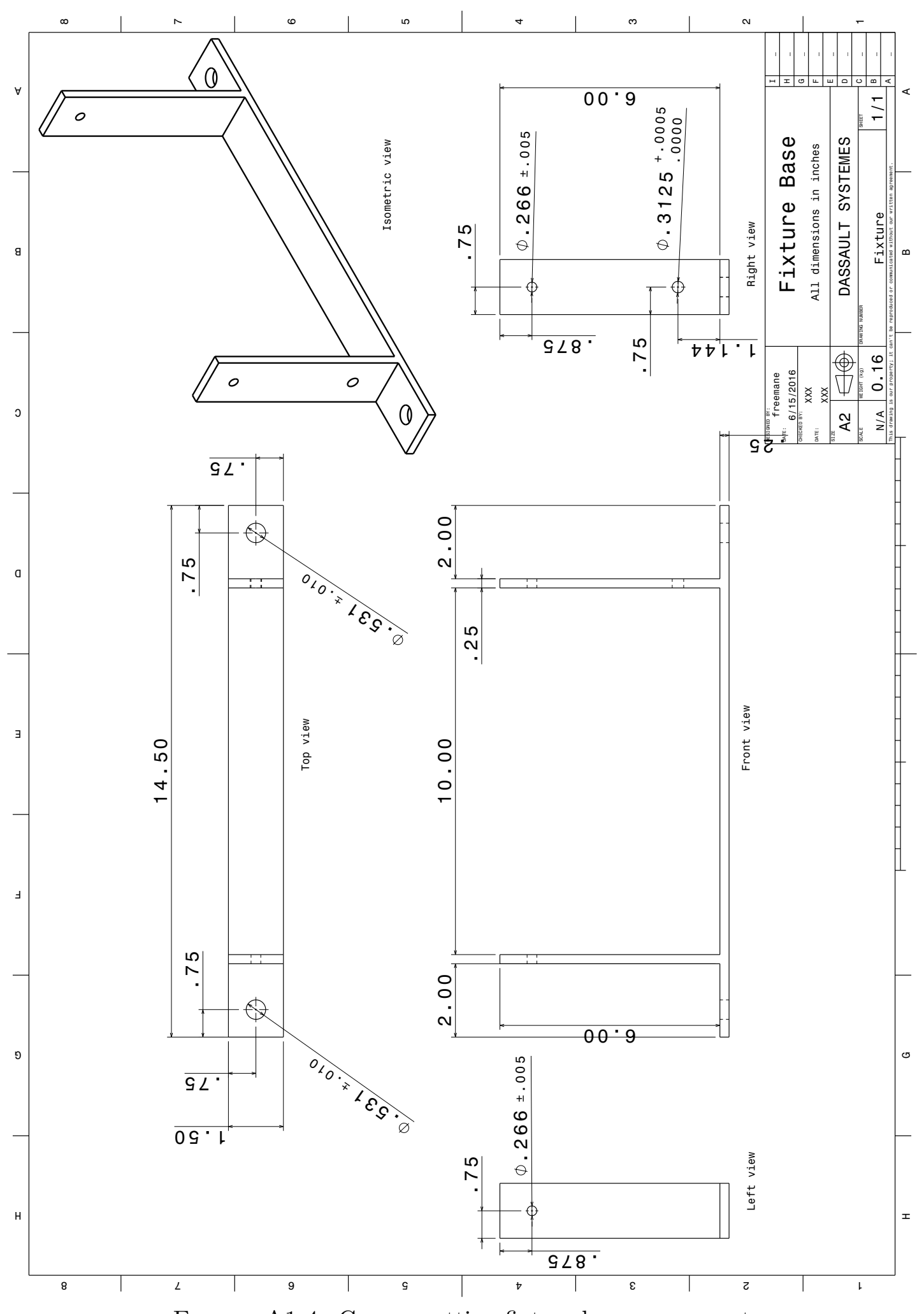

Figure A1.4: Groove cutting fixture base component 


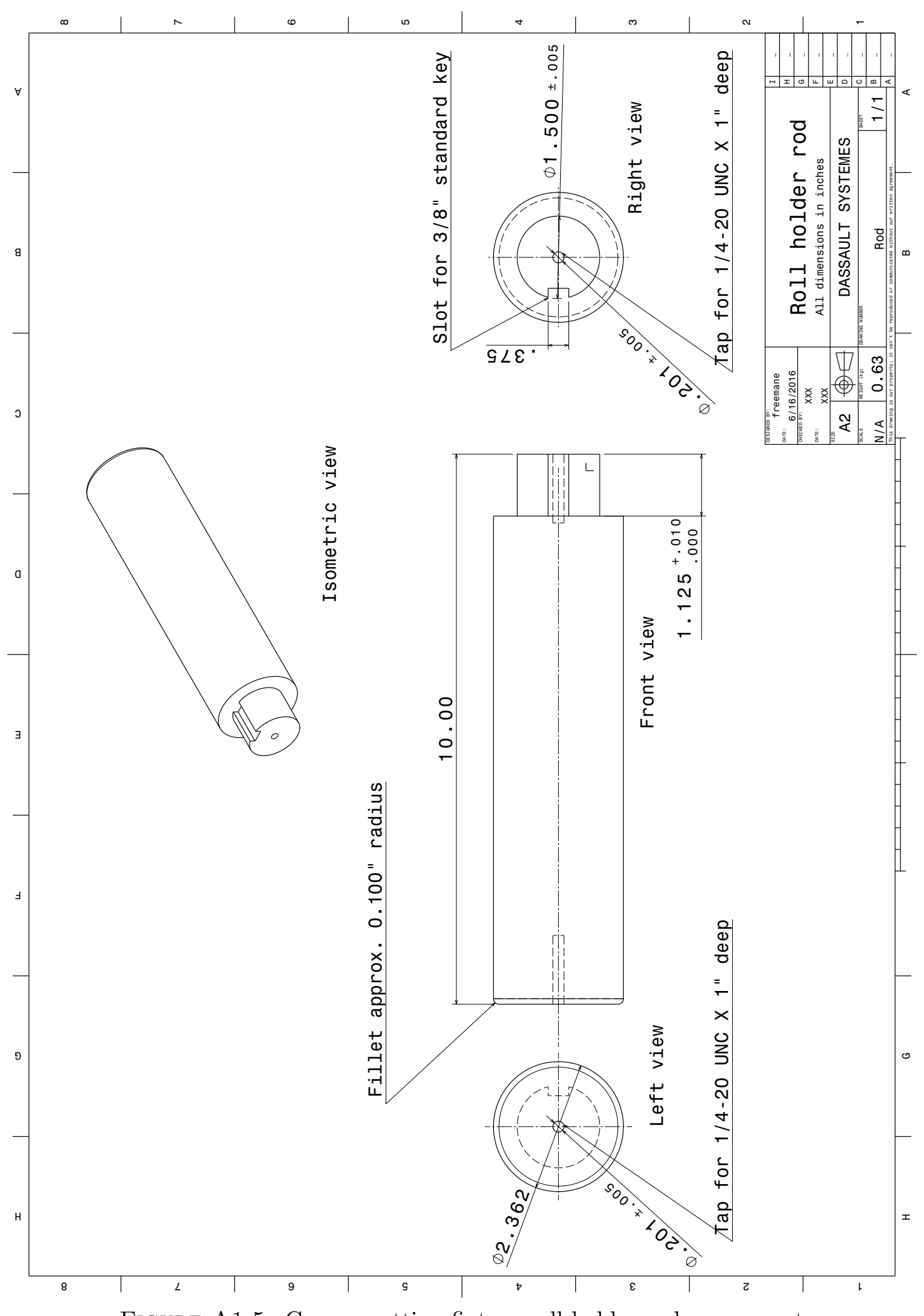

FiguRE A1.5: Groove cutting fixture roll holder rod component 
Appendix 2

Data sheets (see next page) 


\section{PYROFIL ${ }^{\mathrm{TM}}$ TR50S 15K}

\section{Typical Fiber Properties}

\begin{tabular}{|c|c|c|c|c|}
\hline \multirow{2}{*}{ Tow Tensile } & Strength & $\begin{array}{r}710 \\
4,900\end{array}$ & $\begin{array}{l}\mathrm{ksi} \\
\mathrm{MPa}\end{array}$ & \multirow{2}{*}{ JISR 7601} \\
\hline & Modulus & $\begin{array}{c}35 \\
240\end{array}$ & $\begin{array}{l}\mathrm{msi} \\
\mathrm{GPa}\end{array}$ & \\
\hline \multicolumn{2}{|c|}{ Typical Density } & $\begin{array}{c}0.066 \\
1.82\end{array}$ & $\begin{array}{l}\mathrm{lb} . \mathrm{in}^{3} \\
\mathrm{~g} / \mathrm{cm}^{3}\end{array}$ & JISR 7601 \\
\hline Typical Yield & $15 \mathrm{~K}$ & $\begin{array}{c}496 \\
1,000\end{array}$ & $\begin{array}{l}\mathrm{yds} / \mathrm{lb} \\
\mathrm{mg} / \mathrm{m}\end{array}$ & JISR 7601 \\
\hline
\end{tabular}

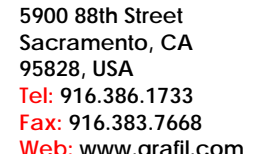

Web: www.grafil.com

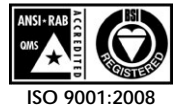

ISO 9001:2008

FM 56416

$03 / 2010$
6, Orchard Court Binley Business Park Hamy Weston Road Binley, Coventry CV3 2TQ UK Tel: $+\mathbf{4 4}$ (0) 2476447272 Fax: +44 (0) 2476449565

Important: The technical information contained herein is not to be construed as warranties and no patent liability can be assumed. This information can be used for material selection purposes only.

FiguRE A2.1: TR50S 15K carbon fiber material data

Retrieved from [10] :

http://www.fibermaxcomposites.com/shop/datasheets/TR50S_15K_03_2010.pdf 


\title{
Vita Auctoris
}

\author{
NAME \\ Evan Freeman-Gibb \\ Place of Birth Windsor, Ontario \\ YEAR OF BIRTH 1994 \\ Education University of Windsor, Windsor, Ontario \\ 2011-2015 B.App.Sc. \\ University of Windsor, Windsor, Ontario \\ 2015-2018 M.App.Sc.
}

